\title{
2014
}

\section{Determinantes de la}

Deserción 


\title{
Sistema de Prevención y Análisis de la Deserción en las Instituciones de Educación Superior
}

\author{
Informe Determinantes de la deserción \\ "Informe mensual sobre el soporte técnico y avance del contrato para \\ garantizar la alimentación, consolidación, validación y uso de la \\ información del SPADIES"
}

Universidad de los Andes

Facultad de Economía

Centro de Estudios sobre Desarrollo Económico CEDE

Bogotá D.C., febrero 14 de 2014 


\section{Presentación}

En cumplimiento del contrato 1250 de 2013, que tiene como objeto “Apoyar a la gestión y consolidación de la información del Sistema para la Prevención de la Deserción SPADIES a través del soporte técnico a las instituciones de educación superior" y ceñidos a las modificaciones establecidas en el Acta No. 01 del 28 de noviembre del 2013, se presenta a continuación un análisis de los factores que afectan la permanencia estudiantil en educación superior con base en los resultados del SPADIES.

Este informe responde al avance en el tercer producto objeto del contrato, que da cuenta de los factores asociados a la deserción en las Instituciones de Educación Superior en Colombia y que constituye un primer resultado con información disponible a diciembre de 2013.

El documento en su totalidad responde a lo solicitado en el producto III "Entregar un informe con la descripción de los factores que afectan la permanencia estudiantil en educación superior con base en los resultados del SPADIES". En el primer capítulo se presenta la introducción, en el segundo capítulo se presenta una revisión de literatura relacionada con los diferentes estudios

que han analizado la deserción estudiantil y sus determinantes, en el tercer capítulo el marco teórico sobre el cual se construyen los modelos de duración, en el cuarto capítulo de identifican las principales fuentes de información utilizadas, el capítulo quinto presenta las principales estadísticas descriptivas de la información utilizada, el sexto capítulo contiene la descripción del modelo utilizado y los principales resultados obtenidos, mientras que en los capítulos finales se presentan la bibliografía utilizada y los anexos correspondientes. 


\section{Tabla de contenido}

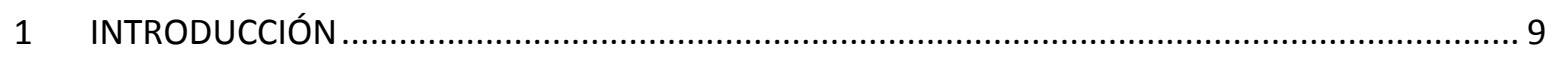

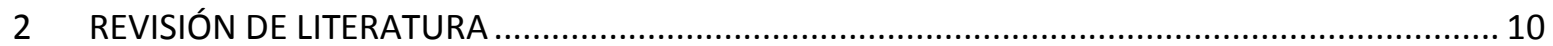

3 MARCO TEÓRICO: LA DESERCIÓN EN EDUCACIÓN SUPERIOR ................................................ 14

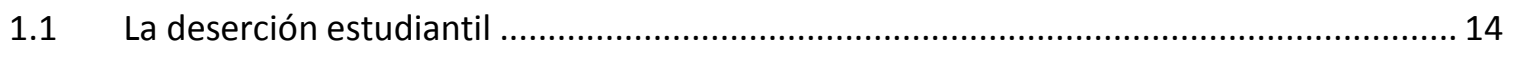

4 LOS MODELOS DE DURACIÓN PARA MEDIR LA DESERCIÓN ESTUDIANTIL .............................. 17

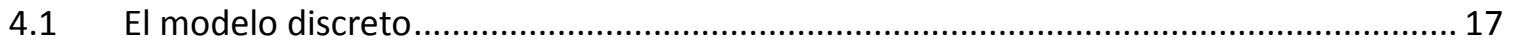

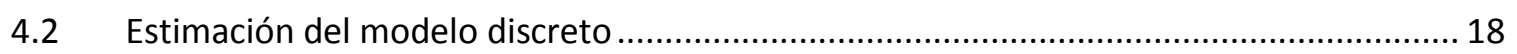

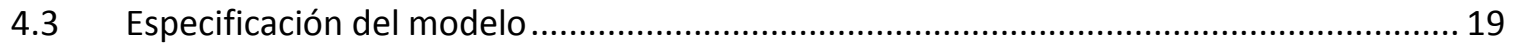

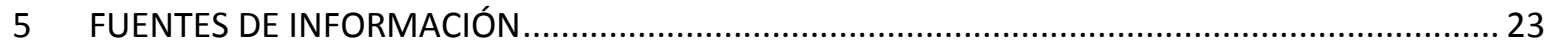

5.1 Instituto Colombiano para el Fomento de la Educación Superior (ICFES) ......................... 23

5.2 Instituto Colombiano de Crédito Educativo y Estudios Técnicos en el Exterior (ICETEX) 24

5.3 Sistema Nacional de Información de la Educación Superior (SNIES) ................................ 24

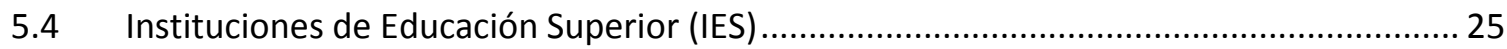

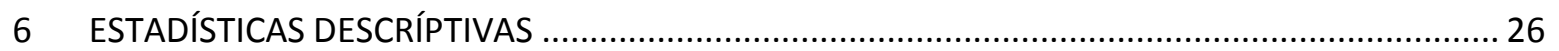

6.1 Caracterización de la población estudiantil .................................................................. 26

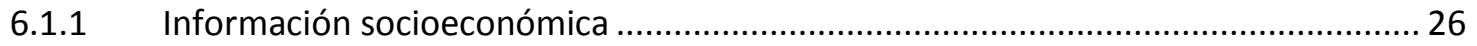

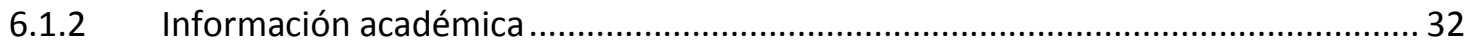

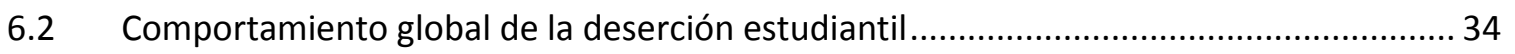

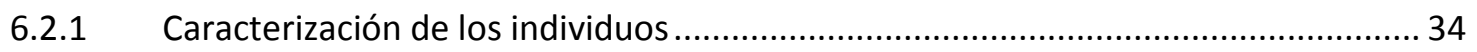

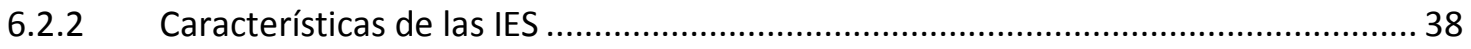

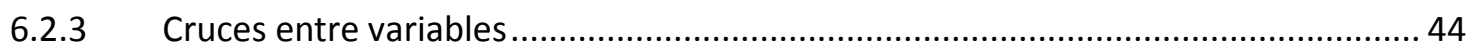

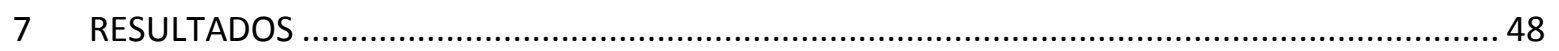

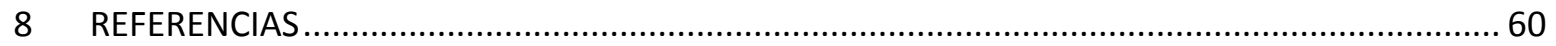

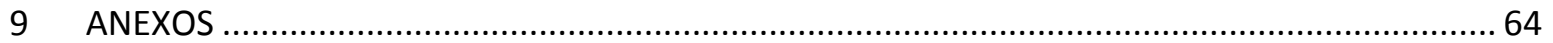




\section{Cuadro de Tablas}

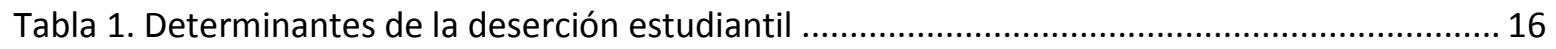

Tabla 2. Variables utilizadas para explicar la deserción en las IES en Colombia. Según modelo

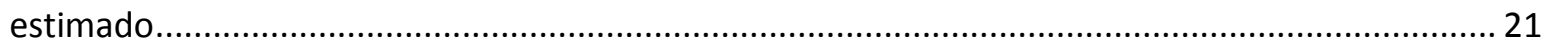

Tabla 3. Variables base de datos consolidada ICFES .................................................................. 23

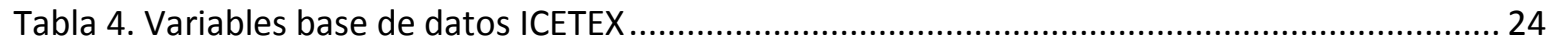

Tabla 5. Deserción por cohorte entre 1998-1 y 2014-1. Agregado Nacional................................... 38

Tabla 6. Porcentaje de Desertores según departamento para 5, 10 y 15 semestres cursados........ 42

Tabla 7. Porcentaje de Graduados según departamento para 5, 10 y 15 semestres cursados........ 43

Tabla 8. Modelo logit con efectos fijos para explicar los factores asociados a la deserción en las IES

en Colombia. Total IES y por categoría de IES............................................................................ 49

Tabla 9. Modelo logit con efectos fijos para explicar los factores asociados a la deserción en las IES

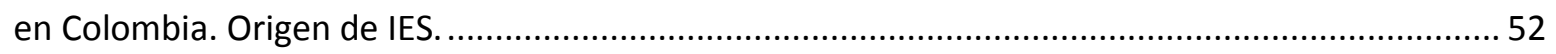

Tabla 10. Modelo logit con efectos fijos para explicar los factores asociados a la deserción en las IES en Colombia. Niveles de formación..................................................................................... 55

Tabla 11. Modelo logit con efectos fijos para explicar los factores asociados a la deserción en las IES en Colombia. Región donde se encuentra la IES. ................................................................. 58 


\section{Cuadro de Gráficas}

Gráfica 1. Porcentaje de Matriculados por Sexo entre 1998-1 y 2013-2. Agregado Nacional. ........ 26

Gráfica 2. Porcentaje de Matriculados según la variable Trabaja al presentar el examen entre 1998-

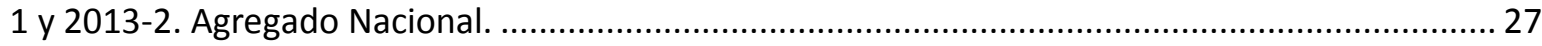

Gráfica 3. Porcentaje de Matriculados por Edad entre 1998-1 y 2013-2. Agregado Nacional........ 28

Gráfica 4. Edad promedio de los matriculados según Sexo entre 1998-1 y 2014-1. Agregado

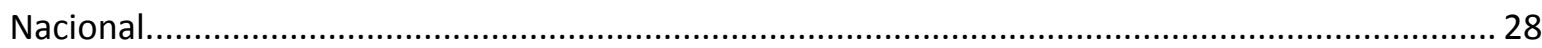

Gráfica 5. Porcentaje de Matriculados según Ingreso de la familia entre 1998-1 y 2013-2. Agregado

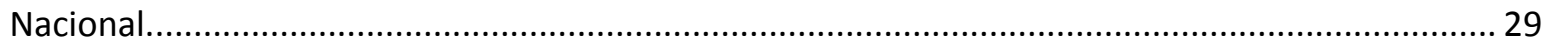

Gráfica 6. Porcentaje de Matriculados por Nivel Educativo de la Madre entre 1998-1 y 2013.2. Agregado Nacional.

30

Gráfica 7. Porcentaje de Primíparos según el Número de hermanos entre 1998-1 y 2013-2. Agregado Nacional.

Gráfica 8. Porcentaje de Primíparos según Posición entre los hermanos entre 1998-1 y 2014-1.

Agregado Nacional. 32

Gráfica 9. Porcentaje de matriculados según Tasa de Repitencia entre 1998-1 a 2013-2. Agregado Nacional. 33

Gráfica 10. Porcentaje de Matriculados según Clasificación en las pruebas de estado entre 1998-1

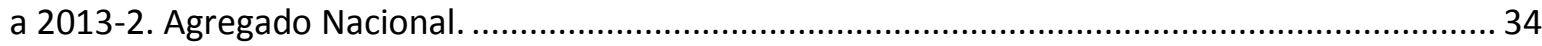

Gráfica 11. Porcentaje de Desertores según Sexo entre 1998-1 y 2014-1. Agregado Nacional....... 35 Gráfica 12. Porcentaje de Desertores según la variable Trabaja al momento de presentar el examen entre 1998-1 y 2014-1. Agregado Nacional........................................................................ 35 Gráfica 13. Porcentaje de Desertores según Edad entre 1998-1 y 2014-1. Agregado Nacional. ..... 36 Gráfica 14. Porcentaje de Desertores según Ingreso de la familia entre 1998-1 y 2014-1. Agregado

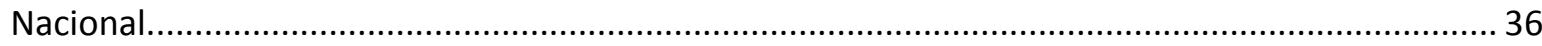

Gráfica 15. Porcentaje de Desertores según el Nivel educativo de la madre entre 1998-1 y 2014-1.

Agregado Nacional. 37

Gráfica 16. Porcentaje de Desertores según Clasificación de examen entre 1998-1 a 2014-1.

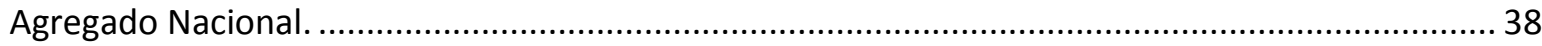

Gráfica 17. Porcentaje de Desertores entre 1998-1 y 2014-1. Agregado Nacional......................... 39

Gráfica 18. Porcentaje de Graduados por Número de semestres cursados entre 1998-1 y 2014-1. Agregado Nacional.

Gráfica 19. Porcentaje de Desertores según Nivel de Formación por número de semestres cursados. Agregado Nacional.

Gráfica 20. Porcentaje de Desertores según la Naturaleza de las IES por número de semestres cursados. Agregado Nacional

Gráfica 21. Porcentaje de Desertores según el Área del conocimiento por número de semestres cursados. Agregado Nacional. 
Gráfica 22. Porcentaje de Desertores según sexo y trabaja al momento de presentar el examen

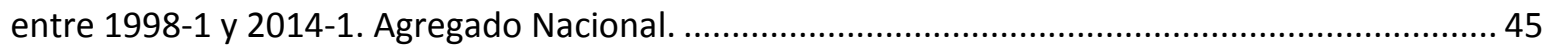

Gráfica 23. Porcentaje de Desertores según sexo y edad. Agregado Nacional. .............................. 45

Gráfica 24. Porcentaje de Desertores según sexo e ingreso de la familia. Agregado Nacional....... 46

Gráfica 25. Porcentaje de Desertores según origen de la institución e ingreso de la familia.

Agregado Nacional.

Gráfica 26. Porcentaje de Desertores según clasificación pruebas de estado y si trabajaba al momento de presentar el examen. Agregado Nacional. 


\section{Cuadro de Anexos}

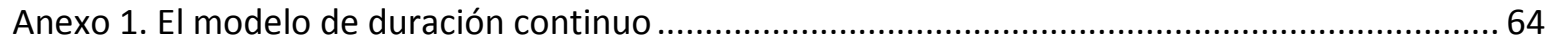




\section{INTRODUCCIÓN}

La deserción es una de las principales problemáticas que aqueja al sistema de educación superior en el país. Ésta es causante de grandes frustraciones en los jóvenes que ingresan al sistema que, por alguna razón, no logran graduarse; deja ver la ineficiencia del sistema de educación superior al no poder mantener a todos los estudiantes que ingresan; limita la ampliación en la cobertura de la educación superior y demora la formación de capital humano de calidad en el país.

Dichos aspectos asociados a la deserción, llevan a una preocupación por explicar la deserción y evitar el crecimiento acelerado de ésta, máxime si se ha observado un notable incremento en las tasas de deserción a lo largo del tiempo. Según las estadísticas arrojadas por el Sistema para la Prevención de la Deserción de la Educación Superior (SPADIES), el 48.47\% de los estudiantes que ingresaron a la educación superior en el primer semestre de 2000 no alcanzaron décimo semestre; mientras que $57.2 \%$ de los que ingresaron en el primer semestre de 2008 no lo hicieron.

Por tal razón, se han realizado esfuerzos en la medición, análisis y seguimiento de las tasas de deserción con el fin de determinar las causas o factores asociados a este fenómeno y diseñar estrategias informadas para prevenirla. Este documento tiene como propósito examinar el comportamiento de la deserción en las Instituciones de Educación Superior de Colombia desde el primer semestre de 1998 hasta el segundo semestre de 2013, identificando los factores asociados a aquella y estableciendo los que más han contribuido a su incremento.

El documento se divide en nueve (9) secciones de las cuales la primera corresponde a esta introducción. En la segunda sección se presentan los antecedentes del problema de la deserción en Colombia, mientras que en la tercera y cuarta sección se expone el marco teórico y se desarrolla brevemente el modelo utilizado, respectivamente. La quinta sección presentan las fuentes de información y la sexta sección presenta algunas estadísticas descriptivas de factores socioeconómicos, académicos e institucionales determinantes de la deserción. En la séptima sección se presentan los resultados de los modelos econométricos desarrollados. Por último, en la octava y novena sección se presentan las referencias y los anexos al documento. 


\section{REVISIÓN DE LITERATURA}

Existe una amplia literatura dedicada a estudiar las causas de la deserción estudiantil. Varias áreas del conocimiento han tratado de explicar este fenómeno social con el fin de acercarse a una solución que logre hacer que los estudiantes se retengan más dentro de las instituciones de educación superior.

Desde el punto de vista de la psicología y la sociología enfatizan para el examen de la deserción aspectos tales como las expectativas personales de éxito, la percepción de la dificultad del programa académico que cursa, los valores familiares y el apoyo e incentivos que los familiares le brindan al estudiante. Fishbein y Ajzen (1975) argumentan que la deserción debe ser concebida como el resultado del debilitamiento de las intenciones iniciales del individuo y de su persistencia; aspectos que a su vez están influenciados por el auto concepto del estudiante. Attinasi (1986) asegura que la decisión de desertar se ve influenciada por las percepciones y el análisis que el individuo hace de su vida universitaria. Otros estudios muestran la relación inversa que existe entre la educación de los padres y la deserción en educación superior (Porto et al., 2001). De igual manera, estos estudios concluyen que la deserción es más común en los primeros semestres de la carrera universitaria (Bank et. al, 1990).

Ethingon (1991), por su parte, incorpora la teoría de las "conductas de logro", que comprenden atributos como la perseverancia, la elección y el desempeño, encontrando que el nivel de aspiraciones y las expectativas de éxito del estudiante son elementos fundamentales para explicar la deserción. Además, el autor explica cómo las aspiraciones y expectativas personales están estrechamente relacionadas con el entorno familiar, con las opiniones que los padres de familia les transmiten a los estudiantes y con el apoyo familiar ante situaciones adversas. Igualmente, hace referencia al rendimiento académico previo, como forma de identificar a los individuos más propensos a no terminar sus estudios. El modelo de integración del estudiante afirma que mayor presencia de esta en el ambiente académico y social contribuye a un compromiso institucional más fuerte lo afecta la decisión del alumno de permanecer o desertar (Spady, 1970; Tinto, 1975; Cabrera, et al. 1993).

Desde una perspectiva organizacional y de interacción entre los diferentes grupos de factores mencionados anteriormente, se introducen factores relacionados con la institución educativa, tales como los servicios que la institución ofrece a sus estudiantes (como bienestar estudiantil), las actividades que generan pertenencia a la institución, la calidad de la enseñanza, la calidad de la docencia, la disponibilidad de recursos de la institución, entre otras variables.

Dentro de los estudios realizados con esta perspectiva, se destacan los trabajos desarrollados por Tinto $(1975,1982)$ sobre la manera en que la integración y adaptación del estudiante a la institución educativa influyen en su decisión de abandonar los estudios antes de culminarlos (cuando el estudiante puede tomar la decisión y no está obligado por razones ajenas a su voluntad). Su teoría se denomina modelo de integración del estudiante, y propone que los 
estudiantes actúan de acuerdo a la teoría del intercambio en la construcción de su integración social y académica, expresada en términos de metas y niveles de compromiso institucional. De esta manera, si los beneficios percibidos de permanecer en la institución son mayores que los costos personales, el estudiante no desertará.

Siguiendo el modelo de Tinto, Bean (1985) introduce características del modelo de productividad en el ámbito laboral para desarrollar el modelo de desgaste del estudiante, al remplazar las variables del ambiente laboral por variables que describen el ambiente en la institución educativa. Desde una visión más integral, considera que la decisión de desertar por parte de un estudiante, depende de factores académicos (desempeño académico en el bachillerato, integración académica y desempeño académico en la universidad); factores psicosociales (metas, interacción con la institución educativa y vínculos con la institución); factores ambientales (relaciones sociales externas y las oportunidades de financiación); y por último, factores de socialización (aceptación, compromiso con la institución, entre otros). En un estudio más reciente, Bean y Vesper (1990), observan que factores no cognitivos y las características del individuo tienen un peso significativo al explicar la deserción (mayor del que se había considerado en el pasado). Por su parte, Cabrera et al. (1993) tratan de juntar el modelo de integración del estudiante con el modelo de desgaste estudiantil, encontrando que los modelos son complementarios, y por tanto la deserción estudiantil se puede explicar utilizando conceptos de ambas teorías.

Por su parte, las primeras investigaciones desde el campo de la economía hicieron énfasis en el modelo de costo-beneficio y el modelo de focalización (una aproximación poco profunda e integral). En el primer modelo, el individuo compara los beneficios sociales y económicos asociados a la permanencia en el sistema con los beneficios de actividades alternativas para así decidir si permanece o no en la institución educativa. Como es de esperarse, el estudiante decide abandonar sus estudios cuando los beneficios de actividades alternativas son mayores. En el segundo modelo, se busca identificar los grupos de alumnos que presenten limitaciones para continuar su formación y por medio de subsidios directos evitar que estos abandonen sus estudios. En estas primeras investigaciones económicas, las variables demográficas y académicas eran consideradas como variables de control, y no como factores determinantes o de riesgo.

Con el tiempo, las investigaciones desde la economía han tenido una posición más ecléctica frente a la deserción, estudiando cómo la interacción entre las variables de las diferentes categorías de factores (individuales, académicos, institucionales y socioeconómicos) inciden en el fenómeno de la deserción. Porto et al. (2001), emplea diferentes indicadores de rendimiento académico (como por ejemplo, la razón entre la cantidad de materias rendidas y los años desde el ingreso), junto con características individuales de las personas, y encuentran que una variable fundamental para explicar la deserción es el nivel educativo de los padres del estudiante. La investigación concluye que existe una relación inversa entre estas dos variables: a mayor educación de los padres, menor deserción del estudiante. En general, este grupo de trabajos encuentran que los alumnos que desertan, comparados con aquellos que permanecen en la institución educativa, tienden a tener peores notas académicas durante su carrera y padres con menor educación y menores ingresos. Otros estudios en el campo económico, dentro de los cuales se destaca el realizado por Bank et al. 
(1990), han probado que los estudiantes con un mayor nivel de interacción con la planta de profesores y con otros estudiantes, tienen menor probabilidad de desertar. De igual forma, estos estudios concluyen que la deserción es más común en los primeros semestres de la carrera universitaria.

Como la deserción es un fenómeno dinámico y puede ocurrir en distintos momentos del tiempo, se han llevado a cabo estimaciones con modelos de duración para determinar el riesgo de desertar en cada periodo involucrando el efecto de factores individuales, institucionales, académicos, socioeconómicos y de apoyos académicos y financieros. Estos estudios han establecido patrones temporales de la deserción comparando distintos grupos o características, donde concluyen que el riesgo de desertar no es constante a lo largo de la vida académica y que la importancia de las variables en el riesgo de deserción varía de acuerdo con el período de tiempo en el que se observa el individuo (Singer y Willet., 1991; Schlechty y Vance., 1981; Alemany et al., 1990). Algunos de los resultados más importantes encontrados a partir de esta metodología sugieren que el aumento en un punto del GPA (Grade Point Average) aumenta más del doble la probabilidad de un estudiante de graduarse (DesJardins, 2003); mientras que se presenta un efecto negativo frente a cambios en el ingreso familiar, la educación de los padres y los estudios secundarios en escuelas privadas (Montoya, 1999). A su vez, el hecho de que el estudiante trabaje, y que sea hombre aumenta significativamente el riesgo de desertar de un individuo (Giovagnoli, 2002).

Uno de los temas más explorados es el efecto de las políticas públicas - subsidios, crédito universitario, becas estatales, etc. - y de los programas de acción afirmativa por parte de las instituciones educativas - facilidades de trabajo en el campus, becas, etc. - sobre la deserción. Al respecto, se ha encontrado que las restricciones de crédito en estudiantes de bajos ingresos no constituyen la razón principal de la decisión de desertar (Stinebrickner y Stinebrickner., 2008).

Para el caso colombiano, la mayoría de los estudios sobre la deserción corresponden a estudios concretos que analizan universidades o instituciones específicas, programas o carreras particulares dentro de las instituciones identificando los principales factores no académicos asociados con el fenómeno de la deserción, como por ejemplo la falta de recursos económicos, que el estudiante trabaje y que tenga una o más personas dependientes económicamente de éste, entre otros (Gordillo, E. y Polanco, J, 1970; Londoño, 2000).

Franco (1991), desde la psicología, estudia los factores que influyen en el ingreso y permanencia de los estudiantes en la Universidad de la Sabana, para concluir que tanto el ingreso como la permanencia en esta universidad están determinados en gran medida por la orientación vocacional recibida en el bachillerato por algunos estudiantes. Argumenta que la elección de la carrera representa una aproximación al concepto que cada persona tiene de sí misma y que este concepto está influenciado por identificaciones tempranas, por grupos sociales, por valores familiares, por la utilidad percibida de la carrera, así como el prestigio social que la profesión representa. De esta forma, atribuye la deserción universitaria a la falta de orientación profesional adecuada para escoger la carrera universitaria a seguir. 
Otros estudios encuentran una relación entre deserción y la calidad de la educación impartida, en contraste con planteamientos anteriores que le dan más peso a los factores académicos propios del estudiante (Contreras, 1994; Cárdenas, 1996). En años más recientes, se han desarrollado estudios que incorporan factores individuales, académicos, socioeconómicos e institucionales como principales determinantes de la deserción en el país (Castaño et al., 2004, Ministerio de Educación, 2009). En esta dirección, un estudio reciente de la Universidad Nacional de Colombia (2007) muestra que la deserción estudiantil presenta dinámicas particulares según la sede, la facultad o la carrera; mostrando que las interacciones entre las tasas de absorción, edad, sexo y antecedentes académicos de los estudiantes con la flexibilidad de los planes de estudio, las modalidades pedagógicas, la integración estudiantil y los programas de bienestar influyen en la deserción ${ }^{1}$, la graduación y el rezago estudiantil (Pérez, R. et al., 2007).

Sánchez et al (2002), desarrollaron un estudio más general sobre la equidad social en el acceso y los determinantes y factores de la permanencia en la universidad pública en el país, en el cual se indica que el acceso a las universidades públicas colombianas está determinado principalmente por el resultado en las pruebas de Estado Saber11 junto a las características de la familia del estudiante. En dicho estudio se encontró también que la existencia de programas de acción afirmativa aumenta en forma positiva y significativa la probabilidad de permanencia de los estudiantes en general y sin efectos diferenciales sobre la permanencia de los estudiantes más pobres. Melguizo et al. (2010) encuentran que la probabilidad de desertar de educación superior disminuye entre $25 \%$ y $29 \%$ de acuerdo al tipo de apoyo financiero recibido por el estudiante en el periodo 1998-2008, y que los apoyos financieros son más eficaces en la reducción de las tasas de deserción de la educación superior al comienzo de la carrera iniciada por el estudiante.

Más recientemente, Sánchez et al. (2012), examinan los determinantes de la deserción de la educación superior para el conjunto del sistema en la primera década del siglo XXI, incorporando el efecto de los programas anti-deserción implementados por las IES y los de crédito educativo implementados por el gobierno.

Así, desde el entorno nacional, son limitados los estudios que analizan los factores determinantes de la deserción bajo una estructura general (para todo el sistema de educación superior). En esta dirección, el presente documento pretende avanzar en dicho análisis teniendo en cuenta los diferentes tipos de instituciones educativas, el carácter de la institución, la modalidad de los programas y las diferentes regiones geográficas del país.

\footnotetext{
${ }^{1}$ Los autores consideran desertor a todos los estudiantes que después de cinco semestres consecutivos o más no se han matriculado en la Universidad.
} 


\section{MARCO TEÓRICO: LA DESERCIÓN EN EDUCACIÓN SUPERIOR}

Este estudio utiliza el enfoque de historia de vida, el cual se centra en la secuencia de eventos y transiciones (Elder, 1985). Este enfoque provee un marco general para conceptualizar cómo se da la deserción de la educación superior teniendo en cuenta la historia educativa del individuo y sus factores individuales, académicos, socioeconómicos e institucionales desde el momento en que ingresa al nivel superior. Los estudios previos demuestran que, para un mismo individuo, la probabilidad de abandonar (o finalizar) los estudios no es constante a través del tiempo ni es constante con la edad, y que a su vez, los efectos de los diferentes factores no son constantes a través del tiempo. Por lo tanto, trabajar con este enfoque permite tener en cuenta no solo el tiempo en la ocurrencia del evento mismo (deserción) sino también cómo cambia en el tiempo el efecto de cada factor determinante.

\subsection{La deserción estudiantil}

No existe una única definición de deserción que pueda captar en su totalidad la complejidad de este fenómeno. De acuerdo con Tinto (1989) la definición de la deserción estudiantil puede analizarse desde varias perspectivas y de acuerdo con los diferentes tipos de abandono. Estas perspectivas dependen de las partes involucradas e interesadas en el proceso, como son los estudiantes, los funcionarios de las instituciones de educación superior y los responsables de la política nacional de educación. En este sentido, el concepto de deserción puede estudiarse desde tres puntos de vista: (i) individual, (ii) institucional y (iii) estatal o nacional.

La deserción definida desde una perspectiva individual implica reconocer que los significados que un estudiante asigna a su comportamiento de abandono pueden diferir sustancialmente de los que un observador atribuye a ese mismo comportamiento. Desertar significa entonces el fracaso individual en completar un determinado curso de acción para alcanzar una meta deseada, la cual fue el objetivo por el cual el sujeto ingresó a una determinada institución de educación superior.

Debido a la complejidad de la definición individual de fracaso, el término deserción puede estar mejor utilizado cuando integra una comunidad de intereses (Tinto, 1989). Esta última comprende al individuo que ingresa a la institución y los observadores externos que tienen como propósito disminuir la deserción estudiantil, como es el caso de los funcionarios de la institución. Desde la perspectiva de éstos, la deserción del individuo representa el fracaso de la institución que no ayudó al estudiante a lograr lo que originalmente se había propuesto al ingresar en la institución de educación superior.

Una forma de lograr un concepto de deserción que integre diversos intereses es realizar el estudio desde una perspectiva institucional, la cual comprende la comunidad de intereses involucrados en un proceso de deserción. Una medida de la deserción puede ser el número de estudiantes que 
abandonan una institución de educación superior en un período determinado, antes de haber obtenido el título correspondiente (ICFES, 2002). Esta perspectiva permite un marco conceptual donde todos los sujetos que se retiran de una institución de educación superior pueden, teniendo en cuenta las razones del abandono, ser clasificados como desertores (Tinto, 1989; Castaño et. al., 2004).

La perspectiva estatal o nacional de la definición de deserción tiene como base la organización educativa del país (ICFES, 2002). En este caso, el concepto de deserción comprende el abandono del estudiante de sistema educativo en general. Por lo tanto, no todos los abandonos instituciones corresponden a deserciones del sistema, sino que algunos pueden definirse como transferencias entre instituciones educativas o cambios al interior del sistema. Por consiguiente, sólo aquellas formas de abandono estudiantil que significan a la vez abandono de todo el sistema formal de educación superior son consideradas como deserción y las transferencias entre instituciones corresponderían a movilidad dentro del sistema (Castaño et. al, 2004; Tinto, 1989). Esta definición enmarca las acciones de política pública en la vigilancia y armonización de los flujos internos de alumnos, así como en la reducción, si es posible, de la pérdida de estudiantes de las instituciones educativas del sistema nacional de educación superior.

De acuerdo con lo anterior, y para el desarrollo de los modelos que a continuación se realizarán, dentro del presente documento se definirá la deserción utilizando una perspectiva institucional. Será entonces considerado un desertor aquel estudiante que abandona la institución educativa durante dos períodos consecutivos, como resultado de la interacción o del efecto individual y combinado de diferentes categorías de variables: individuales, académicas, institucionales, y socioeconómicas. En términos cuantitativos, un desertor es el estudiante que en el tiempo $(t=0)$ está matriculado en un programa dentro de una institución determinada, pero en los dos momentos siguientes del tiempo $(t=1 y t=2)$, no se encuentra matriculado en ese mismo programa o en otro programa dentro de la misma institución. Por lo tanto, los cambios de programa al interior de una misma institución no son considerados como deserción, sino como movilidad intra institucional. Igualmente, las interrupciones temporales (durante un período) no son consideradas deserción. Así, se considera deserción el abandono definitivo de la institución, el cual se supone sucede después de dos períodos consecutivos de interrupción de los estudios superiores en la institución determinada. La mortalidad académica será considerada observando el nivel de aprobación de materias por periodo semestral y mediante la construcción de un índice de aprobación acumulado.

Basados en la literatura sobre el tema, puede decirse que hoy en día existe consenso al afirmar que la deserción estudiantil es el resultado del efecto no de una sola categoría, sino del efecto individual y de la interacción de diferentes categorías de factores, a saber: factores individuales, factores académicos, factores institucionales y factores socioeconómicos ${ }^{2}$. A partir de los diferentes estudios previos, las principales variables consideradas dentro de cada una de las

\footnotetext{
${ }^{2}$ Esta clasificación se encuentra en ICFES (2002), así como en Castaño et. al. (2004).
} 
categorías se resumen a continuación en la tabla 1. Los cuatro (4) grupos de factores presentados coinciden con los que se van a considerar como determinantes de la deserción dentro del presente documento; sin embargo las variables a considerar dentro de cada grupo de factores, dependen de la información disponible en las fuentes de información.

Tabla 1. Determinantes de la deserción estudiantil

\begin{tabular}{llll}
\hline \multicolumn{1}{c}{ Individuales } & Socioeconómicos & Académicos & Institucionales \\
\hline - Edad, género, y & - Estrato social & - Orientación & - Normatividad \\
estado civil & - Situación laboral del & profesional & académica \\
- Calamidad y/o & estudiante & - Tipo de colegio de & - Becas y formas de \\
problema doméstico & - Situación laboral de & secundaria & financiamiento \\
- Integración social & los padres & - Rendimiento & - Recursos \\
- Expectativas no & - Dependencia & académico superior & universitarios \\
satisfechas & económica & - Métodos de estudio & - Relaciones con el \\
- Incompatibilidad & - Personas a cargo & - Calificación en el & profesorado y con \\
horaria con & - Nivel educativo de los & examen de admisión & demás estudiantes \\
actividades extra & padres & - Insatisfacción con el & - Grado de compromiso \\
académicas & - Entorno familiar & programa académico & con la institución \\
& - Entorno & - Carga académica & educativa \\
& macroeconómico del & (número de materias & - Calidad del programa \\
& país & al semestre) & \\
\hline
\end{tabular}

Fuente: ICFES (2002) y Castaño et al. (2004). En: Documento CEDE (2009) 


\section{LOS MODELOS DE DURACIÓN PARA MEDIR LA DESERCIÓN ESTUDIANTIL}

Los modelos de duración son frecuentemente utilizados cuando se dispone de información sobre la duración en un estado en particular hasta la ocurrencia de un evento, en este caso, la duración de un estudiante en educación superior hasta su deserción, su graduación o el momento final de la observación (lo primero que ocurra).

En la aplicación de estos modelos estadísticos se debe tener en cuenta que no se cumplen los supuestos convencionales sobre normalidad ${ }^{3}$ y que la información de los estudiantes por lo general se encuentra censurada ya que en el momento en que se observa un estudiante activo no se sabe si este culminará o no el ciclo ${ }^{4}$. Ahora bien, la información acerca del evento de deserción de los estudiantes en las IES, es capturada de manera semestral, es decir solo se puede saber si un estudiante desertó, dado que en periodos académicos siguientes no registró ningún vínculo con la IES. Los datos de estudiantes en las IES, muestran que el estudiante duró un número definido de semestres en la institución, cuyo valor es discreto (solo valores enteros) y mayores que uno. Dado lo anterior, a continuación se expone brevemente el planteamiento discreto de un modelo de duración, con el cual se dará tratamiento a los datos sobre deserción de los estudiantes en las IES. La definición ampliada del modelo continuo, a partir del cual se formula el modelo discreto se presenta, en el anexo 1.

\subsection{El modelo discreto}

El uso apropiado de modelos de carácter discreto para el tratamiento del fenómeno de la deserción, se basa en la manera en que se registran los datos relacionados con la deserción: de forma semestral. Sin embargo, el evento de desertar puede ocurrir en cualquier momento durante el periodo semestral: por ejemplo, si un individuo deserta en la mitad del tercer semestre y otro lo hace finalizando el tercer semestre, la duración en la institución es diferente para ambos individuos, no obstante, en la base de datos que permitirá estimar los parámetros del modelo, la duración será igual para dichos individuos (tres semestres), tomando así únicamente valores discretos $(1,2,3, \ldots$, etc. $)$.

\footnotetext{
${ }^{3}$ En los modelos de regresión lineal se supone que la distribución de los errores se ajustan a una función de distribución normal. Sin embargo, este supuesto no es razonable porque, por ejemplo, la deserción es un evento de riesgo constante en el tiempo en cuyo caso, la distribución de la duración de los estudiantes podría seguir una distribución exponencial.

${ }^{4}$ Suponga que se tiene información de individuos matriculados hace tres años en primer semestre y también información de los estudiantes que hoy no se han retirado. El censuramiento se produce porque no se puede decir nada acerca de la deserción en los siguientes semestres de estos últimos estudiantes (no se conoce el futuro).
} 
Siguiendo a Jerald F. Lawless (2003), la función de probabilidad que describe la naturaleza discreta de la ocurrencia del evento (registro de ocurrencia) es:

$$
f\left(t_{j}\right)=\operatorname{Pr}\left(T=t_{j}\right) \quad \text { donde } \quad j=1,2, \ldots
$$

La función de supervivencia sería:

$$
S(t)=\operatorname{Pr}(T \geq t)=\sum_{j: t_{j} \geq t} f\left(t_{j}\right)
$$

Considerando que la función anterior existe para todo $t \geq 0$, además que $S(t)$ es una función continúa con $S(0)=1$ y $S(\infty)=0$, la función de riesgo discreta puede definirse como:

$$
\theta\left(t_{j}\right)=\operatorname{Pr}\left(T=t_{j} \mid T \geq t_{j}\right)=\frac{f\left(t_{j}\right)}{S\left(t_{j}\right)} \quad j=1,2, \ldots
$$

Como se muestra en el anexo 1 , en el caso continuo, las funciones de supervivencia y de riesgo permiten encontrar equivalencias para la distribución de $T$. Dado que $f\left(t_{j}\right)=S\left(t_{j}\right)-S\left(t_{j}+1\right)$ se tiene entonces:

$$
\theta\left(t_{j}\right)=1-\frac{f\left(t_{j}+1\right)}{S\left(t_{j}\right)} \quad j=1,2, \ldots
$$

\subsection{Estimación del modelo discreto}

Teniendo información de $i$ individuos durante $k$ semestres; la última observación en el tiempo de cada individuo implica que éste puede seguir estudiando (información censurada) o ha terminado sus estudios (duración completa). De lo anterior, la función de máxima verosimilitud es:

$$
L=\sum_{i=1}^{N}\left[\left[1+\sum_{t=0}^{k_{i}} \exp \left(x_{i t} \beta\right)\right]^{-\frac{1}{\vartheta}}-c_{i}\left[1+\vartheta \sum_{t=0}^{k} \exp \left(x_{i t} \beta\right)\right]^{-\frac{1}{\vartheta}}\right]
$$

donde $c$ es un indicador que vale 1 cuando el individuo está censurado, $x$ es un vector de variables que explican la deserción y $\beta$ mide el impacto de cada una de estas sobre la deserción. Adicionalmente, $\vartheta$ es la varianza de la función de distribución, que se aproxima a los datos reales de duración por un proceso iterativo y corresponde a diferentes formas de una función Gamma. Asimismo, el proceso de maximización implica un proceso iterativo para la estimación de los 
valores de $\beta$ cuyos valores iniciales son tomados de la función de riesgo discreto propuesta por Prentice-Gloeckler (1978) $)^{5}$ :

$$
h(t)=1-\exp \left[-\exp \left(x_{i t} \beta\right)\right]
$$

Los resultados de este modelo se compararán con los de duración continua para escoger el más apropiado.

\subsection{Especificación del modelo ${ }^{6}$}

Con el objeto de describir la heterogeneidad no observada (u omitida) entre los individuos, los modelos estimados incorporan una variable aleatoria que captura el efecto de las diferencias no observables entre los estudiantes. La aproximación es relevante porque la literatura ha documentado ampliamente los sesgos que surgen de la omisión de este problema. En el caso particular del análisis de supervivencia, se ha encontrado que no incorporar el efecto de la heterogeneidad no observada puede: i) sobreestimar la relación negativa entre duración y riesgo inicial ${ }^{7}$, ii) desconocer que el efecto de una variable sobre la tasa de riesgo no es constante, ni independiente del tiempo de supervivencia y iii) atenuar la respuesta proporcional del riesgo a los cambios de las variables independientes en cada momento del tiempo. ${ }^{8}$

Si $\theta(t, X)$ es la función de riesgo sin heterogeneidad no observada, donde $X$ es el vector de variables que resume las diferencias observadas entre los estudiantes en el periodo $t$, el efecto de las diferencias no observables entre individuos se introduce a través de un factor escalar multiplicativo $v .^{9}$ De esta forma, la función de riesgo con heterogeneidad no observada es:

$$
\theta_{v}(t) \equiv \theta(t, X \mid v)=\theta(t, X) \cdot v
$$

La función de supervivencia con heterogeneidad no observada está relacionada con la que no incorpora este efecto de la siguiente forma:

$$
S_{v}(t) \equiv S(t, X \mid v)=\theta(t, X)^{v}
$$

\footnotetext{
${ }^{5}$ Prentice, R. and Gloeckler L. (1978). Regression analysis of grouped survival data with application to breast cancer data. Biometrics 34 : 57-67.

${ }^{6}$ Jenkins (2005)

${ }^{7}$ Estudiantes con una alta heterogeneidad no observada, ceteris paribus, desertan más rápido, razón por la cual los sobrevivientes en cualquier momento del tiempo estarán principalmente compuestos por individuos con baja heterogeneidad no observada y, por lo tanto, tasas de riesgo más bajas (Jenkins, 2005).

${ }^{8}$ Lancaster (1990)

${ }^{9}$ Donde $v$ es una variable aleatoria que toma valores positivos, tiene media normalizada a uno y varianza $\sigma^{2}$. Un supuesto crucial de estos modelos es que $v$ está independientemente distribuida de $X$ y $t$.
} 
Donde se observa que las diferencias no observables entre los estudiantes también implica incorporar en la función de supervivencia la variable $v$. Igualmente, la tasa de riesgo del modelo con heterogeneidad no observada desarrollada por Cox (1972) y citada por Jenkins (2005) puede expresarse como:

$$
\theta_{v} \equiv \theta(t, X \mid \beta, v)=\theta_{0}(t) \cdot \exp \left(\beta^{\prime} X\right) \cdot v=\theta_{0}(t) \cdot \exp \left(\beta^{\prime} X+u\right)
$$

0

$$
\ln \left[\theta_{v}(t)\right]=\ln \left[\theta_{0}(t)\right]+\beta^{\prime} X+u
$$

Donde $\theta_{0}(t)$ es la función de riesgo base y el término de error $u$ es igual a $u \equiv \ln (v)$ que es una variable aleatoria con media cero.

La interpretación más común de la variable $u \equiv \ln (v)$ es aquella que dice que este término resume el impacto de las variables omitidas sobre la tasa de riesgo, bien sea porque las variables omitidas son intrínsecamente no observables, o porque no se encuentran en la información disponible para realizar las estimaciones.

La especificación en tiempo discreto se deriva directamente de la especificación presentada en esta sección. El modelo estándar $c \log \log$ se generaliza a:

$$
c \log \log [p(t, X \mid \beta, v)]=D(t)+\beta^{\prime} X+u
$$

Donde $D(t)$ es la función de riesgo base. La literatura ha señalado que la escogencia de la forma funcional del riesgo depende del criterio del investigador ${ }^{10}$. Los resultados presentados en este documento se obtienen a partir de la especificación $D(t)=\log (t)$, la cuál simula una Weibull.

De forma análoga, el modelo logit está dado por:

$$
\operatorname{logit}[p(t, X \mid \beta, v)]=D(t)+\beta^{\prime} X+e
$$

Donde el término de error $e$ representa una variable aleatoria con media cero y varianza finita. La teoría de análisis de supervivencia indica que es apropiado asumir que los errores $u$ y $e$ se distribuyen normal, sin embargo, la distribución gamma es la más utilizada para este tipo de estimaciones. En este trabajo se intentó esta especificación, pero la no convergencia de las estimaciones $^{11}$ nos llevó a recurrir a una especificación log-normal de la distribución de los errores.

De esta forma, si los errores se distribuyen normalmente, la función de supervivencia es:

$$
S=\exp \left(\sum_{t=1}^{n} \ln \left(1-p_{t}\right)=\prod_{t=1}^{n}\left(1-p_{t}\right)\right)
$$

\footnotetext{
${ }^{10}$ Jenkins (2004)

${ }^{11}$ Explicada en parte por la complejidad de la función de máxima verosimilitud. Por esta razón, se cambió la especificación del modelo propuesto en el informe del mes de mayo.
} 
Donde $p$ es la tasa de riesgo, que para el modelo cloglog se representa:

$$
p=\left[1-\exp (\exp (-X \beta))^{-1}\right]
$$

Para el modelo logit:

$$
p=\left[1+\exp (-X \beta)^{-1}\right]
$$

La forma más sencilla de estimar la especificación del modelo de supervivencia anterior es un panel logit desbalanceado con efectos aleatorios ${ }^{12}$. En total se estimaron diferentes modelos agrupados de acuerdo a las principales características de las instituciones: por carácter de la institución (universidades, instituciones universitarias, instituciones tecnológicas e instituciones técnicas); por origen de la institución (oficial y no oficial); por nivel de formación (técnica profesional, tecnológica y universitaria) y por región donde se encuentra la IES (Atlántica, Pacífica, Centro-Oriente, Centro-Occidente, Orinoquía, Amazonía y Bogotá). Se incluyeron todas las variables socioeconómicas, académicas e institucionales disponibles en la información suministrada por las diferentes fuentes de información, y que hacen parte de los principales determinantes de la deserción de la educación superior.

\begin{tabular}{|c|c|c|}
\hline \multicolumn{3}{|l|}{ Factores Académicos } \\
\hline Variable & Tipo & Descripción \\
\hline & & Valores de 0 a 100 , donde 100 \\
\hline Puntaje en la prueba de Estado ICFES (o la prueba SABER11) & Acotada & es el mejor puntaje \\
\hline \multicolumn{3}{|l|}{ Pertenece al área de conocimiento: } \\
\hline 1. Agronomía, veterinaria y afines & Dummy & $1=\mathrm{SI}, 0=\mathrm{NO}$ \\
\hline 2. Bellas artes & Dummy & $1=\mathrm{SI}, 0=\mathrm{NO}$ \\
\hline 3. Ciencias de la educación & Dummy & $1=\mathrm{SI}, 0=\mathrm{NO}$ \\
\hline 4. Ciencias de la salud & Dummy & $1=\mathrm{SI}, 0=\mathrm{NO}$ \\
\hline 5. Ciencias sociales, derecho, ciencias políticas & Dummy & $1=\mathrm{SI}, 0=\mathrm{NO}$ \\
\hline 6. Economía, administración, contaduría y afines & Dummy & $1=\mathrm{SI}, 0=\mathrm{NO}$ \\
\hline 7. Humanidades y ciencias religiosas & Dummy & $1=\mathrm{SI}, 0=\mathrm{NO}$ \\
\hline 8. Ingeniería, arquitectura, urbanismo y afines & Dummy & $1=\mathrm{SI}, 0=\mathrm{NO}$ \\
\hline 9. Matemáticas y ciencias naturales & Dummy & $1=\mathrm{SI}, 0=\mathrm{NO}$ \\
\hline Tasa de repitencia & Acotada & $\begin{array}{c}\text { Toma valores de } 0 \text { a } 1 \text {. Calculada } \\
\text { como \# de materias perdidas en } \\
\text { el período anterior/\# de } \\
\text { materias tomadas }\end{array}$ \\
\hline \multicolumn{3}{|l|}{ Factores Socioeconómicos } \\
\hline Variable & Tipo & Descripción \\
\hline Número de hermanos en el hogar & Continua & \\
\hline Posición numérica del estudiante dentro de los hijos del hogar & Continua & \\
\hline Madre con nivel educativo: básica primaria completa & Dummy & $1=\mathrm{SI}, 0=\mathrm{NO}$ \\
\hline Madre con nivel educativo: básica secundaria completa & Dummy & $1=\mathrm{SI}, 0=\mathrm{NO}$ \\
\hline Madre con nivel educativo: media vocacional completa o técnico/tecnológico & Dummy & $1=\mathrm{SI}, 0=\mathrm{NO}$ \\
\hline Madre con nivel educativo: superior completo o posgrado & Dummy & $1=\mathrm{SI}, 0=\mathrm{NO}$ \\
\hline & & Medido en salarios mínimos \\
\hline Rango de ingreso en el que se encuentra el hogar del estudiante cuando éste & Categoría & 1 (bajo)=Menos de 2 \\
\hline presentó el ICFES (o la prueba SABER11) & ordenada & 2 (medio)=Entre 2 y 7 \\
\hline & & 3 (alto)=Más de 7 \\
\hline \multicolumn{3}{|l|}{ Factores Individuales } \\
\hline Variable & Tipo & Descripción \\
\hline
\end{tabular}

Tabla 2. Variables utilizadas para explicar la deserción en las IES en Colombia. Según modelo estimado

\footnotetext{
12 La información de cada estudiante fue organizada de forma tal que para cada persona hubiera tantas filas como semestres hubiera cursado. Como se mencionó anteriormente, la especificación de un modelo de sobrevivencia con heterogeneidad no observada en tiempo discreto se puede estimar utilizando la función de máxima verosimilitud de un panel logit desbalanceado con efectos aleatorios.
} 


\begin{tabular}{|c|c|c|}
\hline Sexo & Dummy & $1=\mathrm{SI}, 0=\mathrm{NO}$ \\
\hline Edad & Contínua & Edad en años \\
\hline $\operatorname{Edad}^{\wedge} 2$ & Contínua & $(\text { Edad en años })^{\wedge} 2$ \\
\hline Trabajaba cuando presentó el ICFES (o la prueba SABER11) & Dummy & $1=\mathrm{SI}, 0=\mathrm{NO}$ \\
\hline \multicolumn{3}{|c|}{ Factores Institucionales } \\
\hline Variable & Tipo & Descripción \\
\hline Origen de la institución & Dummy & $1=$ Oficial, $0=$ No oficial \\
\hline \multicolumn{3}{|l|}{ Carácter de la institución: } \\
\hline - Universidad & Dummy & $1=\mathrm{SI}, 0=\mathrm{NO}$ \\
\hline - Institución Universitaria & Dummy & $1=\mathrm{SI}, 0=\mathrm{NO}$ \\
\hline - Institución tecnológica & Dummy & $1=\mathrm{SI}, 0=\mathrm{NO}$ \\
\hline - Técnica profesional & Dummy & $1=\mathrm{SI}, 0=\mathrm{NO}$ \\
\hline \multicolumn{3}{|l|}{ Nivel de formación del programa: } \\
\hline - Universitaria & Dummy & $1=\mathrm{SI}, 0=\mathrm{NO}$ \\
\hline - Tecnológica & Dummy & $1=\mathrm{SI}, 0=\mathrm{NO}$ \\
\hline - Técnica profesional & Dummy & $1=\mathrm{SI}, 0=\mathrm{NO}$ \\
\hline Recibió apoyo financiero durante el semestre & Dummy & $1=\mathrm{SI}, 0=\mathrm{NO}$ \\
\hline Recibió apoyo académico durante el semestre & Dummy & $1=\mathrm{SI}, 0=\mathrm{NO}$ \\
\hline Recibió otros apoyos durante el semestre & Dummy & $1=\mathrm{SI}, 0=\mathrm{NO}$ \\
\hline Recibió crédito ICETEX de Largo Plazo & Dummy & $1=\mathrm{SI}, 0=\mathrm{NO}$ \\
\hline Recibió crédito ICETEX de Mediano Plazo & Dummy & $1=\mathrm{SI}, 0=\mathrm{NO}$ \\
\hline Recibió crédito ICETEX ACCES & Dummy & $1=\mathrm{SI}, 0=\mathrm{NO}$ \\
\hline
\end{tabular}

fuente: Elaboración propia. 


\section{FUENTES DE INFORMACIÓN}

A continuación se presentan las fuentes de información utilizadas para llevar la estimación de los factores determinantes en la deserción dentro de las instituciones de educación superior. El modelo definido en el aparte anterior, se desarrolló a partir de información proveniente de cuatro principales fuentes de información:

\subsection{Instituto Colombiano para el Fomento de la Educación Superior (ICFES)}

La información del ICFES provee los principales factores individuales, académicos y socioeconómicos al momento de presentar el Examen de Estado (ICFES o SABER11) que pueden tener un impacto sobre la probabilidad de desertar. Hasta el momento, se cuenta con las bases de datos de los Exámenes de Estado desde marzo de 1997 hasta el segundo semestre de 2010. De estas bases de datos se obtuvo dos tipos de información: los resultados por estudiante en los exámenes de Estado para cada una de las áreas: matemáticas, ciencias, lenguaje, etc., y se obtuvo una calificación estandarizada entre 0 y 100 por estudiante; e información relacionada con algunos datos de los estudiantes en el momento de la inscripción para presentar el examen.

Se obtuvo entonces información relevante de una gran base de datos del ICFES, utilizando los distintos semestres comprendidos en el lapso 1997-I a 2010-II con un total de 4'018.254 registros y las 18 variables presentadas en la Tabla 3

Tabla 3. Variables base de datos consolidada ICFES

\begin{tabular}{ll}
\hline & \\
\hline 1 & Identificador del estudiante: \\
2 & Documento de Identidad \\
3 & Nombre \\
& Individuales: \\
4 & Sexo \\
5 & Edad \\
& Socioeconómicas: \\
6 & Nivel Educativo de la Madre \\
7 & Número de Hermanos \\
8 & Posición entre los hermanos \\
9 & Número de personas del grupo familiar \\
10 & Si vive en vivienda propia \\
11 & Sí Trabaja \\
12 & Ingreso Familiar \\
& Académicas*: \\
13 & Biología \\
14 & Química \\
15 & Física
\end{tabular}


16 Sociales

17 Matemáticas

18 Lenguaje

Fuente: ICFES.

* Los resultados de las pruebas se homogenizaron debido a que a partir del año 2000, el sistema de evaluación se modificó.

\subsection{Instituto Colombiano de Crédito Educativo y Estudios Técnicos en el Exterior (ICETEX)}

La información del ICETEX permite identificar a los estudiantes que se les aprobaron créditos estudiantiles, y a aquellos que solicitaron algún crédito y no les fue concedido el préstamo, en el período comprendido entre 2003-II a 2008-13. De tal forma, las bases de datos con las que se cuenta presentan información relevante para 63.659 registros y la de créditos legalizados con 29.263. Los estudiantes se identificaron de acuerdo con el número de documento de identificación, con lo cual fue posible realizar el cruce de las variables que se presentan en la tabla 4.

Tabla 4. Variables base de datos ICETEX

\begin{tabular}{ll}
\hline & \multicolumn{1}{c}{ Variables } \\
\hline 1 & Identificador del estudiante: \\
2 & Documento de Identidad \\
& Nombre \\
3 & Tinformación del crédito: \\
4 & Institución de Educación Superior \\
5 & Programa a cursar o cursado \\
6 & Semestre cursado \\
\hline Fuente: ICETEX
\end{tabular}

\subsection{Sistema Nacional de Información de la Educación Superior (SNIES)}

EI SNIES provee información general sobre las IES, tales como el carácter, la modalidad, la metodología de enseñanza, etc., así como de los programas académicos (áreas de conocimiento). Adicionalmente, ofrece información del número de docentes no sólo de tiempo completo, sino también los de cátedra y su nivel de formación.

\footnotetext{
${ }^{13}$ No se cuenta con información del período comprendido entre 1999-I a 2003-I debido a que, al parecer, el ICETEX no cuenta con esta información digitalizada sino en archivo físico.
} 


\subsection{Instituciones de Educación Superior (IES)}

Finalmente, se utiliza la información reportada por las IES al Sistema para la Prevención de la Deserción de la Educación Superior, entre el primer semestre de 1998 y el segundo semestre de 2013. La información relevante reportada por las IES es de dos tipos: una institucional y una individual (por alumno). La información institucional incluye los criterios de admisión de estudiantes a primer semestre, si cuentan con programas para evitar la deserción y la descripción de estos programas. La información individual se refiere principalmente al programa cursado, el número de materias tomadas y aprobadas, el estado de los estudiantes (primíparo, matriculado o graduado) y si el estudiante recibe algún tipo de apoyo por parte de la institución. 


\section{ESTADÍSTICAS DESCRÍPTIVAS}

\subsection{Caracterización de la población estudiantil}

\subsubsection{Información socioeconómica}

\subsubsection{Sexo}

En la gráfica 1 se muestra el porcentaje de matriculados según el sexo para cada periodo. Como se puede observar, las mujeres han tenido una participación superior a los hombres para todos los periodos de matrícula. Mientras que el porcentaje de mujeres siempre supera el $50 \%$ del total de matriculados en cada periodo, el de hombres sólo alcanza el $48 \%$. La diferencia en la participación de los sexos se mantuvo entre un rango de $2 \%$ y $5 \%$.

Gráfica 1. Porcentaje de Matriculados por Sexo entre 1998-1 y 2013-2. Agregado Nacional.

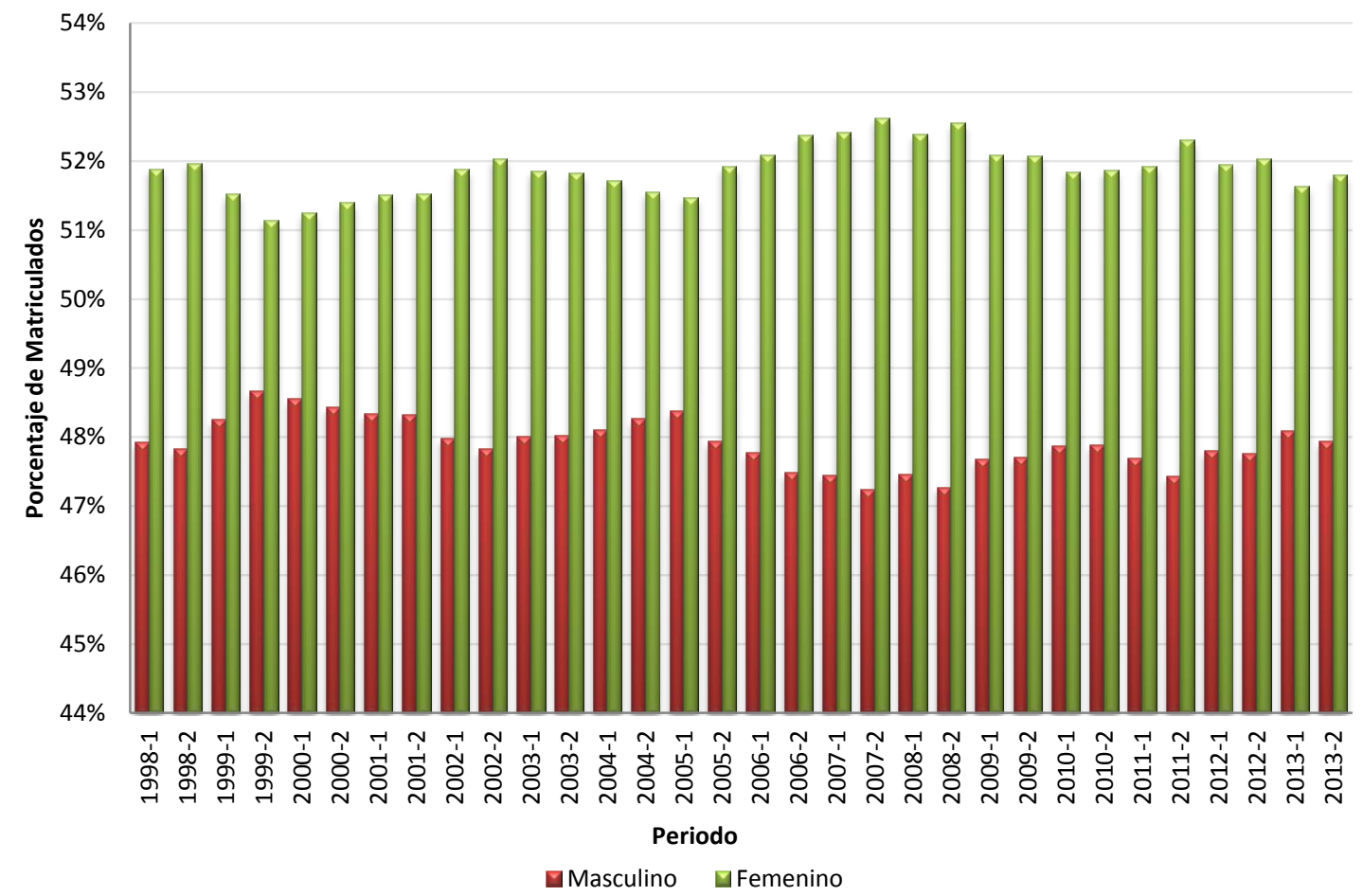

Fuente: Aplicativo SPADIES.

\subsubsection{Trabaja al momento de presentar el examen}

En la gráfica 2 se observa que la mayor parte de los individuos (más del 89\% para todos los periodos) no trabajaban a la hora de presentar el examen. Además se observa una tendencia a la reducción del trabajo de los estudiantes, mientras que antes del año 2000 alrededor del $10 \%$ de los estudiantes trabajaba y estudiada al tiempo, para después la tendencia es siempre hacia la reducción de esta proporción. 
Gráfica 2. Porcentaje de Matriculados según la variable Trabaja al presentar el examen entre 1998-1 y 2013-2. Agregado Nacional.

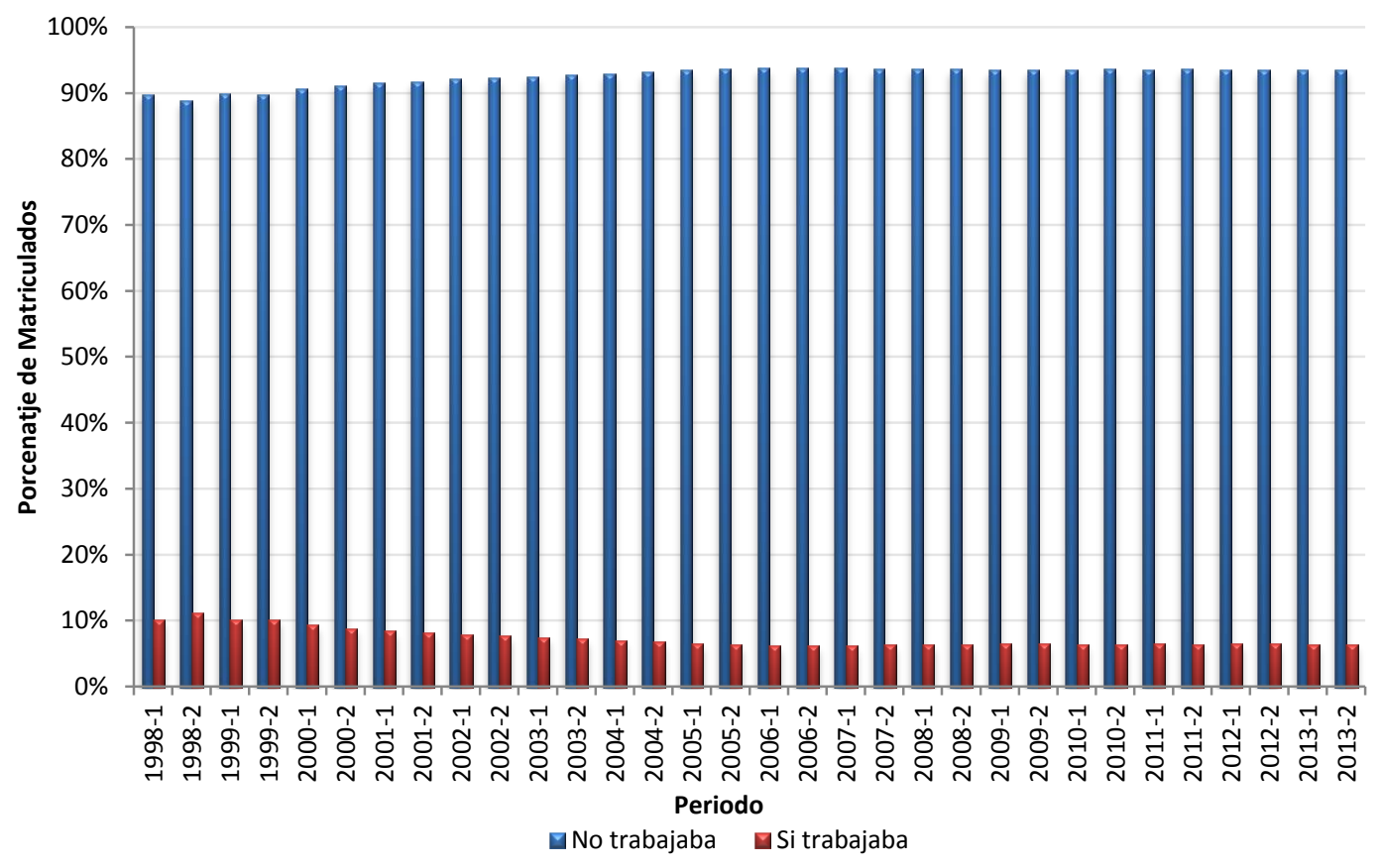

Fuente: Aplicativo SPADIES.

\subsubsection{Edad}

En la gráfica 3 se puede apreciar que la mayor parte de los individuos que presentan el examen se encuentran en un rango de edad de entre 16 y 20 años. Además, el porcentaje que pertenece a este rango presenta un crecimiento en los últimos años, coincidiendo con una tendencia negativa en el porcentaje de individuos de todos los demás rangos. Esto es un indicador importante de que la mayor porción de estudiantes que ingresan a educación superior se encuentran en este rango de edad 
Gráfica 3. Porcentaje de Matriculados por Edad entre 1998-1 y 2013-2. Agregado Nacional.

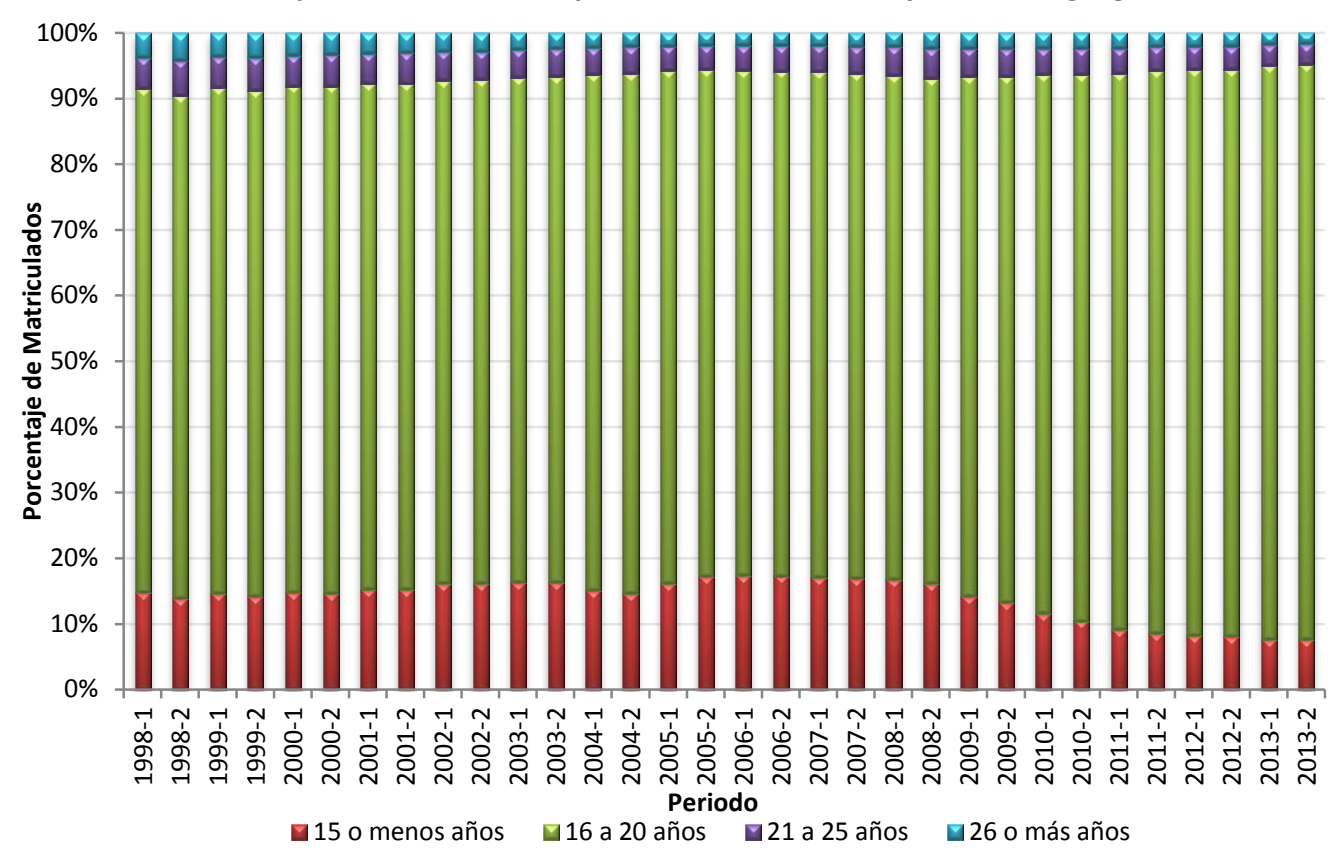

Fuente: Aplicativo SPADIES.

\subsubsection{Sexo y Edad}

Como se observa en la gráfica 4, el promedio de edad a la que los individuos presentan el examen ha disminuido en los últimos años, pasando de cerca de 18 años a 17 para el último periodo. Se puede apreciar también que para todos los periodos las mujeres son menores a los hombres.

Gráfica 4. Edad promedio de los matriculados según Sexo entre 1998-1 y 2014-1. Agregado Nacional.

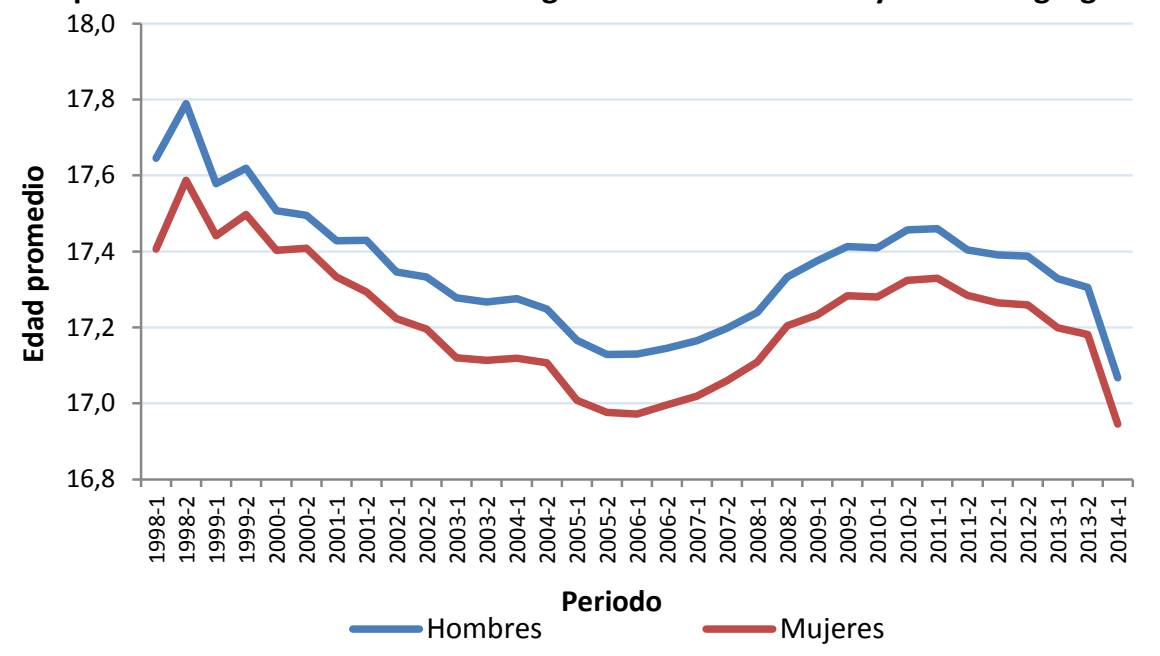

Fuente: SPADIES.

\subsubsection{Ingreso de la familia}

En la Gráfica 5 se observa que en los últimos años el mayor porcentaje de individuos que están matriculados son aquellos cuya familia tiene un ingreso de entre 1 y 2 salarios mínimos, 
alcanzando un 35\% para el 2013-2. Además, se observa que el porcentaje de matriculados pertenecientes a familias con menores rangos salariales (entre 0 y 1 , y entre 1 y 2 salarios mínimos), han aumentado considerablemente en los últimos años. En contraste, los porcentajes de matriculados cuyas familias tienen los ingresos salariales más altos (entre 3 y 5,5 y 7,7 y 10 , y 10 o más salarios mínimos) han disminuido palatinamente.

Gráfica 5. Porcentaje de Matriculados según Ingreso de la familia entre 1998-1 y 2013-2. Agregado Nacional.

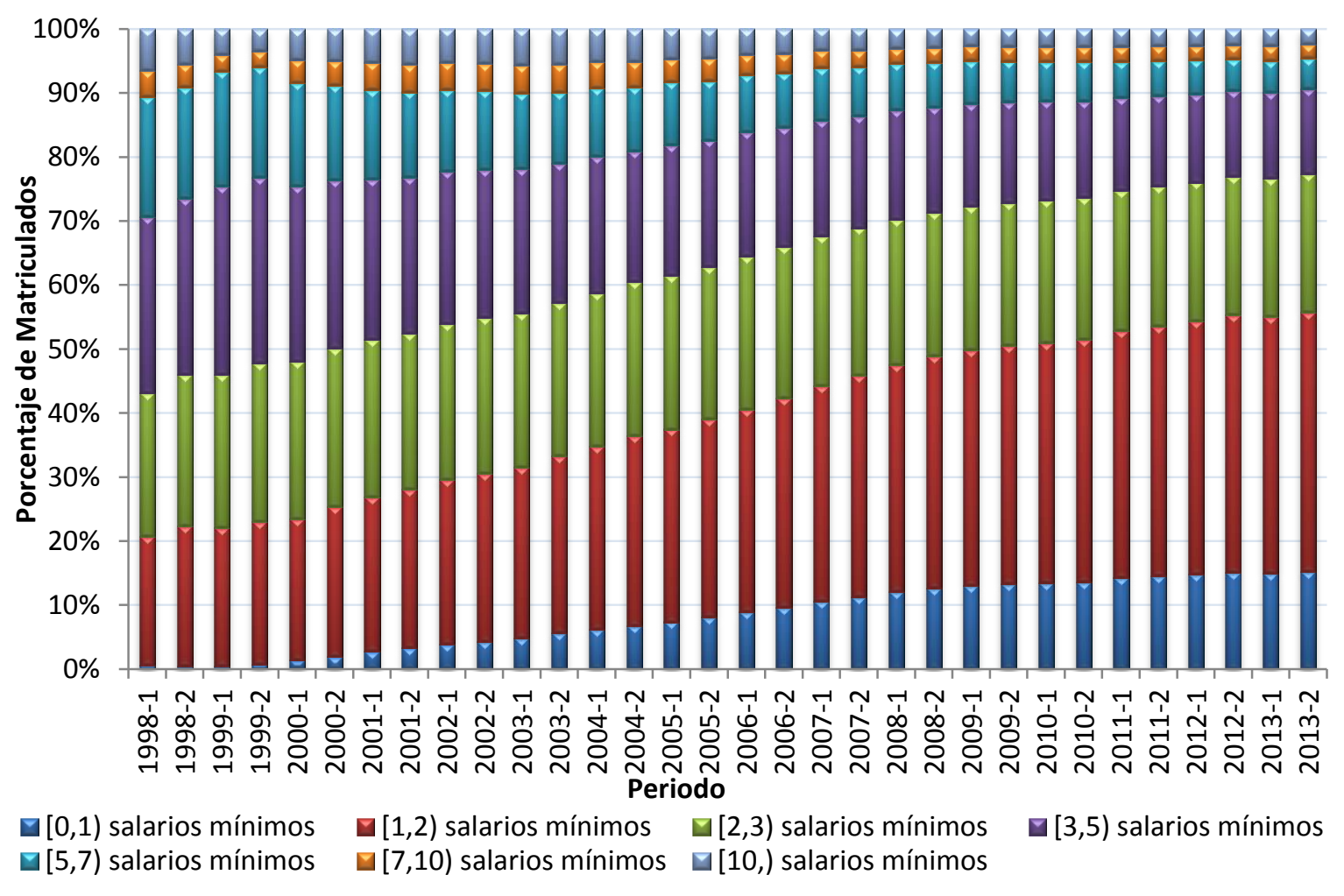

Fuente: Aplicativo SPADIES.

\subsubsection{Nivel educativo de la madre}

En la gráfica 6 se encuentra el porcentaje del total de matriculados según el nivel educativo de la madre. Es posible observar una clara tendencia decreciente en el porcentaje de matriculados cuya madre tiene un nivel educativo de básica primaria o inferior, mientras hay un aumento considerable en el porcentaje de matriculados cuya madre tiene educación básica secundaria. Lo anterior, puede indicar que ha habido un aumento promedio en la educación de las madres, aunque puede haber un sesgo de selección en la población que entra a la educación superior. Por otro lado, el porcentaje de matriculados cuya madre tienen educación universitaria tuvo una tendencia creciente hasta el 2007, y de ahí en adelante comenzó a decrecer. 
Gráfica 6. Porcentaje de Matriculados por Nivel Educativo de la Madre entre 1998-1 y 2013.2. Agregado Nacional.

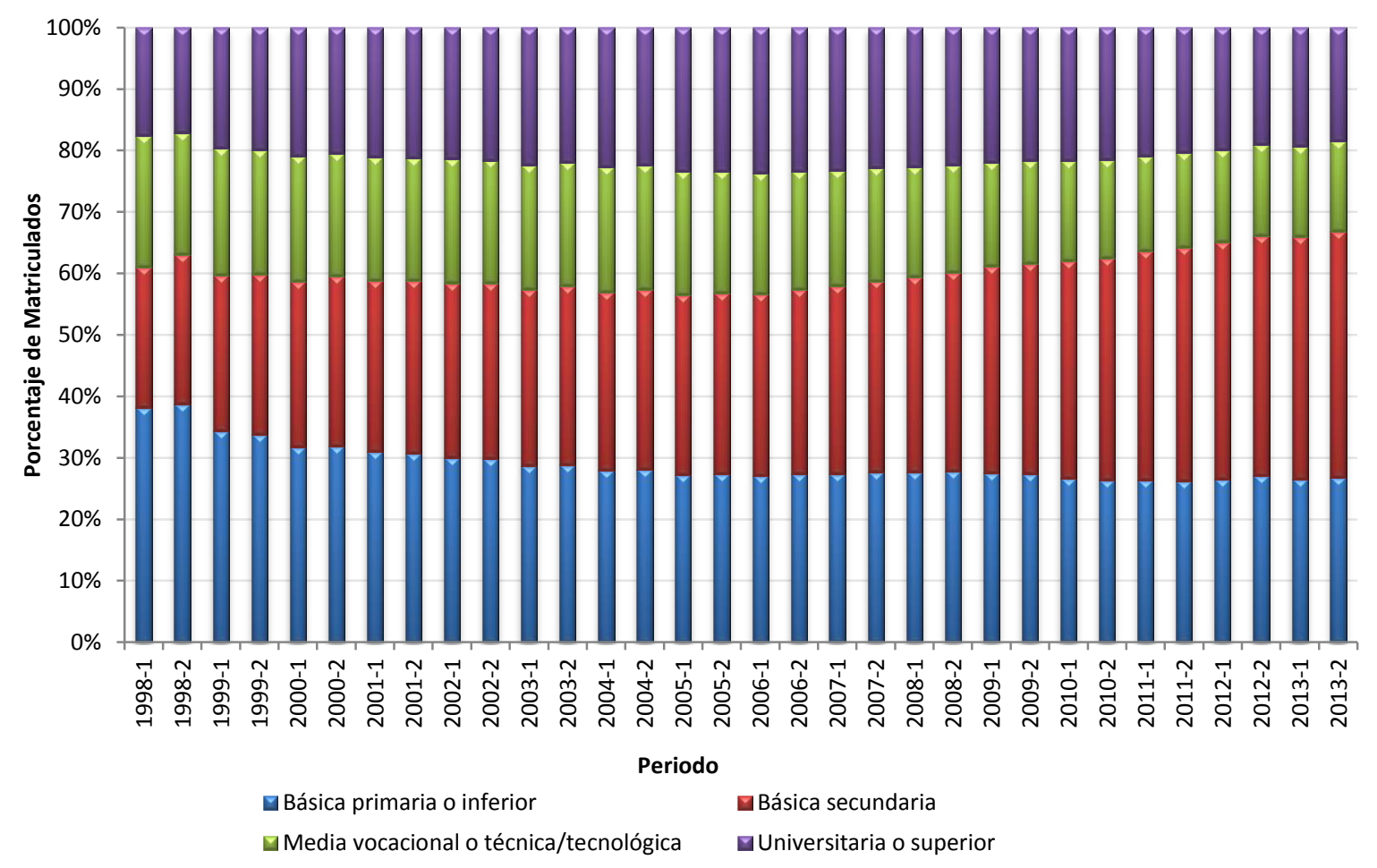

Fuente: Aplicativo SPADIES.

\subsubsection{Número de hermanos}

El cálculo del porcentaje de matriculados según el número de hermanos se realiza únicamente para los primíparos en cada periodo y se presenta en la gráfica 7. Se observa que las categorías con mayor porcentaje de primíparos son las que tienen menor número de hermanos, ya que el porcentaje de primíparos que no tienen hermanos es aproximadamente el $30 \%$ para todos los periodos, igual al porcentaje de primíparos que tienen solo un hermano. 
Gráfica 7. Porcentaje de Primíparos según el Número de hermanos entre 1998-1 y 2013-2. Agregado Nacional.

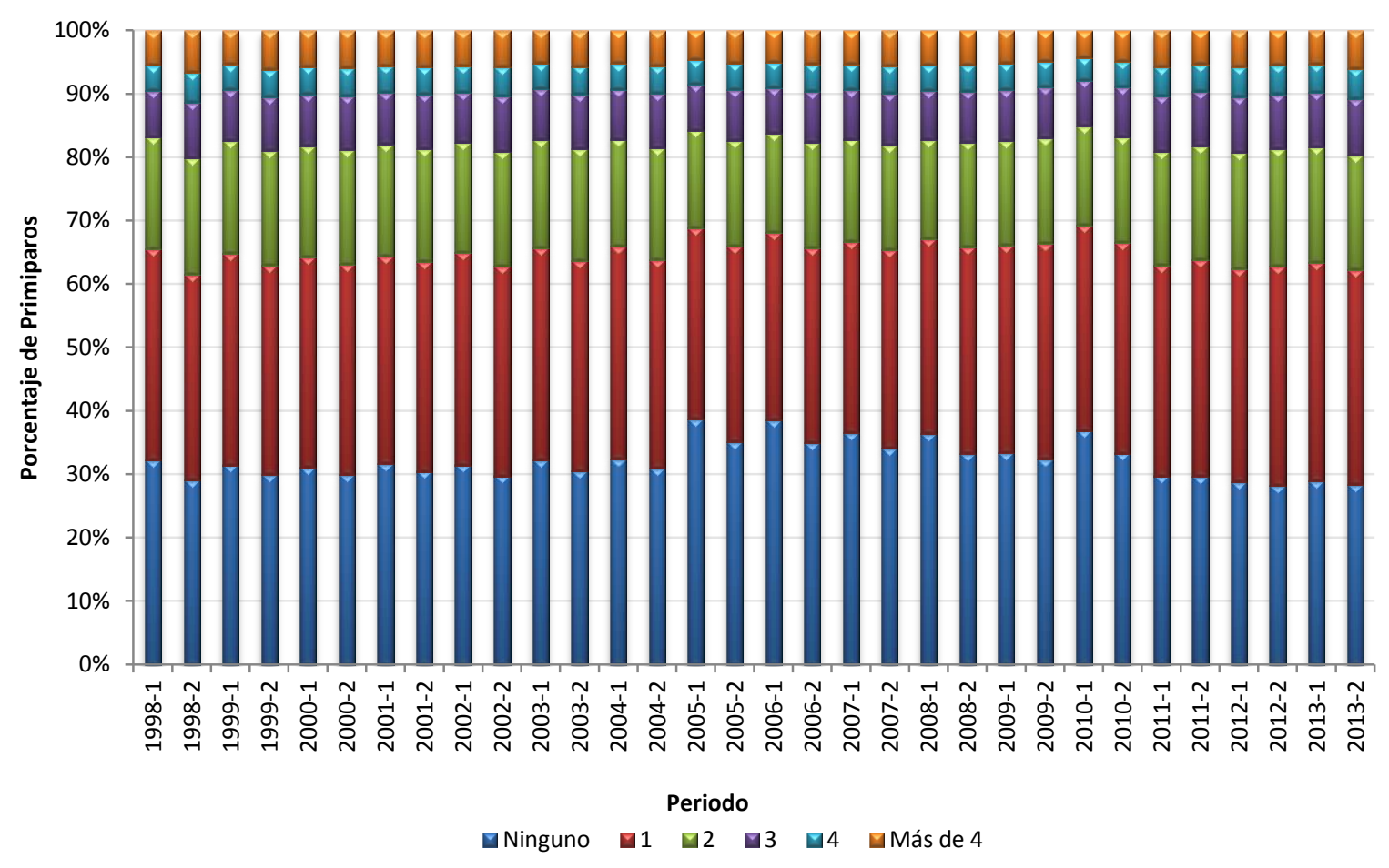

Fuente: Aplicativo SPADIES.

\subsubsection{Posición entre hermanos}

La Gráfica 8 presenta el porcentaje de primíparos según su posición entre hermanos. Los datos muestran que cerca del $50 \%$ de los primíparos en cada semestre son los primeros hijos del hogar, mientras que un $30 \%$ adicional son sólo el segundo y cerca de un $10 \%$ el tercero. Si bien esto es evidencia de la composición de los hogares de los estudiantes que ingresan a educación superior, no necesariamente indica que quienes ingresen a educación superior pertenezcan a hogares de un solo hijo. 
Gráfica 8. Porcentaje de Primíparos según Posición entre los hermanos entre 1998-1 y 2014-1. Agregado Nacional.

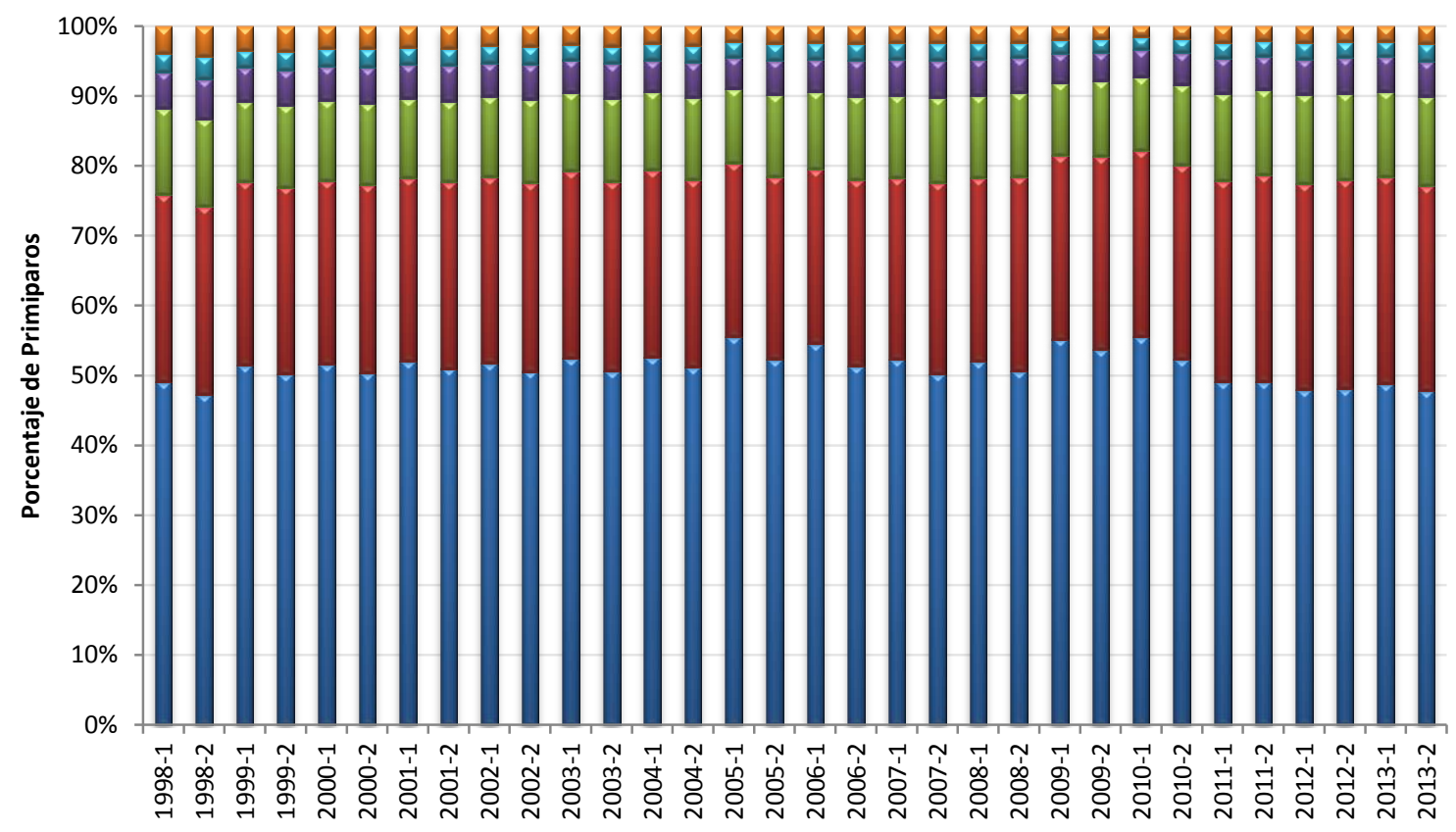

Periodo

घPrimero $\square$ Segundo $\square$ Tercero $\square$ Cuarto $\square$ Quinto $\square$ Posterior al quinto

Fuente: Aplicativo SPADIES.

\subsubsection{Información académica}

\subsubsection{Tasa de repitencia}

La tasa de repitencia se define como la cantidad de materias perdidas sobre materias vistas del periodo anterior. En la gráfica 9 se puede observar la tasa de repitencia de los estudiantes matriculados para cada periodo. Se aprecia que la mayor tasa de repitencia para todos los periodos esta entre el $0 \%$ y el $10 \%$, pero que a lo largo de los periodos ha venido disminuyendo paulatinamente. Por otro lado, las demás tasas han venido aumentando, lo que significa que cada vez la tasa de repitencia es mayor. 
Gráfica 9. Porcentaje de matriculados según Tasa de Repitencia entre 1998-1 a 2013-2. Agregado Nacional.

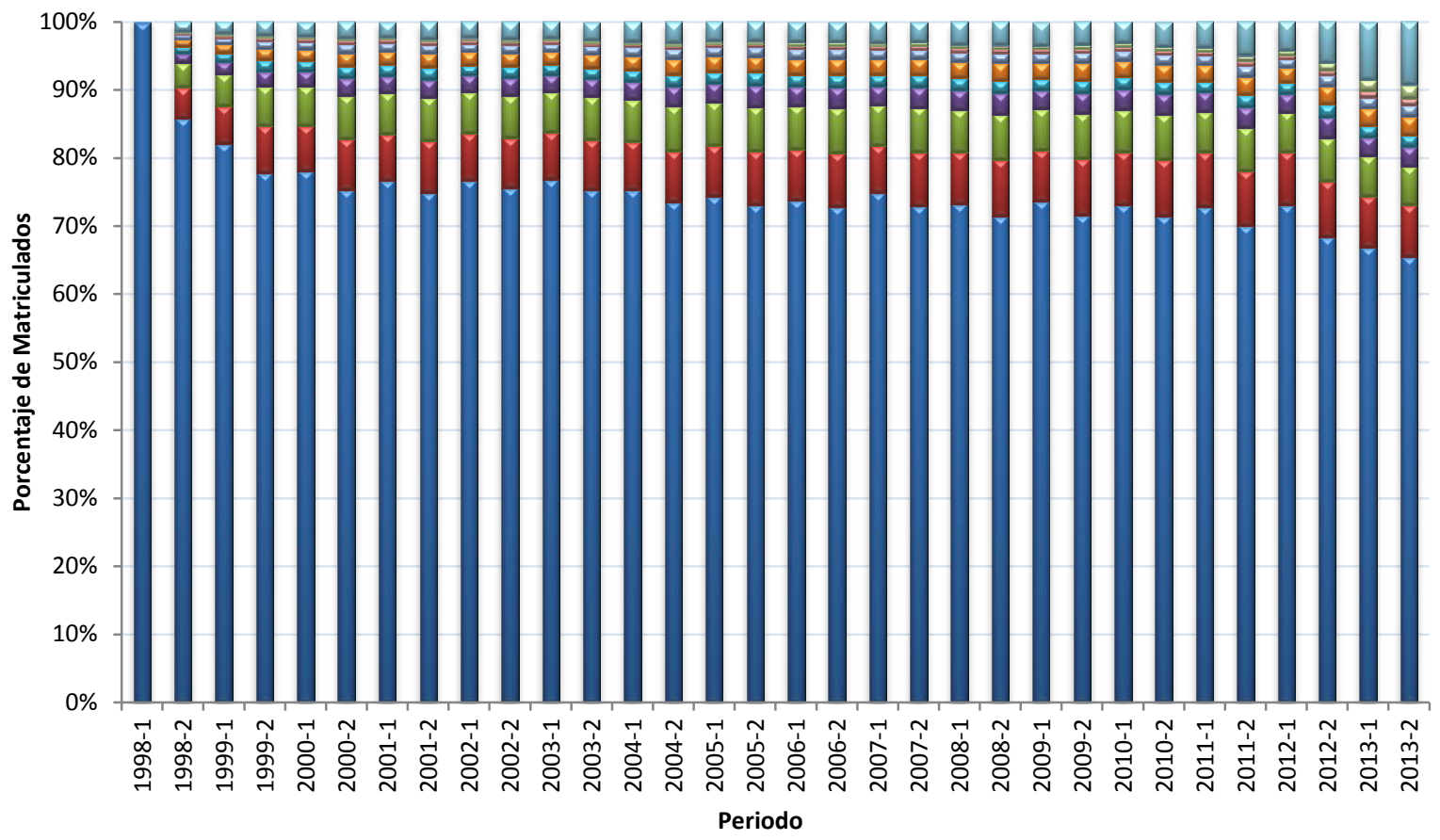

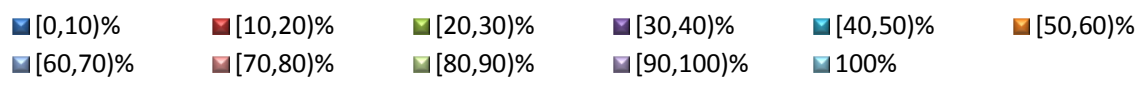

Fuente: Aplicativo SPADIES.

\subsubsection{Clasificación pruebas de estado}

En la gráfica 10 se encuentran el porcentaje de estudiantes matriculados según su clasificación en las pruebas de estado Saber 11. Como se puede observar, en los últimos años ha habido una disminución del porcentaje de estudiantes con calificación alta matriculados en educación superior y en contraste, el porcentaje de estudiantes con calificación baja ha aumentado. 
Gráfica 10. Porcentaje de Matriculados según Clasificación en las pruebas de estado entre 1998-1 a 20132. Agregado Nacional.

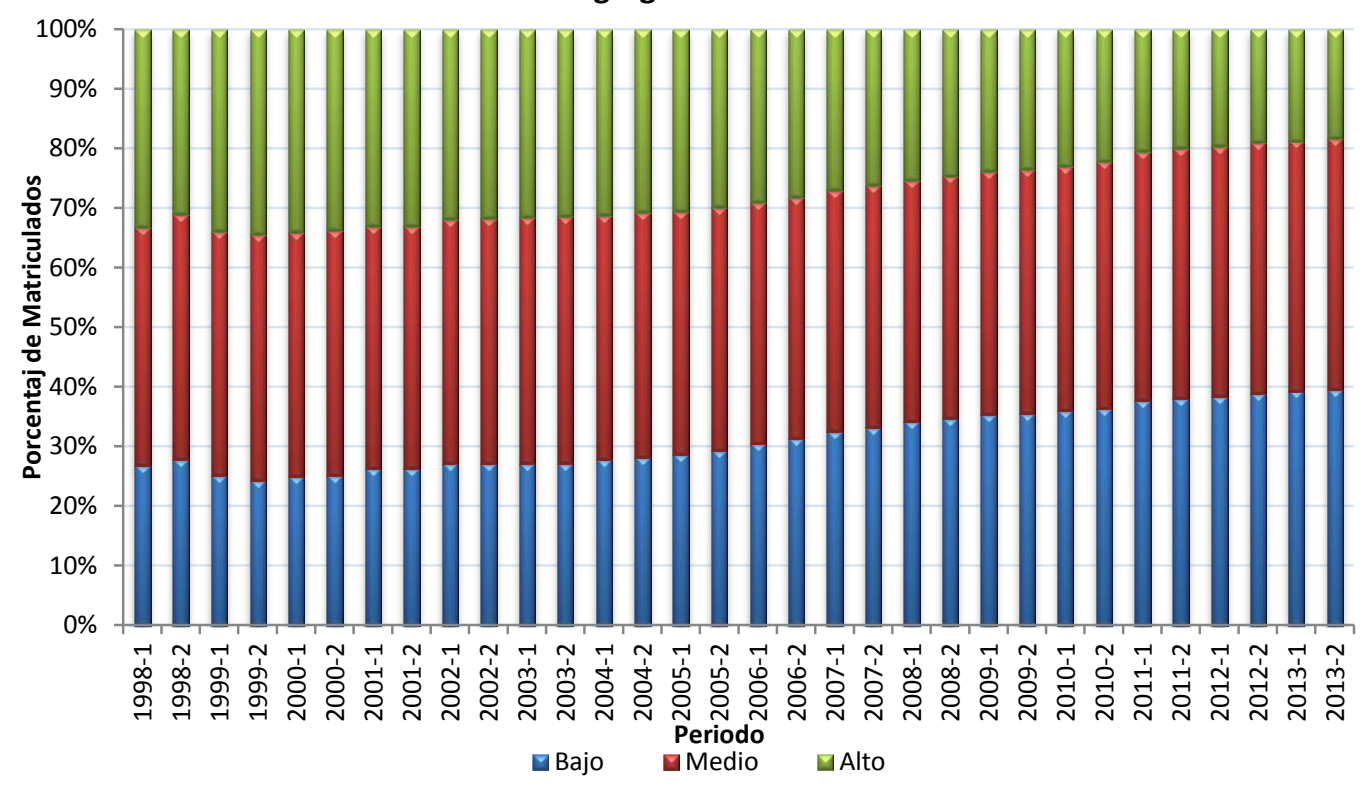

Fuente: Aplicativo SPADIES.

\subsection{Comportamiento global de la deserción estudiantil}

Las gráficas o continuación caracterizan el comportamiento de la deserción promedio acumulada de acuerdo a las características sociodemográficas de los estudiantes.

\subsubsection{Caracterización de los individuos}

\subsubsection{Sexo}

La gráfica 11 presenta la tasa de deserción promedio acumulada nacional por semestres cursados según sexo. Al observar la gráfica, se encuentra que para todos los semestres los hombres presentan una mayor tasa de deserción que las mujeres, con una diferencia que alcanza a se de 10 puntos porcentuales en noveno semestre. 
Gráfica 11. Porcentaje de Desertores según Sexo entre 1998-1 y 2014-1. Agregado Nacional.

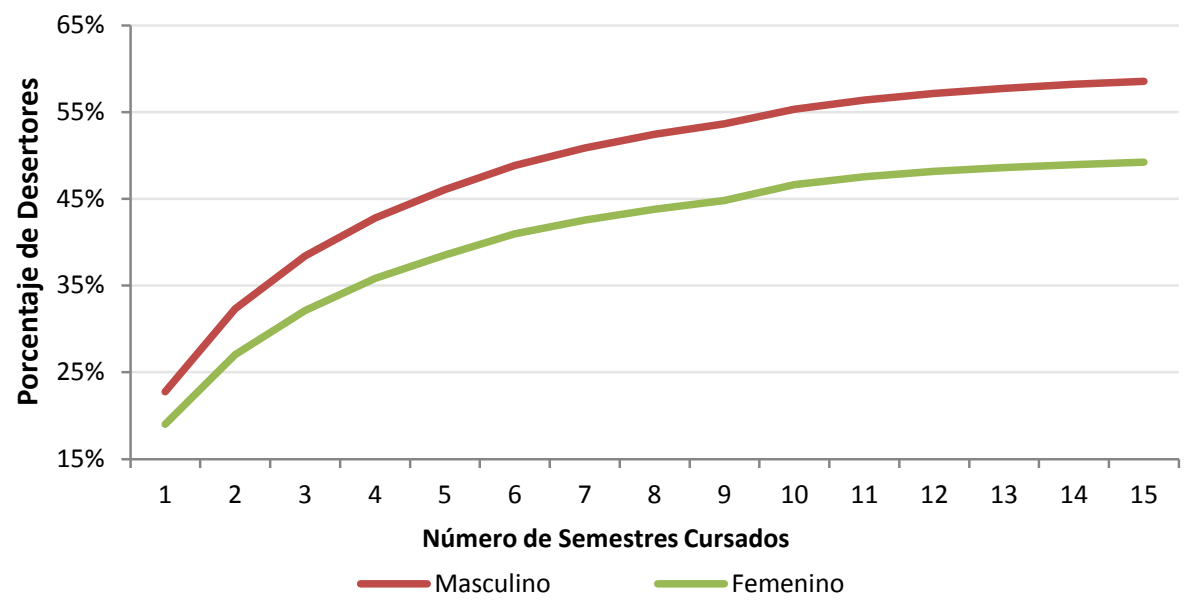

Fuente: Aplicativo SPADIES.

\subsubsection{Trabaja al momento de presentar el examen}

En la gráfica 12 se puede apreciar que para cualquier número de semestres cursados, la tasa de deserción siempre es mayor para los individuos que trabajaban que los que no. Esto se pude explicar ya que la demanda de tiempo del trabajo puede hacer más difícil estudiar, causando mayor deserción.

Gráfica 12. Porcentaje de Desertores según la variable Trabaja al momento de presentar el examen entre 1998-1 y 2014-1. Agregado Nacional.

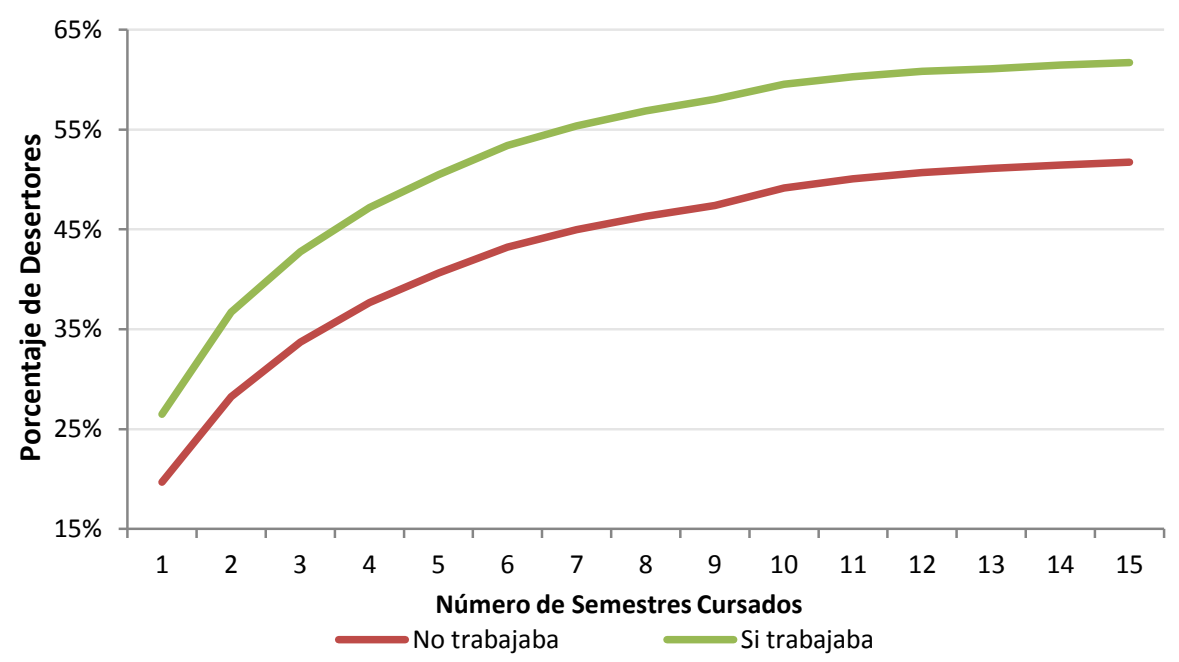

Fuente: Aplicativo SPADIES.

\subsubsection{Edad}

Cómo se puede observar en la gráfica 13, el rango de edad para el cual se presenta una menor tasa de deserción para todos los semestres es 15 o menos años. Así mismo, el rango de edad que presenta mayor porcentaje de desertores es entre 21 y 25 años. 
Gráfica 13. Porcentaje de Desertores según Edad entre 1998-1 y 2014-1. Agregado Nacional.

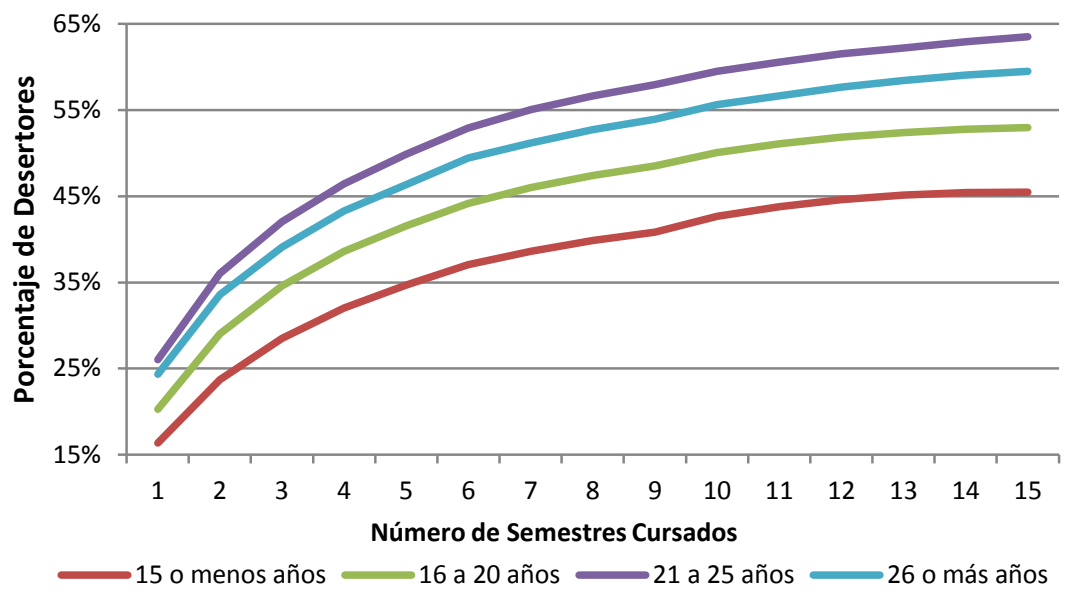

Fuente: Aplicativo SPADIES.

\subsubsection{Ingreso de la familia}

Al observar la gráfica de porcentaje de desertores según ingreso salarial de la familia, se observa una fuerte relación inversa entre el ingreso y la deserción. El rango salarial de las familia para el cual hay mayor tasa de deserción es para aquellas que ganan entre 0 y 1 salario mínimo. El segundo rango para el cual hay más porcentaje de desertores es de 1 a 2 salarios mínimos, y a medida que se aumenta el rango salarial de la familia disminuye la tasa de deserción para todos los semestres. Para el único caso que no se cumple esta regla es para los rangos entre 5 y 7 salarios y entre 7 y 10 salarios mínimos. En este caso, el porcentaje de desertores es mayor para aquellos estudiantes que pertenecen a una familia con un ingreso entre 7 y 10 salarios que para los estudiantes que pertenecen a una familia con un ingreso entre 5 y 7 salarios mínimos.

\section{Gráfica 14. Porcentaje de Desertores según Ingreso de la familia entre 1998-1 y 2014-1. Agregado} Nacional.

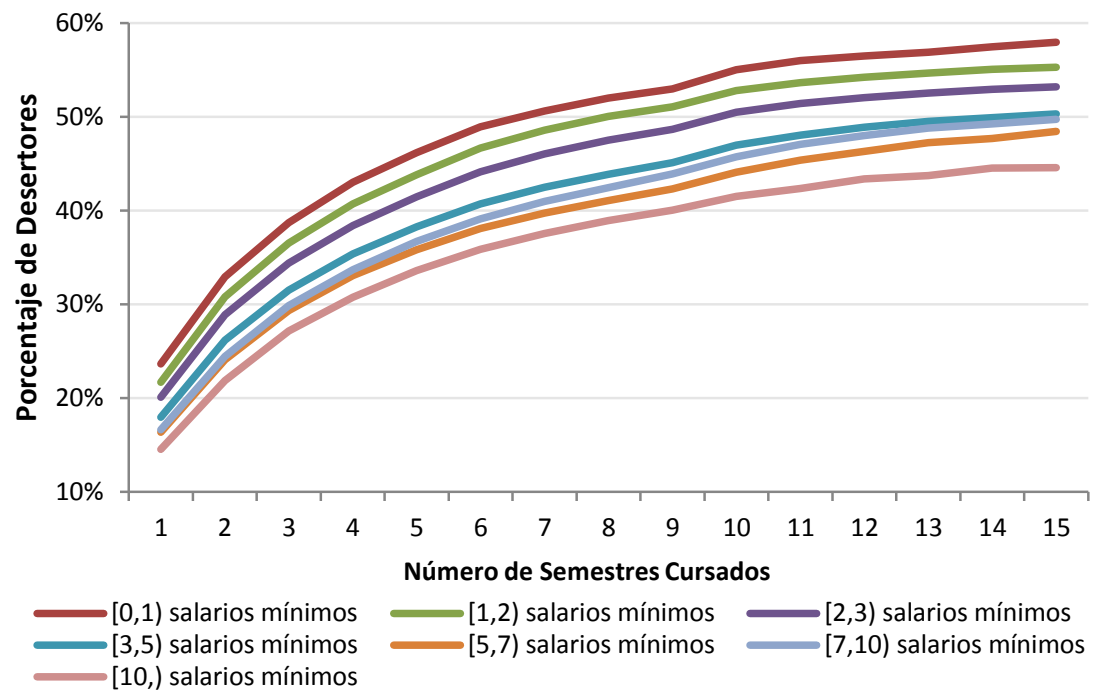


Fuente: Aplicativo SPADIES.

\subsubsection{Nivel educativo de la madre}

Observando la gráfica 15, es posible distinguir una relación inversa entre el nivel educativo de la madre y el porcentaje de desertores. Se observa que a medida que la madre tiene un nivel mayor de educación, por ejemplo, de básica secundaria a medio vocacional o técnica/tecnológica, el porcentaje de desertores disminuye para todos los semestres cursados.

Gráfica 15. Porcentaje de Desertores según el Nivel educativo de la madre entre 1998-1 y 2014-1. Agregado Nacional.

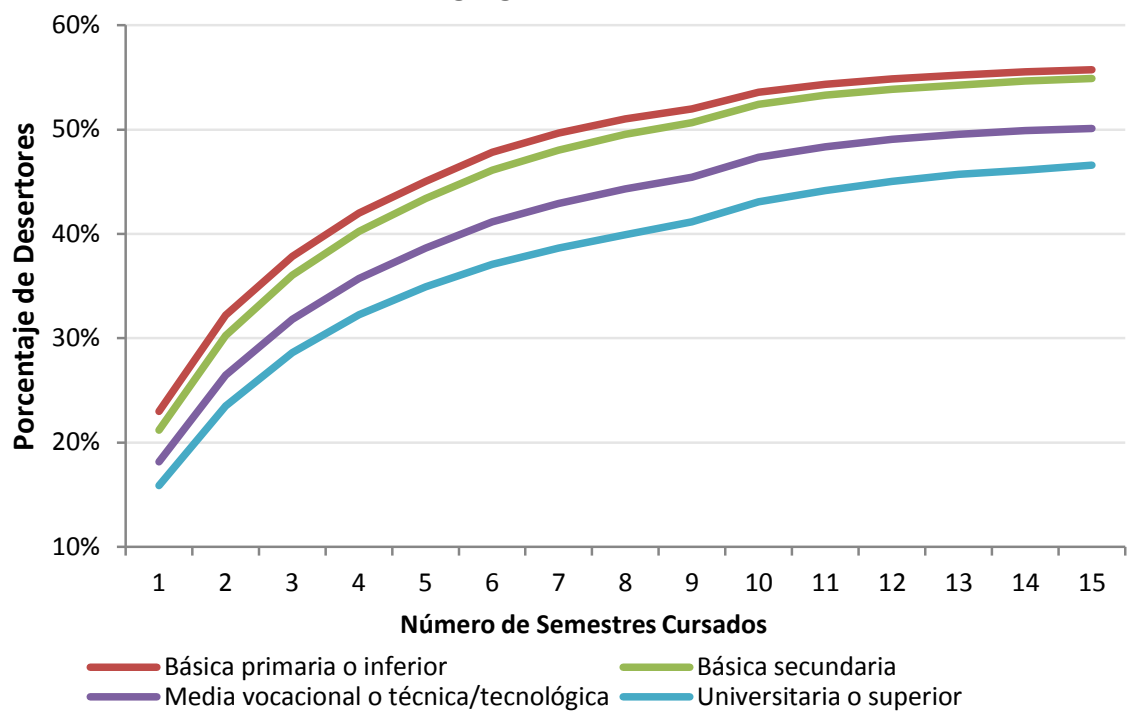

Fuente: Aplicativo SPADIES.

\subsubsection{Clasificación examen de estado}

Cómo se observa en la gráfica 16 , hay una clara relación inversa entre la clasificación de los estudiantes según los resultados en el examen y la tasa de deserción, ya que los estudiantes con peor clasificación presentan mayor tasa de deserción y los de mejor las menores tasas. 
Gráfica 16. Porcentaje de Desertores según Clasificación de examen entre 1998-1 a 2014-1. Agregado Nacional.

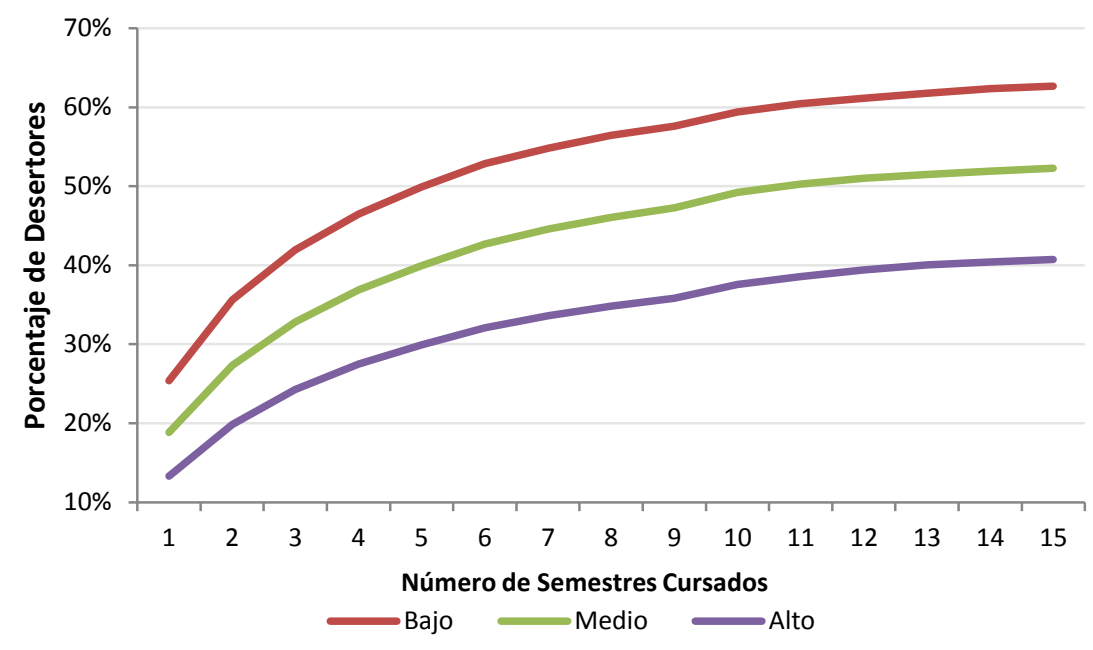

Fuente: Aplicativo SPADIES.

\subsubsection{Características de las IES}

\subsubsection{Deserción por cohorte}

La tabla 5 muestra el porcentaje de deserción por semestre de acuerdo a la cohorte de ingreso hasta el semestre 12. Los valores señalados en verde son las deserciones de cohorte más bajas de cada semestre y por el contrario, las señaladas en rojo son las más altas. De manera consistente, se observa que la cohorte que ingresó en el primer semestre de 2001 presenta las deserciones más bajas para los semestres $1,5,6,7,9,10,11$ y 12 . De hecho, la deserción más baja de la que se tiene registro se presentó en la cohorte de primer semestre de 2000 en donde a primer semestre, desertaron $17.05 \%$ de estudiantes. Por otra parte, las deserciones más altas se presentan en las cohortes que entraron en los periodos más recientes, en particular desde 2007-2 en adelante. La deserción más alta se presentó en el semestre 12 de la cohorte de 2007-2 siendo de 58,44\%. Cabe señalar que, al tratarse de deserciones acumuladas para cada cohorte, entre más bajo sea el semestre más baja será la deserción y entre más alto sea el semestre la deserción será más alta.

Tabla 5. Deserción por cohorte entre 1998-1 y 2014-1. Agregado Nacional.

\begin{tabular}{|l|rrrrrrrrrrrrr|}
\hline Cohorte & $\mathbf{1}$ & $\mathbf{2}$ & $\mathbf{3}$ & $\mathbf{4}$ & $\mathbf{5}$ & $\mathbf{6}$ & $\mathbf{7}$ & $\mathbf{8}$ & $\mathbf{9}$ & $\mathbf{1 0}$ & $\mathbf{1 1}$ & $\mathbf{1 2}$ \\
\hline $\mathbf{1 9 9 8 - 1}$ & $17,24 \%$ & $25,78 \%$ & $31,19 \%$ & $34,80 \%$ & $37,56 \%$ & $40,46 \%$ & $42,15 \%$ & $43,64 \%$ & $44,84 \%$ & $46,59 \%$ & $47,84 \%$ & $48,77 \%$ \\
$\mathbf{1 9 9 8 - 2}$ & $20,33 \%$ & $28,92 \%$ & $34,57 \%$ & $38,40 \%$ & $41,31 \%$ & $43,62 \%$ & $45,30 \%$ & $46,71 \%$ & $48,29 \%$ & $49,68 \%$ & $51,03 \%$ & $51,96 \%$ \\
$\mathbf{1 9 9 9 - 1}$ & $17,66 \%$ & $26,21 \%$ & $31,48 \%$ & $35,64 \%$ & $38,36 \%$ & $40,47 \%$ & $42,21 \%$ & $43,88 \%$ & $45,41 \%$ & $47,37 \%$ & $48,52 \%$ & $49,77 \%$ \\
$\mathbf{1 9 9 9 - 2}$ & $18,99 \%$ & $27,23 \%$ & $32,55 \%$ & $36,47 \%$ & $39,09 \%$ & $41,18 \%$ & $43,15 \%$ & $44,65 \%$ & $46,45 \%$ & $48,02 \%$ & $49,43 \%$ & $50,36 \%$ \\
$\mathbf{2 0 0 0 - 1}$ & $17,05 \%$ & $25,62 \%$ & $30,92 \%$ & $34,66 \%$ & $37,19 \%$ & $39,79 \%$ & $41,56 \%$ & $43,11 \%$ & $44,49 \%$ & $46,53 \%$ & $47,69 \%$ & $48,58 \%$ \\
$\mathbf{2 0 0 0 - 2}$ & $19,10 \%$ & $28,14 \%$ & $33,41 \%$ & $36,91 \%$ & $40,03 \%$ & $42,28 \%$ & $44,33 \%$ & $45,71 \%$ & $47,24 \%$ & $48,70 \%$ & $49,81 \%$ & $50,77 \%$ \\
$\mathbf{2 0 0 1 - 1}$ & $19,73 \%$ & $28,26 \%$ & $33,39 \%$ & $37,19 \%$ & $40,07 \%$ & $42,59 \%$ & $44,51 \%$ & $46,64 \%$ & $47,92 \%$ & $49,38 \%$ & $50,42 \%$ & $51,55 \%$ \\
$\mathbf{2 0 0 1 - 2}$ & $19,48 \%$ & $27,89 \%$ & $33,40 \%$ & $37,00 \%$ & $40,04 \%$ & $42,55 \%$ & $44,92 \%$ & $46,40 \%$ & $47,60 \%$ & $49,10 \%$ & $50,42 \%$ & $51,56 \%$ \\
$\mathbf{2 0 0 2 - 1}$ & $18,89 \%$ & $27,95 \%$ & $33,04 \%$ & $36,84 \%$ & $39,55 \%$ & $42,80 \%$ & $44,50 \%$ & $45,80 \%$ & $47,04 \%$ & $48,78 \%$ & $49,94 \%$ & $51,01 \%$ \\
$\mathbf{2 0 0 2 - 2}$ & $19,95 \%$ & $27,87 \%$ & $33,64 \%$ & $37,38 \%$ & $41,10 \%$ & $43,62 \%$ & $45,48 \%$ & $46,98 \%$ & $48,34 \%$ & $49,91 \%$ & $51,33 \%$ & $52,30 \%$ \\
$\mathbf{2 0 0 3 - 1}$ & $18,63 \%$ & $26,96 \%$ & $32,29 \%$ & $36,52 \%$ & $39,47 \%$ & $41,88 \%$ & $43,66 \%$ & $45,36 \%$ & $46,65 \%$ & $48,47 \%$ & $49,79 \%$ & $50,83 \%$
\end{tabular}




\begin{tabular}{|c|c|c|c|c|c|c|c|c|c|c|c|c|}
\hline 2003-2 & $20,35 \%$ & $28,75 \%$ & $34,88 \%$ & $39,12 \%$ & $41,94 \%$ & $44,61 \%$ & $46,87 \%$ & $48,50 \%$ & $49,72 \%$ & $51,44 \%$ & $52,64 \%$ & $53,63 \%$ \\
\hline 2004-1 & $20,35 \%$ & $29,43 \%$ & $35,02 \%$ & $38,70 \%$ & $41,40 \%$ & $44,11 \%$ & $45,93 \%$ & $47,34 \%$ & $48,66 \%$ & $50,31 \%$ & $51,61 \%$ & $52,87 \%$ \\
\hline 2004-2 & $22,11 \%$ & $31,07 \%$ & $36,54 \%$ & $40,24 \%$ & $43,34 \%$ & $45,86 \%$ & $47,74 \%$ & $49,28 \%$ & $50,50 \%$ & $52,01 \%$ & $53,53 \%$ & $54,72 \%$ \\
\hline 2005-1 & $20,70 \%$ & $29,40 \%$ & $34,63 \%$ & $38,47 \%$ & $41,28 \%$ & $43,90 \%$ & $45,91 \%$ & $47,35 \%$ & $48,56 \%$ & $50,75 \%$ & $52,25 \%$ & $53,47 \%$ \\
\hline 2005-2 & $20,11 \%$ & $28,49 \%$ & $34,38 \%$ & $38,13 \%$ & $41,24 \%$ & $43,94 \%$ & $46,09 \%$ & $47,67 \%$ & $49,06 \%$ & $50,94 \%$ & $52,33 \%$ & $53,67 \%$ \\
\hline 2006-1 & $20,03 \%$ & $29,13 \%$ & $34,40 \%$ & $38,35 \%$ & $41,63 \%$ & $44,19 \%$ & $46,15 \%$ & $47,72 \%$ & $49,14 \%$ & $51,21 \%$ & $52,85 \%$ & $54,24 \%$ \\
\hline 2006-2 & $21,86 \%$ & $30,13 \%$ & $36,02 \%$ & $40,10 \%$ & $43,29 \%$ & $46,03 \%$ & $48,05 \%$ & $49,77 \%$ & $51,27 \%$ & $53,37 \%$ & $55,18 \%$ & $56,63 \%$ \\
\hline 2007-1 & $19,99 \%$ & $30,19 \%$ & $35,88 \%$ & $40,17 \%$ & $43,42 \%$ & $46,25 \%$ & $48,49 \%$ & $50,09 \%$ & $51,58 \%$ & $54,14 \%$ & $56,01 \%$ & $57,80 \%$ \\
\hline 2007-2 & $21,64 \%$ & $30,98 \%$ & $36,71 \%$ & $40,84 \%$ & $44,31 \%$ & $47,57 \%$ & $49,69 \%$ & $51,42 \%$ & $53,11 \%$ & $55,89 \%$ & $58,33 \%$ & $58,44 \%$ \\
\hline 2008-1 & $22,32 \%$ & $31,44 \%$ & $37,08 \%$ & $41,25 \%$ & $44,84 \%$ & $47,70 \%$ & $49,77 \%$ & $51,59 \%$ & $53,40 \%$ & $57,20 \%$ & $57,36 \%$ & \\
\hline 2008-2 & $21,84 \%$ & $31,12 \%$ & $37,15 \%$ & $41,93 \%$ & $45,32 \%$ & $48,17 \%$ & $50,41 \%$ & $52,45 \%$ & $54,58 \%$ & $54,80 \%$ & & \\
\hline 2009-1 & $22,16 \%$ & $31,04 \%$ & $37,10 \%$ & $41,78 \%$ & $45,03 \%$ & $48,21 \%$ & $50,46 \%$ & $52,60 \%$ & $52,71 \%$ & & & \\
\hline 2009-2 & $22,02 \%$ & $30,95 \%$ & $36,69 \%$ & $41,00 \%$ & $44,53 \%$ & $47,80 \%$ & $50,54 \%$ & $50,62 \%$ & & & & \\
\hline 2010-1 & $21,51 \%$ & $30,06 \%$ & $36,04 \%$ & $40,78 \%$ & $44,54 \%$ & $48,28 \%$ & $48,40 \%$ & & & & & \\
\hline 2010-2 & $21,16 \%$ & $30,30 \%$ & $36,82 \%$ & $41,37 \%$ & $45,24 \%$ & $45,36 \%$ & & & & & & \\
\hline 2011-1 & $22,58 \%$ & $31,75 \%$ & $37,04 \%$ & $41,83 \%$ & $41,96 \%$ & & & & & & & \\
\hline 2011-2 & $23,87 \%$ & $31,89 \%$ & $37,68 \%$ & $37,83 \%$ & & & & & & & & \\
\hline 2012-1 & $20,87 \%$ & $29,96 \%$ & $30,15 \%$ & & & & & & & & & \\
\hline 2012-2 & $23,98 \%$ & $24,26 \%$ & & & & & & & & & & \\
\hline 2013-1 & $18,43 \%$ & & & & & & & & & & & \\
\hline
\end{tabular}

Fuente: Aplicativo SPADIES.

\subsubsection{Deserción por periodo}

La gráfica 17 presenta el comportamiento de la deserción promedio de educación superior observada en cada periodo. Se observa que esta tasa presenta un comportamiento a lo largo de los distintos periodos.

Gráfica 17. Porcentaje de Desertores entre 1998-1 y 2014-1. Agregado Nacional.

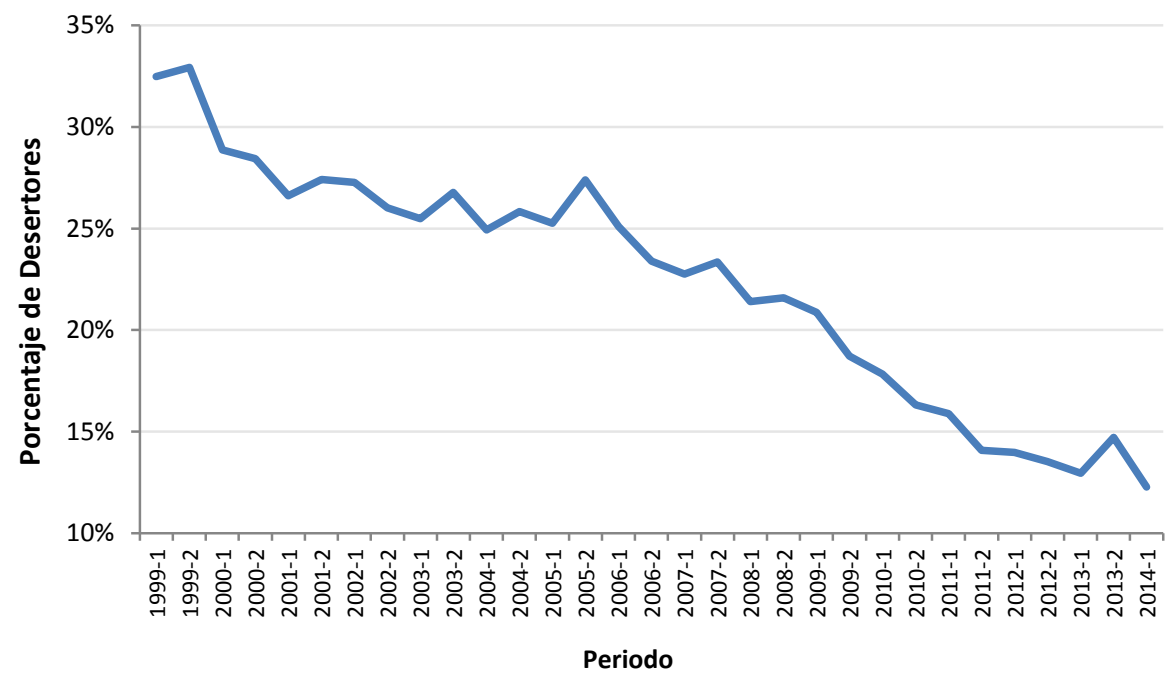

Fuente: Aplicativo SPADIES. 


\subsubsection{Graduación por cohorte}

La gráfica 18 muestra el porcentaje de graduados por cohorte entre 1998 -1 y 2014-1 para el agregado nacional. Lo que muestran estos datos es que a partir del octavo semestre, el porcentaje de graduados en cada cohorte va en aumento, llegando a ser del 35\% para el semestre 15.

Gráfica 18. Porcentaje de Graduados por Número de semestres cursados entre 1998-1 y 2014-1. Agregado Nacional.

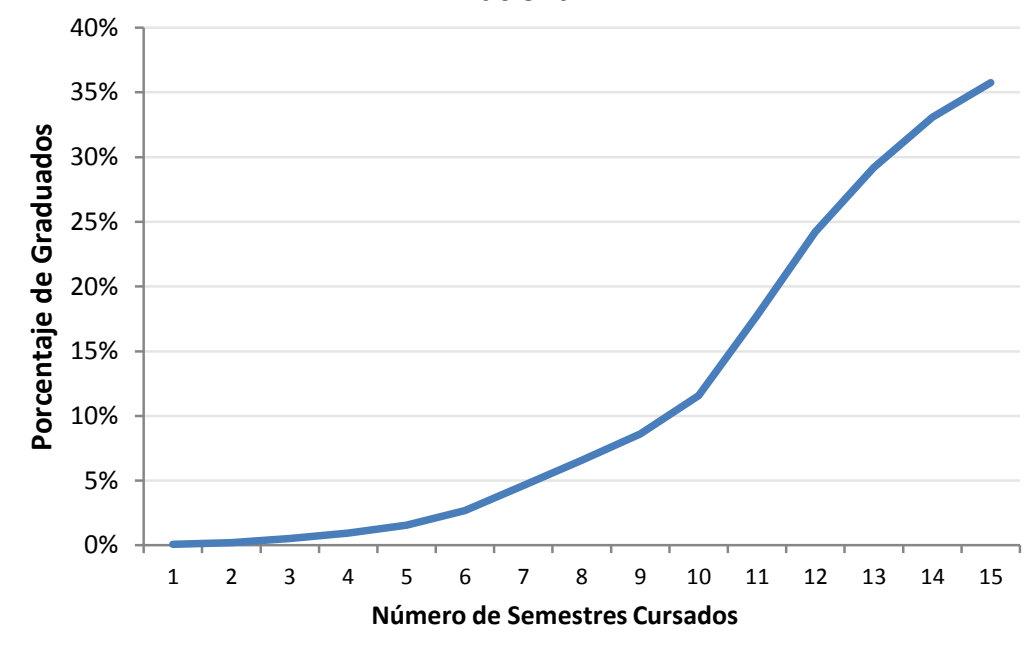

Fuente: Aplicativo SPADIES.

\subsubsection{Nivel de formación}

Como se puede apreciar en la gráfica 19, hay una relación inversa entre nivel de formación al que pertenece el programa académico del estudiante y la deserción. El nivel de formación con mayor porcentaje de desertores para todos los semestres es Técnico profesional con una deserción promedio de 65\%; seguido por el nivel Tecnológico, cuya deserción aumenta a medida que se avanza en la cohorte observada, pasado de $50 \%$ en quinto semestre a $65 \%$ en $15^{\circ}$ semestre; mientras que el nivel de formación con menor tasa de deserción es Universitario con una deserción que no supera el $50 \%$ en el semestre más avanzado. 
Gráfica 19. Porcentaje de Desertores según Nivel de Formación por número de semestres cursados. Agregado Nacional.

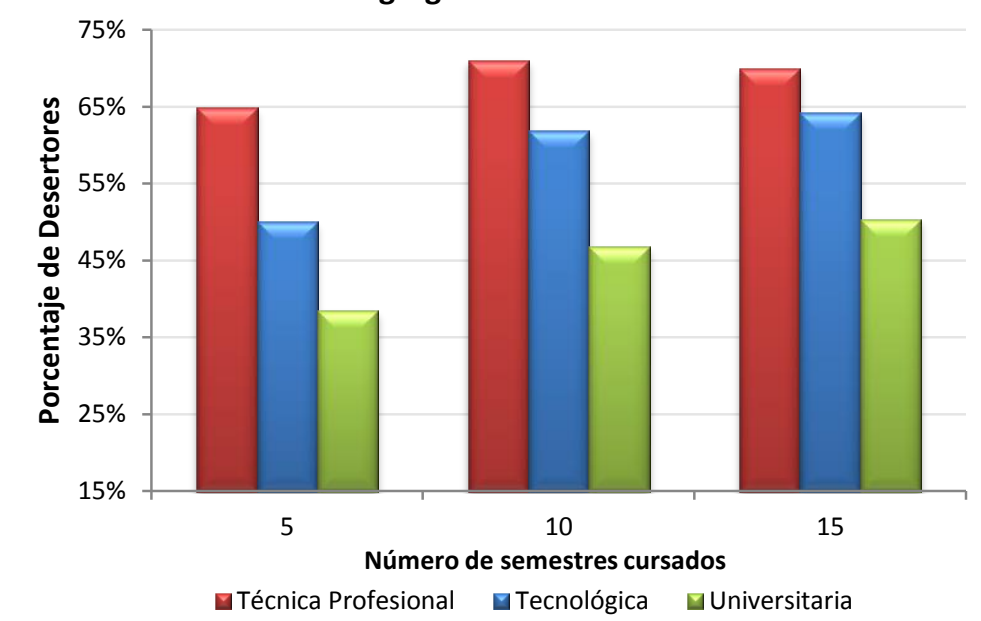

Fuente: Aplicativo SPADIES.

\subsubsection{Naturaleza de la IES}

En la gráfica 20 se presenta el porcentaje de desertores según la naturaleza de la IES del estudiante. Se aprecia que las IES que menor tasa de deserción tienen son las Universidades, seguidas de cerca por las instituciones universitarias. Además, la que más tiene porcentaje de desertores es la técnica profesional, aunque esto no se cumple para el semestre 10.

En el quinto semestre por ejemplo, mientras que la deserción de Universidades la deserción es del $40 \%$, en las instituciones universitarias es del $45 \%$, de las tecnológicas es de un poco más del $55 \%$ y de las técnicas del $70 \%$. Estas brechas se mantienen para el $15^{\circ}$ semestre aunque la tasa de deserción aumenta para todos los grupos, pasando a ser de 50\%, 55\%, 65\% y $85 \%$ respectivamente.

Gráfica 20. Porcentaje de Desertores según la Naturaleza de las IES por número de semestres cursados. Agregado Nacional.

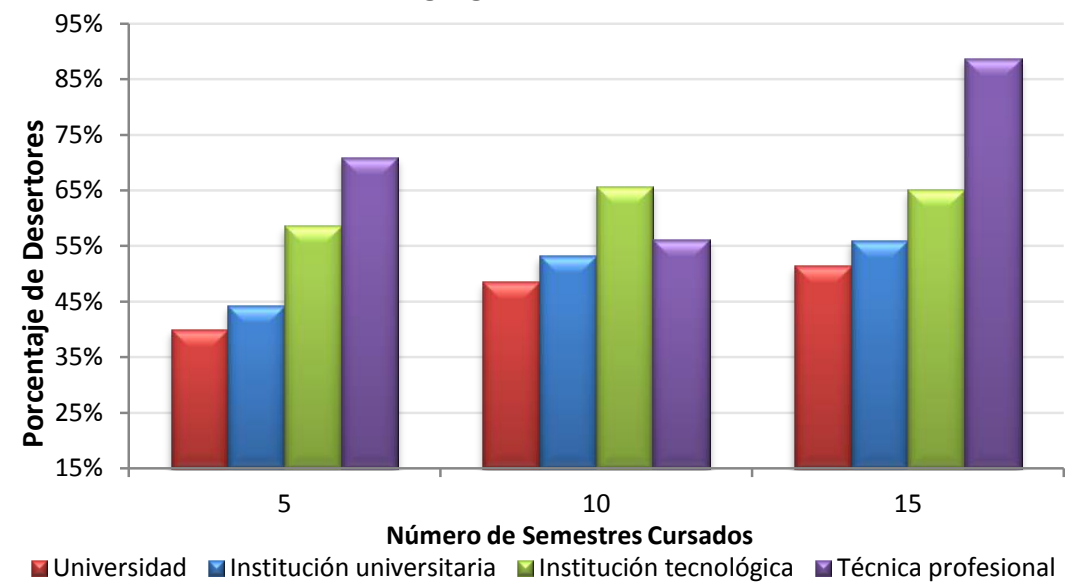

Fuente: Aplicativo SPADIES. 


\subsubsection{6 Área del conocimiento}

En la gráfica 21 se encuentra el porcentaje de desertores por área del conocimiento al cual pertenecen los programas académicos. Se encuentra que para todos los semestres el área con la mayor tasa de deserción es Agronomía, veterinaria y afines, seguido de Ingeniería, arquitectura, urbanismo y afines, con deserciones que superan el $45 \%$. Por otro lado, el área del conocimiento que presenta menor porcentaje de desertores son las ciencias de la salud, programas cuya deserción nunca supera el $40 \%$.

Gráfica 21. Porcentaje de Desertores según el Área del conocimiento por número de semestres cursados. Agregado Nacional.

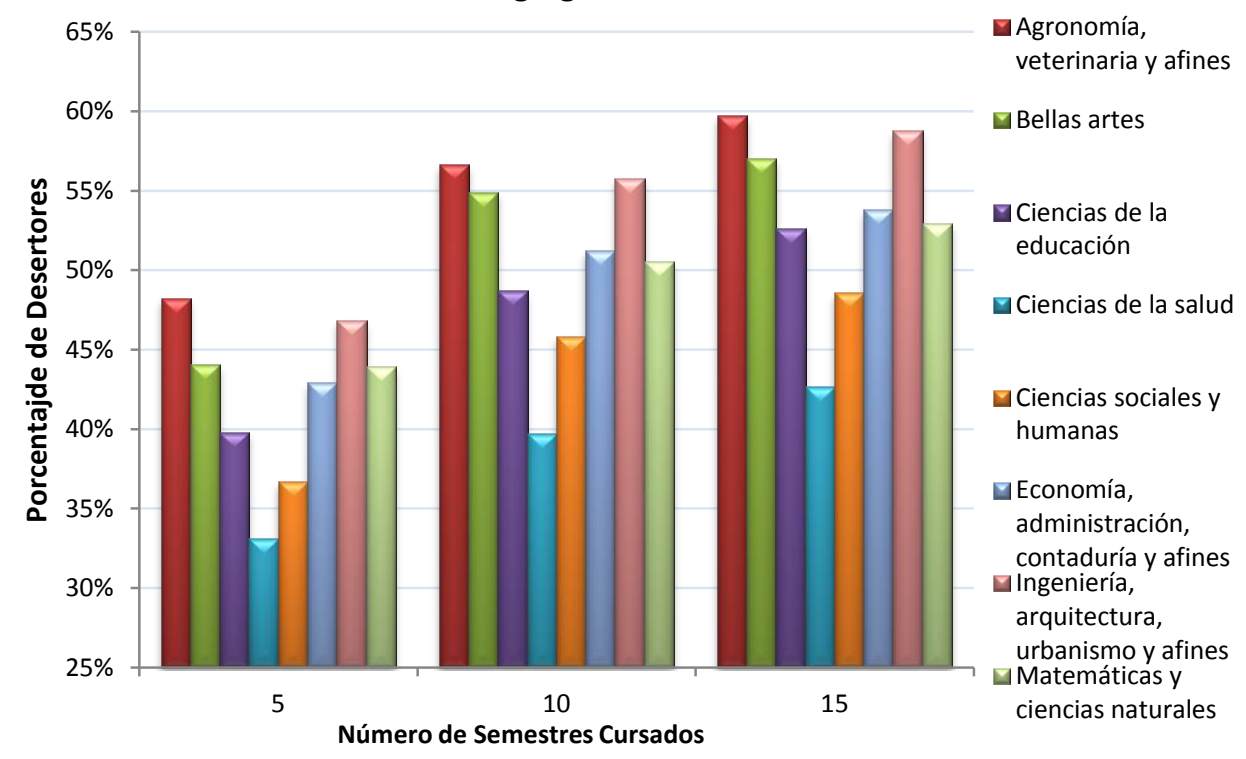

Fuente: Aplicativo SPADIES.

\subsubsection{Deserción por departamentos}

En la tabla 6 se presenta la tasa de deserción por departamento para $5^{\circ}, 10^{\circ}$ y $15^{\circ}$ semestres cursados. Se encuentra que el departamento con mayor tasa de deserción para todos los semestres es Putumayo, con tasas de $67.69 \%, 79.06 \%$ y $71.21 \%$ en $5^{\circ}, 10^{\circ}$ y $15^{\circ}$ semestre respectivamente. Además, es de destacar las bajas tasa de deserción observadas en el departamento de Chocó que para la cohorte del $10^{\circ}$ semestre tuvo la deserción acumulada promedio más baja, con $37.14 \%$. Similar es el caso con Arauca y Amazonas, en donde también se registran las deserciones más bajas en $5^{\circ}$ y $15^{\circ}$ semestre respectivamente.

Tabla 6. Porcentaje de Desertores según departamento para 5, 10 y 15 semestres cursados.

\begin{tabular}{|l|rrr|}
\hline \multicolumn{1}{|c|}{ Departamento } & \multicolumn{3}{|c}{ Número de Semestres Cursados } \\
\hline & 5 & 10 & 15 \\
\hline Antioquia & $41,52 \%$ & $49,82 \%$ & $52,24 \%$ \\
Atlántico & $41,55 \%$ & $50,62 \%$ & $53,60 \%$ \\
Bogotá & $44,48 \%$ & $52,96 \%$ & $56,01 \%$ \\
Bolívar & $42,44 \%$ & $51,70 \%$ & $53,67 \%$ \\
Boyacá & $38,78 \%$ & $45,22 \%$ & $48,99 \%$
\end{tabular}




\begin{tabular}{|l|rrr|} 
Caldas & $34,86 \%$ & $41,23 \%$ & $44,39 \%$ \\
Caquetá & $40,12 \%$ & $48,65 \%$ & $54,75 \%$ \\
Cauca & $38,15 \%$ & $49,04 \%$ & $52,01 \%$ \\
Cesar & $39,07 \%$ & $48,20 \%$ & $53,32 \%$ \\
Córdoba & $39,97 \%$ & $48,84 \%$ & $52,75 \%$ \\
Cundinamarca & $35,67 \%$ & $50,24 \%$ & $53,09 \%$ \\
Chocó & $33,29 \%$ & $37,54 \%$ & \\
Huila & $32,16 \%$ & $40,00 \%$ & $43,26 \%$ \\
La Guajira & $43,05 \%$ & $59,02 \%$ & $65,45 \%$ \\
Magdalena & $42,67 \%$ & $51,22 \%$ & $55,91 \%$ \\
Meta & $36,36 \%$ & $43,92 \%$ & $47,99 \%$ \\
Nariño & $34,62 \%$ & $44,34 \%$ & $48,19 \%$ \\
Norte de Santander & $44,52 \%$ & $52,64 \%$ & $53,41 \%$ \\
Quindío & $43,06 \%$ & $55,59 \%$ & $60,34 \%$ \\
Risaralda & $44,59 \%$ & $51,36 \%$ & $51,85 \%$ \\
Santander & $40,36 \%$ & $49,29 \%$ & $51,35 \%$ \\
Sucre & $35,52 \%$ & $47,08 \%$ & $51,27 \%$ \\
Tolima & $42,86 \%$ & $52,14 \%$ & $59,03 \%$ \\
Valle del Cauca & $44,70 \%$ & $54,02 \%$ & $57,01 \%$ \\
Arauca & $23,98 \%$ & $55,61 \%$ & $66,17 \%$ \\
Casanare & $50,82 \%$ & $60,48 \%$ & $55,56 \%$ \\
Putumayo & $67,69 \%$ & $79,06 \%$ & $71,21 \%$ \\
San Andrés y Providencia & $64,49 \%$ & $64,51 \%$ & $57,19 \%$ \\
Amazonas & $28,57 \%$ & $42,86 \%$ & $42,86 \%$ \\
\hline
\end{tabular}

Fuente: Aplicativo SPADIES.

\subsubsection{Graduados por departamento}

Por otra parte, la tabla 7 presenta el porcentaje de graduados por cohorte acumulada. Aunque la graduación del $5^{\circ}$ semestre para Cundinamarca se resalta como alta (12.61\%), es importante tener presente que es atípicamente alta, tratándose de un semestre tan reciente. Para la graduación, interesarían especialmente las tasas para $10^{\circ}$ y $15^{\circ}$ semestre. Lo que se observa es que la tasa de graduación para Amazonas y San Andrés es particularmente alta en estas cohortes, siendo de $30.53 \%$ y $53.57 \%$ respectivamente. Sin embargo, la tasa de graduación en Amazonas puede es particular, en cuanto que para el $10^{\circ}$ semestre reportan $0 \%$ de graduados.

Tabla 7. Porcentaje de Graduados según departamento para 5, 10 y 15 semestres cursados.

\begin{tabular}{|l|rrr|}
\hline & \multicolumn{3}{|c|}{$\begin{array}{c}\text { Número de Semestres } \\
\text { Cursados }\end{array}$} \\
\hline & $\mathbf{5}$ & $\mathbf{1 0}$ & $\mathbf{1 5}$ \\
\hline Antioquia & $2,45 \%$ & $16,14 \%$ & $37,64 \%$ \\
Atlántico & $1,33 \%$ & $10,41 \%$ & $38,21 \%$
\end{tabular}




\begin{tabular}{|l|rrr|} 
Bogotá & $1,40 \%$ & $10,94 \%$ & $34,60 \%$ \\
Bolívar & $1,22 \%$ & $15,91 \%$ & $38,94 \%$ \\
Caldasá & $0,29 \%$ & $5,47 \%$ & $34,40 \%$ \\
Caquetá & $1,17 \%$ & $16,31 \%$ & $46,65 \%$ \\
Cauca & $0,03 \%$ & $5,09 \%$ & $32,82 \%$ \\
Cesar & $0,63 \%$ & $6,93 \%$ & $28,80 \%$ \\
Córdoba & $0,01 \%$ & $1,94 \%$ & $27,87 \%$ \\
Cundinamarca & $0,11 \%$ & $5,13 \%$ & $30,22 \%$ \\
Chocó & $12,61 \%$ & $13,35 \%$ & $37,00 \%$ \\
Huila & $0,07 \%$ & $0,96 \%$ & $42,76 \%$ \\
La Guajira & $0,53 \%$ & $10,56 \%$ & $42,20 \%$ \\
Magdalena & $0,94 \%$ & $5,88 \%$ & $24,64 \%$ \\
Meta & $1,94 \%$ & $10,96 \%$ & $33,22 \%$ \\
Nariño & $0,34 \%$ & $6,76 \%$ & $37,33 \%$ \\
Norte de Santander & $0,30 \%$ & $9,16 \%$ & $36,43 \%$ \\
Quindío & $0,54 \%$ & $8,87 \%$ & $34,05 \%$ \\
Risaralda & $4,42 \%$ & $10,83 \%$ & $31,55 \%$ \\
Santander & $3,18 \%$ & $10,41 \%$ & $34,69 \%$ \\
Sucre & $1,44 \%$ & $13,85 \%$ & $37,65 \%$ \\
Tolima & $0,23 \%$ & $6,98 \%$ & $38,16 \%$ \\
Valle del Cauca & $1,44 \%$ & $11,44 \%$ & $35,44 \%$ \\
Arauca & $0,84 \%$ & $11,90 \%$ & $33,23 \%$ \\
Casanare & $0,00 \%$ & $0,00 \%$ & $36,73 \%$ \\
Putumayo & $0,00 \%$ & $1,71 \%$ & $32,77 \%$ \\
San Andrés y Providencia & $0,53 \%$ & $16,60 \%$ & $28,44 \%$ \\
Amazonas & $10,94 \%$ & $30,53 \%$ & $40,78 \%$ \\
\hline & $0,00 \%$ & $0,00 \%$ & $53,57 \%$ \\
\hline
\end{tabular}

Fuente: Aplicativo SPADIES.

\subsubsection{Cruces entre variables}

\subsubsection{Sexo - Trabaja al momento de presentar el examen}

En la gráfica 22 se observa el porcentaje de desertores para cada semestre, según sexo y si trabajaba o no al momento de presentar el examen. Se puede observar que dentro de las personas que no trabajaban la tasa de deserción es mayor para hombres que para mujeres. Lo mismo ocurre para las personas que sí trabajaban, la menor tasa de deserción se encuentra en las mujeres. 
Gráfica 22. Porcentaje de Desertores según sexo y trabaja al momento de presentar el examen entre 1998-1 y 2014-1. Agregado Nacional.

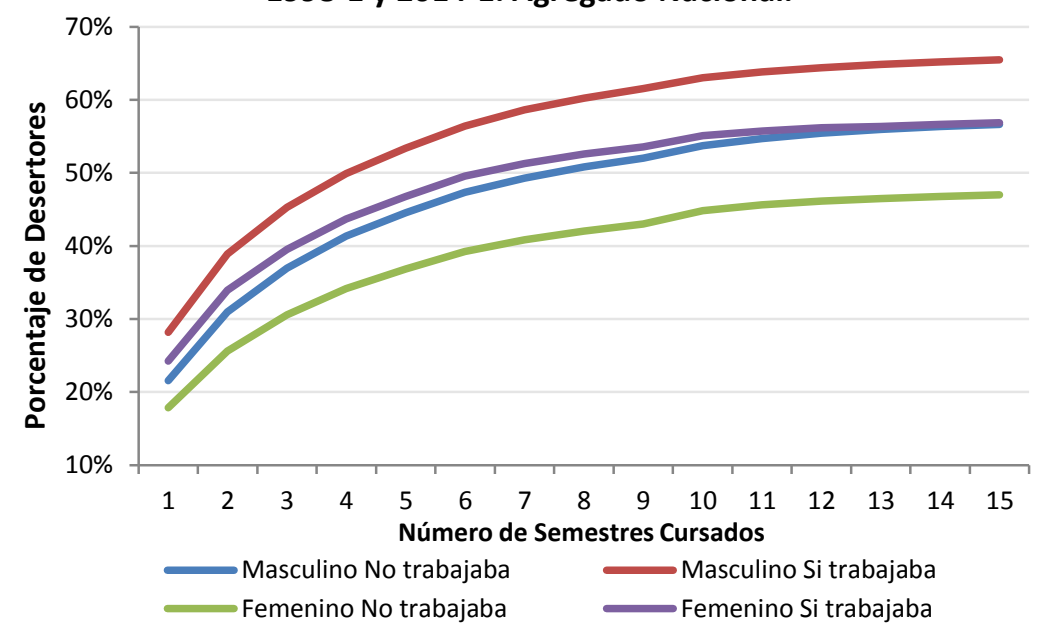

Fuente: Aplicativo SPADIES.

\subsubsection{Sexo-Edad}

En la gráfica 23 es posible observar que para cada rango de edad, siempre las mujeres tienen una tasa de deserción menor que la de los hombres. Además, la deserción en hombres es tan alta que las dos categorías con mayor porcentaje de desertores incluyen a los hombres.

\section{Gráfica 23. Porcentaje de Desertores según sexo y edad. Agregado Nacional.}

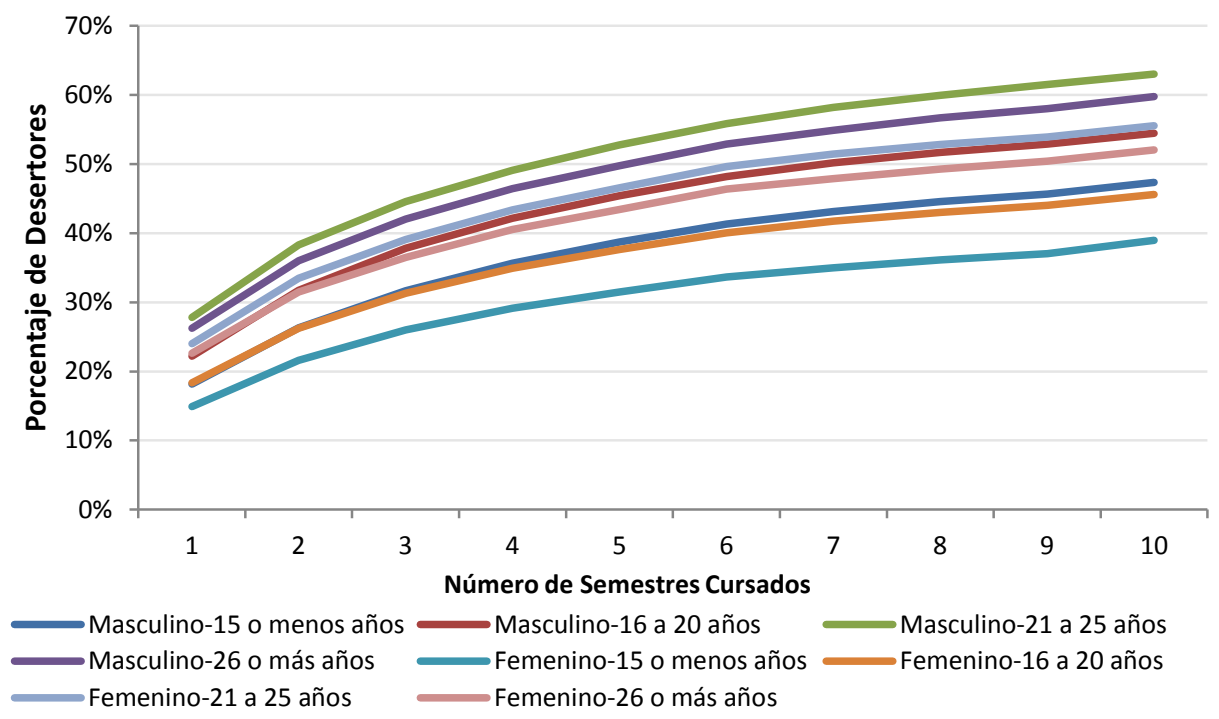

Fuente: Aplicativo SPADIES. 


\subsubsection{Sexo - Ingreso de la familia}

Como se observa en la gráfica 24, para cualquier rango de salario de la familia, siempre las mujeres tienen menor porcentaje de desertores que los hombres. Además, es posible ver que la deserción guarda una relación inversa con el ingreso de la familia, ya que tanto para hombres como para mujeres cuando la familia registra un rango salarial más alto, la tasa de deserción es más baja.

Gráfica 24. Porcentaje de Desertores según sexo e ingreso de la familia. Agregado Nacional.

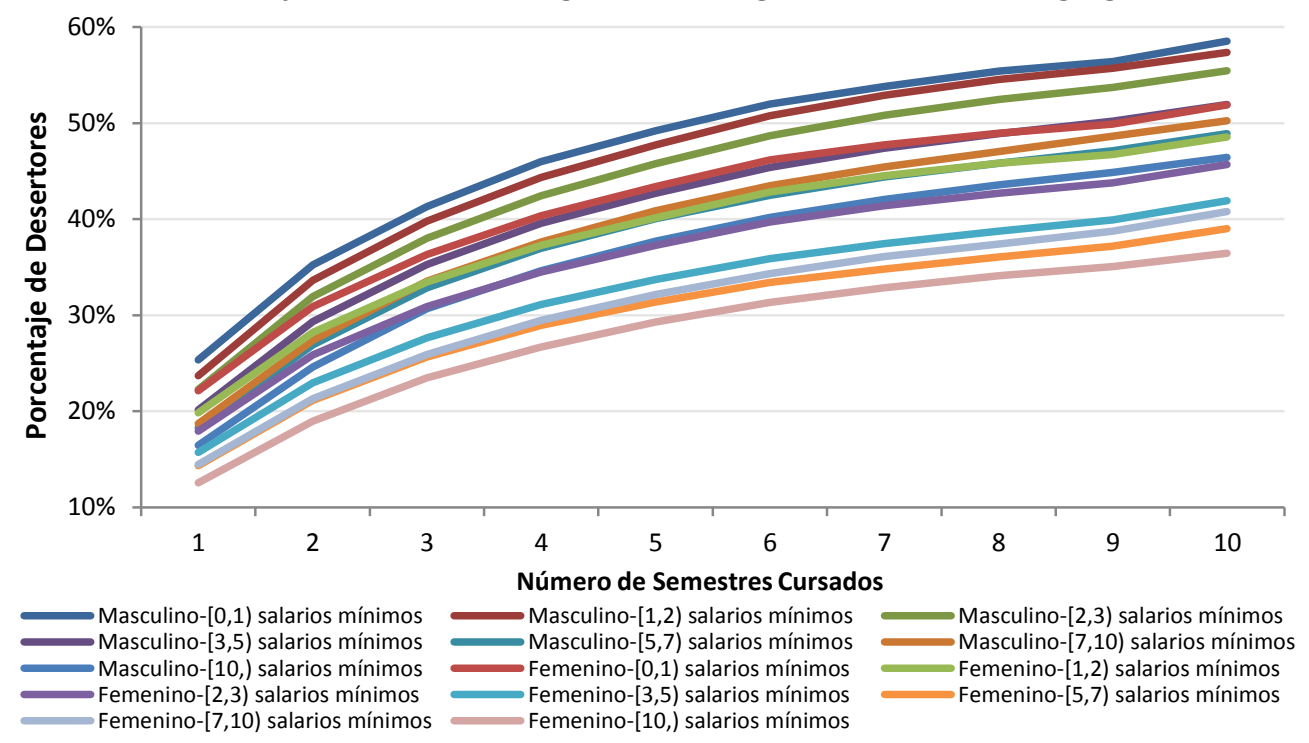

Fuente: Aplicativo SPADIES.

\subsubsection{Origen de la Institución - Ingreso de la familia}

En la gráfica 25 se presenta el porcentaje de desertores por origen de la institución y por ingreso de la familia. Se puede apreciar que para todos los rangos de ingreso de la familia, siempre hay mayor tasa de deserción en los estudiantes de entidades no oficiales. 
Gráfica 25. Porcentaje de Desertores según origen de la institución e ingreso de la familia. Agregado Nacional.

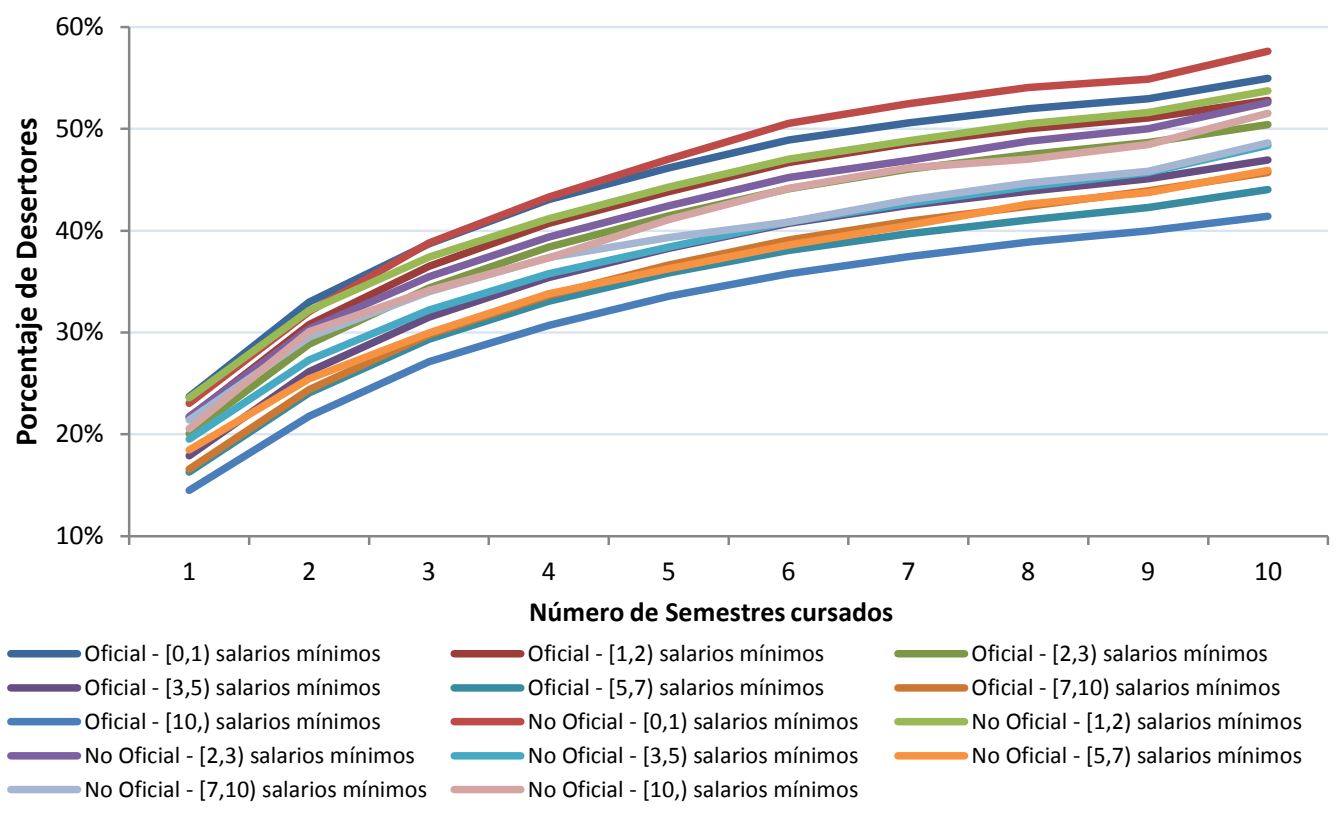

Fuente: Aplicativo SPADIES.

\subsubsection{Trabaja-Clasificación de pruebas de estado}

Como se observa en la gráfica 26, la mayor tasa de deserción se encuentra en los estudiantes que trabajaban y que tuvieron una clasificación baja. Por el contrario, los estudiantes con menor porcentaje de desertores son aquellos que no trabajaban y que tuvieron clasificación alta, un resultado que se esperaba encontrar.

Gráfica 26. Porcentaje de Desertores según clasificación pruebas de estado y si trabajaba al momento de presentar el examen. Agregado Nacional.

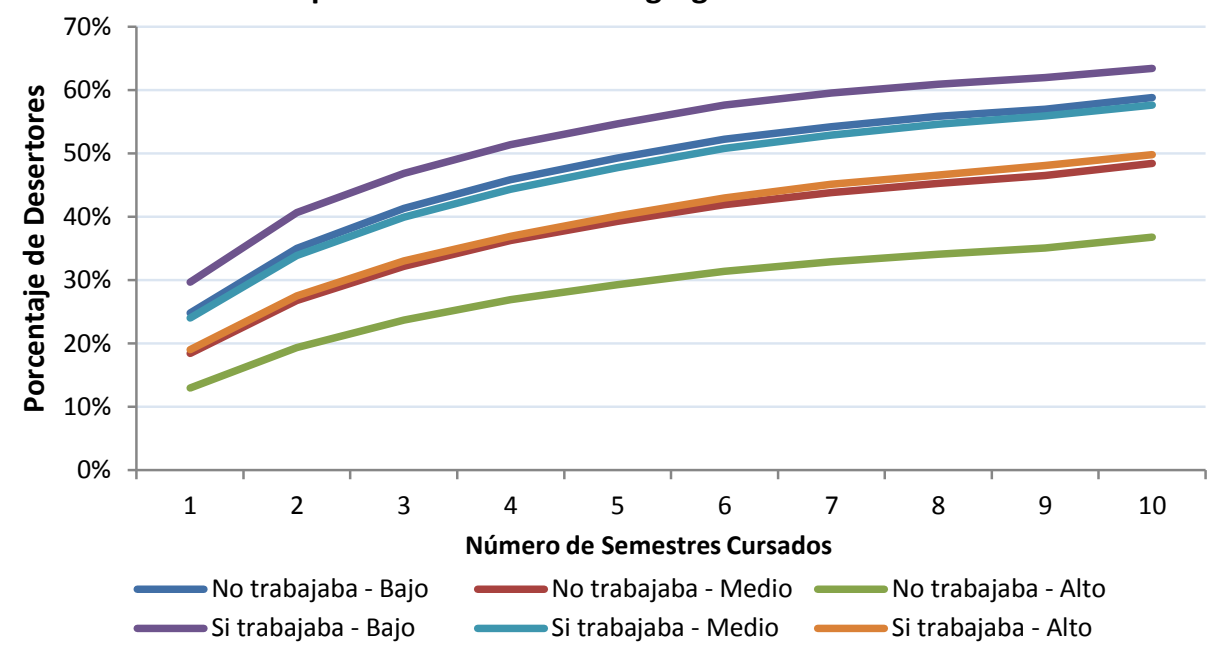

Fuente: Aplicativo SPADIES. 


\section{RESULTADOS}

A continuación se presentan los resultados de las estimaciones de los modelos de duración para diferentes grupos de análisis (carácter de la institución, origen, nivel de formación y región). Los coeficientes de los modelos, se interpretan como el cambio promedio en el riesgo de deserción por cada vez que ocurre el evento asociado a cada característica.

La tabla 10 muestra las estimaciones de acuerdo al carácter de la IES (Técnicas, Instituciones tecnológicas, Instituciones universitarias y Universidades). El análisis de las variables se agrupa de acuerdo a los factores descritos previamente (individuales, socioeconómicos, institucionales y académicos). Todos los modelos incluyen controles del departamento de origen y el año, e incluyen la variable de tiempo, que permite capturar el riesgo de deserción por cada semestre.

\section{- Factores individuales}

En promedio, ser un estudiante que trabaja al tiempo que estudia y tener una mayor edad incrementa el riesgo de deserción para cada semestre cursado, independientemente del carácter de la institución. Mientras que ser mujer disminuye dicho riesgo.

El tamaño del riesgo de deserción asociado a estas características varía de acuerdo al carácter de la IES. En particular, ser mujer disminuye más el riesgo de deserción dentro de las instituciones tecnológicas y técnicas en comparación con las universidades e instituciones universitarias; mientras que trabajar y ser mayor lo aumenta más.

\section{- Factores socioeconómicos}

En comparación con los hogares de ingreso bajo, pertenecer a un hogar de ingreso medio o de ingreso alto tiene efectos heterogéneos en el riesgo de deserción de acuerdo al carácter de la IES. Mientras que en las instituciones universitarias y universidades, el riesgo siempre es menor cuando aumenta el ingreso del hogar, para las instituciones tecnológicas el riesgo se incrementa conforme se incrementa el ingreso. Para las IES Técnicas, si bien pertenecer a un hogar de ingreso medio disminuye el riesgo de deserción, no hay un efecto significativo cuando se trata de un hogar de ingreso alto.

El efecto de ingreso del hogar se invierte cuando se interactúa la variable con el tipo de institución. Para los estudiantes que están en IES oficiales, aumentar el nivel de ingreso del hogar incrementa el riesgo de deserción en las instituciones universitarias y universidades, mientras que lo disminuye en las instituciones tecnológicas para los hogares de ingreso medio.

En cuanto al nivel educativo de la madre, para todos los casos un estudiante con una madre más educada tiene un mayor riesgo de deserción, el cual es particularmente importante en las IES de carácter técnico.

Lo mismo ocurre con el número de hermanos. Más hermanos, incrementa el riesgo de deserción, particularmente en las IES técnicas. 


\section{- Factores académicos}

La tasa de repitencia incrementa el riesgo de deserción en todos los casos, en mayor medida dentro de las IES de carácter técnico. Mientras que un mayor puntaje en las pruebas de estado disminuye este riesgo, aunque dicho efecto es muy bajo. Dicho efecto es más pequeño en las instituciones universitarias y universidades.

En cuanto al área del programa académico, se observa que programas pertenecientes a las ciencias de la educación incrementan el riesgo de deserción especialmente en las IES de carácter técnico e instituciones tecnológicas. Mientras que para instituciones universitarias y universidades el mayor riesgo de deserción se presenta en los programas que pertenecen al área de matemáticas y ciencias naturales.

\section{- Factores institucionales}

Sobre el nivel de formación, se observa que programas técnicos profesionales incrementan para las instituciones de todo carácter el riesgo de deserción (específicamente en las instituciones tecnológicas). Mientras que programas de formación universitaria y tecnológica disminuyen el riesgo de deserción dentro de las IES técnicas y tecnológicas; no siendo así para las instituciones universitarias y universidades.

El origen de la IES también afecta de manera heterogénea el riesgo de deserción. Mientras que en las IES técnicas estudiar en una institución oficial aumenta de manera importante el riesgo de deserción, así como en las instituciones tecnológicas (donde sin embargo el efecto es de menor proporción), en las universidades dicho riesgo se disminuye.

Todos los créditos y apoyos (académicos, financieros y otros apoyos) disminuyen el riesgo de deserción, independientemente del carácter de la IES. Dentro de los créditos, los que más disminuyen la deserción son los ACCES y los de largo plazo del ICETEX. Entre los apoyos, los financieros son los que más reducen el riesgo de deserción en 3 de los 4 caracteres de la institución (Éstas son las instituciones tecnológicas, instituciones universitarias y universidades). Mientras que para las técnicas, recibir apoyo académico durante un semestre reduce en mayor medida el riesgo de deserción.

Tabla 8. Modelo de duración (logit) con efectos fijos año y departamento para explicar los factores asociados a la deserción en las IES en Colombia. Total IES y por categoría de IES.

\begin{tabular}{|c|c|c|c|c|c|}
\hline \multirow{2}{*}{$\begin{array}{c}\text { Variable dependiente: } \\
\text { Grupo de análisis }\end{array}$} & \multicolumn{5}{|c|}{ Deserción, discreto a a nivel del individuo (Al Desertor=1; Mientras No Desertor=0) } \\
\hline & Total IES & Técnicas & $\begin{array}{l}\text { Instituciones } \\
\text { Tecnológicas }\end{array}$ & $\begin{array}{l}\text { Instituciones } \\
\text { Universitarias }\end{array}$ & Universidades \\
\hline Número de observaciones & $13,792,336$ & 293,356 & 466,898 & $2,597,173$ & $10,189,013$ \\
\hline LR Chi2(77) & 1013540.94 & 19349.41 & 32467.24 & 163769.06 & 650445.51 \\
\hline Prob>Chi2 & 0 & 0 & 0 & 0 & 0 \\
\hline Pseudo R2 & 0.124 & 0.0615 & 0.0783 & 0.0876 & 0.1203 \\
\hline Log likelihood & -3581145.4 & -147551.34 & -191144.33 & -853140.58 & -2377317.3 \\
\hline Variables Independientes & Total IES & Técnicas & $\begin{array}{l}\text { Instituciones } \\
\text { Tecnológicas }\end{array}$ & $\begin{array}{l}\text { Instituciones } \\
\text { Universitarias }\end{array}$ & Universidades \\
\hline Mujer & $-0.011^{* * *}$ & $-0.020 * * *$ & $-0.025 * * *$ & $-0.017^{* * *}$ & $-0.010 * * *$ \\
\hline
\end{tabular}




\begin{tabular}{|c|c|c|c|c|c|}
\hline \multirow{2}{*}{$\begin{array}{c}\text { Variable dependiente: } \\
\text { Grupo de análisis }\end{array}$} & \multicolumn{5}{|c|}{ Deserción, discreto a a nivel del individuo (Al Desertor=1; Mientras No Desertor=0) } \\
\hline & Total IES & Técnicas & $\begin{array}{l}\text { Instituciones } \\
\text { Tecnológicas }\end{array}$ & $\begin{array}{l}\text { Instituciones } \\
\text { Universitarias }\end{array}$ & Universidades \\
\hline trabaja & $0.003^{* * *}$ & $0.008 * * *$ & $0.008^{* * *}$ & $0.002^{* * *}$ & $0.003^{* * *}$ \\
\hline edad & $0.006 * * *$ & $0.018 * * *$ & $0.013^{* * *}$ & $0.009 * * *$ & $0.005^{* * *}$ \\
\hline edad2 & $-0.000 * * *$ & $-0.000 * * *$ & $-0.000 * * *$ & $-0.000 * * *$ & $-0.000 * * *$ \\
\hline Ingreso del Hogar (medio) & $-0.002 * * *$ & $-0.004 * *$ & $0.007 * * *$ & $-0.005 * * *$ & $-0.002 * * *$ \\
\hline Ingreso del Hogar (alto) & $-0.005 * * *$ & 0.000 & $0.026 * * *$ & $-0.006 * * *$ & $-0.005 * * *$ \\
\hline IES Oficial & $-0.005 * * *$ & $0.090 * * *$ & $0.009 * * *$ & 0.000 & $-0.007 * * *$ \\
\hline Ingreso del Hogar (medio)*IES Oficial & $0.002 * * *$ & 0.006 & $-0.013 * * *$ & $0.009 * * *$ & $0.002 * * *$ \\
\hline Ingreso del Hogar (alto)*IES Oficial & $0.010 * * *$ & -0.007 & -0.009 & $0.024 * * *$ & $0.011 * * *$ \\
\hline Número de hermanos & $0.001^{* * *}$ & $0.003^{* * *}$ & $0.001^{* * *}$ & $0.001^{* * *}$ & $0.001^{* * *}$ \\
\hline $\begin{array}{l}\text { Nivel educativo de la madre: Básica primaria } \\
\text { completa }\end{array}$ & $0.006^{* * *}$ & $0.020 * * *$ & $0.006 * * *$ & $0.008 * * *$ & $0.006^{* * *}$ \\
\hline Nivel educativo de la madre: Básica & & & & & \\
\hline $\begin{array}{l}\text { secundaria completa } \\
\text { Nivel educativo de la madre: Media }\end{array}$ & $0.005^{* * *}$ & $0.022^{* * *}$ & $0.006 * * *$ & $0.008 * * *$ & $0.004^{* * *}$ \\
\hline vocacional completa & $0.004^{* * *}$ & $0.017^{* * *}$ & $0.006^{* * *}$ & $0.005^{* * *}$ & $0.004^{* * *}$ \\
\hline Tasa de repitencia & $0.085^{* * *}$ & $0.170 * * *$ & $0.138 * * *$ & $0.126 * * *$ & $0.079 * * *$ \\
\hline Puntaje en las pruebas de Estado SABER11 & $-0.000 * * *$ & $-0.001 * * *$ & $-0.001 * * *$ & $-0.000 * * *$ & $-0.000 * * *$ \\
\hline Nivel de formación Técnica profesional & $0.028 * * *$ & $0.027 * * *$ & $0.032^{* * *}$ & $0.018 * * *$ & $0.072 * * *$ \\
\hline Nivel de formación Tecnológico & $0.010 * * *$ & $-0.024 * * *$ & $-0.011 * * *$ & 0.001 & $0.019 * * *$ \\
\hline Nivel de formación Universitaria & $-0.005 * * *$ & $-0.076 * * *$ & $-0.024 * * *$ & $-0.016 * * *$ & $0.001 * * *$ \\
\hline Recibió crédito ICETEX de largo plazo & & & & & \\
\hline durante el semestre & $-0.017^{* * *}$ & $-0.081 * * *$ & $-0.044 * * *$ & $-0.033 * * *$ & $-0.013^{* * *}$ \\
\hline $\begin{array}{l}\text { Recibió crédito ICETEX de mediano plazo } \\
\text { durante el semestre }\end{array}$ & $-0.013 * * *$ & $-0.055^{* * *}$ & $-0.026 * *$ & $-0.025 * * *$ & $-0.011^{* * *}$ \\
\hline $\begin{array}{l}\text { Recibió crédito ICETEX ACCES durante el } \\
\text { semestre }\end{array}$ & $-0.019 * * *$ & $-0.081 * * *$ & $-0.046 * * *$ & $-0.033 * * *$ & $-0.016 * * *$ \\
\hline $\begin{array}{l}\text { Recibió apoyo financiero durante el } \\
\text { semestre }\end{array}$ & $-0.014 * * *$ & $-0.047 * * *$ & $-0.041 * * *$ & $-0.015 * * *$ & $-0.013 * * *$ \\
\hline $\begin{array}{l}\text { Recibió apoyo académico durante el } \\
\text { semestre }\end{array}$ & $-0.005^{* * *}$ & $-0.057 * * *$ & $-0.030 * * *$ & $-0.008 * * *$ & $-0.003 * * *$ \\
\hline Recibió otros apoyos durante el semestre & $-0.012^{* * *}$ & $-0.013^{*}$ & $-0.029 * * *$ & $-0.021^{* * *}$ & $-0.011 * * *$ \\
\hline $\begin{array}{l}\text { Pertenece al A1: Agronomía, veterinaria y } \\
\text { afines }\end{array}$ & $0.019 * * *$ & $0.056 * * *$ & $0.121 * * *$ & $0.038 * * *$ & $0.014 * * *$ \\
\hline Pertenece al A2: Bellas artes & $0.013 * * *$ & $0.057^{* * *}$ & $0.120 * * *$ & $0.034 * * *$ & $0.009 * * *$ \\
\hline Pertenece al A3: Ciencias de la educación & $0.016^{* * *}$ & $0.150 * * *$ & $0.179 * * *$ & $0.010 * * *$ & $0.013^{* * *}$ \\
\hline $\begin{array}{l}\text { Pertenece al A5: Ciencias sociales, humanas, } \\
\text { derecho y ciencias políticas }\end{array}$ & $0.010^{* * *}$ & $0.044 * * *$ & $0.045^{* * *}$ & $0.011 * * *$ & $0.008^{* * *}$ \\
\hline $\begin{array}{l}\text { Pertenece al A6: Economía, administración, } \\
\text { contaduría y afines }\end{array}$ & $0.013^{* * *}$ & $0.058^{* * *}$ & $0.067 * * *$ & $0.025^{* * *}$ & $0.009 * * *$ \\
\hline $\begin{array}{l}\text { Pertenece al A8: Ingeniería, arquitectura, } \\
\text { urbanismo y afines }\end{array}$ & $0.020 * * *$ & $0.077^{* * *}$ & $0.085 * * *$ & $0.042 * * *$ & $0.015^{* * *}$ \\
\hline $\begin{array}{l}\text { Pertenece al A9: Matemáticas y ciencias } \\
\text { naturales }\end{array}$ & $0.026^{* * *}$ & & & $0.065^{* * *}$ & $0.022 * * *$ \\
\hline Instituciones Universitarias & $0.006 * * *$ & & & & \\
\hline Instituciones Tecnológicas & $0.011 * * *$ & & & & \\
\hline Instituciones Técnicas Profesionales & $0.015^{* * *}$ & & & & \\
\hline Año 1999 & -0.001 & -0.004 & -0.006 & 0.000 & $-0.001 * *$ \\
\hline Año 2000 & 0.000 & 0.008 & 0.004 & $0.007 * * *$ & $-0.001 *$ \\
\hline Año 2001 & $0.001 * * *$ & -0.011 & -0.004 & $0.007 * * *$ & 0.000 \\
\hline Año 2002 & $0.001 * * *$ & $0.017^{*}$ & -0.003 & $0.004 * *$ & 0.000 \\
\hline Año 2003 & $0.002 * * *$ & 0.014 & 0.009 & $0.009 * * *$ & 0.000 \\
\hline Año 2004 & $0.005^{* * *}$ & $0.033^{* * *}$ & 0.005 & $0.006^{* * *}$ & $0.004^{* * *}$ \\
\hline Año 2005 & $0.004^{* * *}$ & 0.014 & $0.029^{* * *}$ & $0.010^{* * *}$ & $0.001^{* * *}$ \\
\hline Año 2006 & $0.007^{* * *}$ & $0.018^{*}$ & $0.017^{* *}$ & $0.025 * * *$ & $0.003^{* * *}$ \\
\hline Año 2007 & $0.007^{* * *}$ & $0.074 * * *$ & $0.019^{* * *}$ & $0.013^{* * *}$ & $0.004^{* * *}$ \\
\hline Año 2008 & $0.013^{* * *}$ & $0.068^{* * *}$ & $0.055^{* * *}$ & $0.017^{* * *}$ & $0.009 * * *$ \\
\hline Año 2009 & $0.012^{* * *}$ & $0.081 * * *$ & $0.020 * * *$ & $0.018^{* * *}$ & $0.010^{* * *}$ \\
\hline Año 2010 & $0.008 * * *$ & $0.052^{* * *}$ & 0.008 & $0.009 * * *$ & $0.008^{* * *}$ \\
\hline Año 2011 & $0.011 * * *$ & $0.087 * * *$ & $0.013 * *$ & $0.005^{* * *}$ & $0.011 * * *$ \\
\hline Año 2012 & $0.008^{* * *}$ & $0.065^{* * *}$ & 0.007 & $0.017 * * *$ & $0.005^{* * *}$ \\
\hline Año 2013 & $-0.063 * * *$ & & & & $-0.052 * * *$ \\
\hline IES en Atlántico & $0.007 * * *$ & & $0.048 * * *$ & $0.009 * * *$ & $0.004 * * *$ \\
\hline IES en Bogotá D.C. & $0.004 * * *$ & $0.171^{* * *}$ & $0.060 * * *$ & $0.008^{* * *}$ & $0.002 * * *$ \\
\hline
\end{tabular}




\begin{tabular}{|c|c|c|c|c|c|}
\hline \multirow{2}{*}{$\begin{array}{c}\text { Variable dependiente: } \\
\text { Grupo de análisis }\end{array}$} & \multicolumn{5}{|c|}{ Deserción, discreto a a nivel del individuo (Al Desertor=1; Mientras No Desertor=0) } \\
\hline & Total IES & Técnicas & $\begin{array}{l}\text { Instituciones } \\
\text { Tecnológicas }\end{array}$ & $\begin{array}{l}\text { Instituciones } \\
\text { Universitarias }\end{array}$ & Universidades \\
\hline IES en Bolívar & $-0.004 * * *$ & & $0.032^{* * *}$ & $0.005^{* * *}$ & $-0.005^{* * *}$ \\
\hline IES en Boyacá & $-0.007 * * *$ & & & $-0.015 * * *$ & $-0.006 * * *$ \\
\hline IES en Caldas & $-0.004 * * *$ & $0.067 * * *$ & & & $-0.004 * * *$ \\
\hline IES en Caquetá & $-0.010 * * *$ & & & & $-0.009 * * *$ \\
\hline IES en Cauca & $-0.009 * * *$ & & & $-0.010 * * *$ & $-0.008 * * *$ \\
\hline IES en Cesar & $0.009 * * *$ & & & & $0.007 * * *$ \\
\hline IES en Córdoba & $0.004 * * *$ & & & & $0.003 * * *$ \\
\hline IES en Cundinamarca & $-0.020 * * *$ & & $-0.133^{* * *}$ & $-0.063 * * *$ & $-0.014 * * *$ \\
\hline IES en Chocó & $-0.024 * * *$ & & & $0.010^{*}$ & $-0.023 * * *$ \\
\hline IES en Huila & $-0.009 * * *$ & & & $-0.012 * * *$ & $-0.008 * * *$ \\
\hline IES en La Guajira & $0.009 * * *$ & $0.024 * *$ & & & $0.010 * * *$ \\
\hline IES en Magdalena & $0.006 * * *$ & $0.120 * * *$ & & & $0.003 * * *$ \\
\hline IES en Meta & $0.002 * * *$ & & & $-0.037 * * *$ & $0.011 * * *$ \\
\hline IES en Nariño & $-0.004 * * *$ & & & $0.010 * * *$ & $-0.003 * * *$ \\
\hline IES en Norte de Santander & $0.008 * * *$ & & $0.053^{* * *}$ & & $0.006 * * *$ \\
\hline IES en Quindío & $0.011 * * *$ & $0.116^{* * *}$ & & $0.025 * * *$ & $0.012 * * *$ \\
\hline IES en Risaralda & $0.003 * * *$ & $0.188 * * *$ & & $-0.006 * * *$ & $0.002 * * *$ \\
\hline IES en Santander & $0.001 * * *$ & $0.331 * * *$ & $0.023 * * *$ & $0.003^{* * *}$ & $-0.001 * * *$ \\
\hline IES en Sucre & $-0.009 * * *$ & & & $-0.004 * * *$ & $-0.007 * * *$ \\
\hline IES en Tolima & $0.007 * * *$ & $0.079 * * *$ & $0.060 * * *$ & $0.056 * * *$ & $0.005^{* * *}$ \\
\hline IES en Valle del Cauca & $0.005^{* * *}$ & $0.082 * * *$ & $0.028 * * *$ & 0.002 & $0.010 * * *$ \\
\hline IES en Arauca & -0.004 & & & & -0.003 \\
\hline IES en Casanare & 0.003 & & & 0.009 & \\
\hline IES en Putumayo & $0.024 * * *$ & & $0.094 * * *$ & & \\
\hline IES en San Andrés y Providencia & $0.058 * * *$ & $0.236 * * *$ & & & \\
\hline Logaritmo del tiempo & $-0.049 * * *$ & $-0.119 * * *$ & $-0.096 * * *$ & $-0.079 * * *$ & $-0.044 * * *$ \\
\hline
\end{tabular}

*** $p<0.01,{ }^{* *} p<0.05, * p<0.1$

Fuente: SPADIES. Cálculos propios.

Nota: se presentan los efectos marginales.

La tabla 9 presenta las mismas estimaciones del ejercicio anterior pero teniendo como grupo de análisis el origen de la IES: oficial o no oficial.

\section{- Factores individuales}

De manera consistente, ser mujer disminuye el riesgo promedio de deserción en IES oficiales y no oficiales. Dicha reducción es más importante en las no oficiales.

Asimismo, trabajar y tener mayor edad aumenta el riesgo de deserción en las IES oficiales y no oficiales. En las IES no oficiales tener mayor edad tiene un mayor efecto en comparación con las oficiales, donde trabajar incrementa en mayor medida el riesgo de desertar.

\section{- Factores socioeconómicos}

Hogares con mayor ingreso disminuyen la deserción en las IES no oficiales, por el contrario en las IES oficiales dichos hogares aumentan el riesgo de deserción.

Por otro lado, mayor número de hermanos y madres con mayor nivel educativo incrementan para ambos orígenes de la IES el riesgo promedio de deserción. Observándose mayores efectos dentro de las IES no oficiales. 


\section{- Factores académicos}

De manera consistente con los resultados anteriores, mayor tasa de repitencia aumenta el riesgo promedio de deserción. El efecto es muy similar en para las IES oficiales y no oficiales.

El puntaje obtenido en las pruebas Saber 11 tiene un signo negativo. Al multiplicar el coeficiente por el valor medio de la variable (de 0 a 100) se obtiene que es una de las variables que más influye en el riesgo de deserción.

Por otra parte, independientemente del área a la cual pertenece el programa, el riesgo de deserción aumenta. Dicho efecto es en todos los casos, mayor para las IES oficiales.

El carácter de la institución aumenta en todos los casos el riesgo de deserción. Sin embargo, pertenecer a una institución técnica profesional incrementa más dicho riesgo dentro de las IES no oficiales. Además, pertenecer a una institución tecnológica o universitaria incrementa más el riesgo de deserción en las IES oficiales.

\section{- Factores institucionales}

Para todos los casos, tener un crédito educativo disminuye el riesgo de deserción. Dicha disminución es mayor en las IES no oficiales. Por otro lado, tener apoyos académicos y financieros disminuye más el riesgo de deserción dentro de las IES oficiales.

Pertenecer a un programa cuyo nivel de formación es técnico incrementa el riesgo de deserción para todas las IES, oficiales y no oficiales; mientras que pertenecer a una de formación tecnológica o universitaria la disminuye.

Tabla 9. Modelo de duración ( logit) con efectos fijos para explicar los factores asociados a la deserción en las IES en Colombia. Origen de IES.

\begin{tabular}{|c|c|c|}
\hline \multirow{2}{*}{$\begin{array}{c}\text { Variable dependiente: } \\
\text { Grupo de análisis }\end{array}$} & \multicolumn{2}{|c|}{$\begin{array}{c}\text { Deserción, discreto a a nivel del individuo (Al Desertor=1; Mientras No } \\
\text { Desertor=0) }\end{array}$} \\
\hline & No Oficial & Oficial \\
\hline Número de observaciones & $7,734,568$ & $6,057,768$ \\
\hline LR Chi2(77) & 556893.07 & 465140.59 \\
\hline Prob>Chi2 & 0 & 0 \\
\hline Pseudo R2 & 0.1183 & 0.1342 \\
\hline Log likelihood & -2074758.5 & -1500876 \\
\hline Variables Independientes & No Oficial & Oficial \\
\hline Mujer & $-0.012 * * *$ & $-0.010 * * *$ \\
\hline trabaja & $0.002 * * *$ & $0.003 * * *$ \\
\hline edad & $0.006^{* * *}$ & $0.005 * * *$ \\
\hline edad2 & $-0.000 * * *$ & $-0.000 * * *$ \\
\hline Ingreso del Hogar (medio) & $-0.002 * * *$ & $0.001 * * *$ \\
\hline Ingreso del Hogar (alto) & $-0.006 * * *$ & $0.006 * * *$ \\
\hline Número de hermanos & $0.001 * * *$ & $0.001 * * *$ \\
\hline Nivel educativo de la madre: Básica primaria completa & $0.008 * * *$ & $0.003^{* * *}$ \\
\hline Nivel educativo de la madre: Básica secundaria completa & $0.007 * * *$ & $0.002 * * *$ \\
\hline Nivel educativo de la madre: Media vocacional completa & $0.006 * * *$ & $0.001 * * *$ \\
\hline Tasa de repitencia & $0.084 * * *$ & $0.085 * * *$ \\
\hline Puntaje en las pruebas de Estado SABER11 & $-0.000 * * *$ & $-0.000 * * *$ \\
\hline Nivel de formación Técnica profesional & $0.025 * * *$ & $0.034 * * *$ \\
\hline Nivel de formación Tecnológico & $0.007 * * *$ & $0.007 * * *$ \\
\hline
\end{tabular}




\begin{tabular}{|c|c|c|}
\hline \multirow{2}{*}{$\begin{array}{c}\text { Variable dependiente: } \\
\text { Grupo de análisis }\end{array}$} & \multicolumn{2}{|c|}{$\begin{array}{l}\text { Deserción, discreto a a nivel del individuo (Al Desertor=1; Mientras No } \\
\text { Desertor }=0 \text { ) }\end{array}$} \\
\hline & No Oficial & Oficial \\
\hline Nivel de formación Universitaria & $-0.007 * * *$ & $-0.006^{* * *}$ \\
\hline Recibió crédito ICETEX de largo plazo durante el semestre & $-0.019 * * *$ & $-0.015^{* * *}$ \\
\hline Recibió crédito ICETEX de mediano plazo durante el semestre & $-0.015^{* * *}$ & $-0.007 * * *$ \\
\hline Recibió crédito ICETEX ACCES durante el semestre & $-0.021 * * *$ & $-0.017 * * *$ \\
\hline Recibió apoyo financiero durante el semestre & $-0.012^{* * *}$ & $-0.017 * * *$ \\
\hline Recibió apoyo académico durante el semestre & -0.000 & $-0.011 * * *$ \\
\hline Recibió otros apoyos durante el semestre & $-0.011 * * *$ & $-0.011 * * *$ \\
\hline Pertenece al A1: Agronomía, veterinaria y afines & $0.009 * * *$ & $0.030^{* * *}$ \\
\hline Pertenece al A2: Bellas artes & $0.009 * * *$ & $0.027 * * *$ \\
\hline Pertenece al A3: Ciencias de la educación & $0.018^{* * *}$ & $0.019 * * *$ \\
\hline $\begin{array}{l}\text { Pertenece al A5: Ciencias sociales, humanas, derecho y } \\
\text { ciencias políticas }\end{array}$ & $0.008 * * *$ & $0.016 * * *$ \\
\hline Pertenece al A6: Economía, administración, contaduría y & & \\
\hline afines & $0.012^{* * *}$ & $0.017^{* * *}$ \\
\hline Pertenece al A8: Ingeniería, arquitectura, urbanismo y afines & $0.017^{* * *}$ & $0.025 * * *$ \\
\hline Pertenece al A9: Matemáticas y ciencias naturales & $0.009 * * *$ & $0.036 * * *$ \\
\hline Instituciones Universitarias & $0.005^{* * *}$ & $0.007 * * *$ \\
\hline Instituciones Tecnológicas & $0.010 * * *$ & $0.015^{* * *}$ \\
\hline Instituciones Técnicas Profesionales & $0.019 * * *$ & $0.003 * * *$ \\
\hline Año 1999 & -0.001 & -0.000 \\
\hline Año 2000 & -0.001 & $0.003 * * *$ \\
\hline Año 2001 & $-0.001^{* *}$ & $0.006^{* * *}$ \\
\hline Año 2002 & $-0.003 * * *$ & $0.009 * * *$ \\
\hline Año 2003 & -0.000 & $0.007 * * *$ \\
\hline Año 2004 & -0.000 & $0.014 * * *$ \\
\hline Año 2005 & $-0.002 * * *$ & $0.014 * * *$ \\
\hline Año 2006 & $-0.001^{*}$ & $0.020 * * *$ \\
\hline Año 2007 & $0.002 * * *$ & $0.017 * * *$ \\
\hline Año 2008 & $0.007 * * *$ & $0.023 * * *$ \\
\hline Año 2009 & $0.006 * * *$ & $0.024 * * *$ \\
\hline Año 2010 & $0.003 * * *$ & $0.017 * * *$ \\
\hline Año 2011 & $0.002 * * *$ & $0.024 * * *$ \\
\hline Año 2012 & $0.004^{* * *}$ & $0.014^{* * *}$ \\
\hline Año 2013 & $-0.070 * * *$ & $-0.054 * * *$ \\
\hline IES en Atlántico & $0.009 * * *$ & $0.005^{* * *}$ \\
\hline IES en Bogotá D.C. & $0.008 * * *$ & $0.001 * * *$ \\
\hline IES en Bolívar & $0.005^{* * *}$ & $-0.010 * * *$ \\
\hline IES en Boyacá & $-0.002 * *$ & $-0.008 * * *$ \\
\hline IES en Caldas & $0.004 * * *$ & $-0.009 * * *$ \\
\hline IES en Caquetá & & $-0.012 * * *$ \\
\hline IES en Cauca & $-0.004 * * *$ & $-0.010 * * *$ \\
\hline IES en Cesar & & $0.007 * * *$ \\
\hline IES en Córdoba & $0.011 * * *$ & $-0.001 * *$ \\
\hline IES en Cundinamarca & $-0.017 * * *$ & $-0.023 * * *$ \\
\hline IES en Chocó & 0.001 & $-0.025 * * *$ \\
\hline IES en Huila & $-0.003 * * *$ & $-0.009 * * *$ \\
\hline IES en La Guajira & & $0.005^{* * *}$ \\
\hline IES en Magdalena & $0.009 * * *$ & $0.005^{* * *}$ \\
\hline IES en Meta & $-0.023 * * *$ & $0.012 * * *$ \\
\hline IES en Nariño & -0.001 & $-0.005 * * *$ \\
\hline IES en Norte de Santander & $0.018^{* * *}$ & $0.003 * * *$ \\
\hline IES en Quindío & $-0.005 * * *$ & $0.017^{* * *}$ \\
\hline IES en Risaralda & $0.007 * * *$ & $0.001^{*}$ \\
\hline IES en Santander & $0.007^{* * *}$ & $-0.004 * * *$ \\
\hline IES en Sucre & $-0.006 * * *$ & $-0.011 * * *$ \\
\hline IES en Tolima & $0.017^{* * *}$ & $0.003 * * *$ \\
\hline IES en Valle del Cauca & $0.015^{* * *}$ & $-0.002 * * *$ \\
\hline IES en Arauca & & -0.002 \\
\hline IES en Putumayo & & $0.012 * * *$ \\
\hline IES en San Andrés y Providencia & & $0.065^{* * *}$ \\
\hline IES en Casanare & $0.014 * * *$ & \\
\hline Logaritmo del tiempo & $-0.048 * * *$ & $-0.050 * * *$ \\
\hline
\end{tabular}


Fuente: SPADIES. Cálculos propios.

Nota: se presentan los efectos marginales.

La tabla 10 tiene como grupos de análisis los niveles de formación de los programas ofrecidos. De manera general, se observa que las variables analizadas afectan en mayor medida (según sea la dirección del efecto) a los programas de formación técnica profesional. También se observa que la dirección del efecto de las variables es similar a los dos ejercicios anteriores.

\section{- Factores individuales}

Se observa una mayor reducción en el riesgo de desertar para las mujeres que estudian en programas de formación técnica profesional. Asimismo, trabajar y tener mayor edad también aumentan más el riesgo de deserción en este tipo de programas.

\section{- Factores socioeconómicos}

En este caso, tener mayores ingresos en el hogar disminuye el riesgo de deserción principalmente en programas técnicos profesionales (ingreso medio del hogar) y programas universitarios (ingreso alto).

Estudiar en una IES oficial y pertenecer a un hogar de ingreso medio o alto, disminuye el riesgo de deserción de programas técnicos profesionales, pero lo aumenta en los programas tecnológicos y universitarios.

Mayor número de hermanos aumenta el riesgo de deserción sin importar el tipo de programa. Además, tener una madre más educada aumenta el riesgo de deserción, particularmente de programas técnicos profesionales.

\section{- Factores académicos}

La tasa de repitencia aumenta la deserción en mayor medida en los programas técnicos profesionales.

Un mejor desempeño en las pruebas Saber 11 disminuye el riesgo de deserción pero marginalmente.

En cuanto a las áreas, los programas en las áreas de agronomía, veterinaria y afines; bellas artes y ciencias de la educación el riesgo de deserción aumenta especialmente en los programas tecnológicos. En comparación, los programas que pertenecen a las áreas de ciencias sociales, humanas, derecho y ciencias políticas; economía, administración, contaduría y afines; ingeniería, arquitectura, urbanismo y afines; y matemáticas y ciencias naturales aumentan también el riesgo de deserción, pero especialmente en los programas técnicos profesionales.

\section{- Características institucionales}


El carácter de la institución siempre disminuye el riesgo de deserción en los programas técnicos profesionales, mientras que lo aumenta en los programas tecnológicos y universitarios. Adicionalmente, estudiar en una IES oficial incrementa el riesgo de deserción dentro de los programas técnicos profesionales, mientras que dicho riesgo disminuye si el programa es tecnológico o universitario.

Finalmente, los créditos y apoyos recibidos disminuyen el riesgo de deserción en todos los casos, especialmente en los programas de formación técnica profesional.

Tabla 10. Modelo de duración ( logit) con efectos fijos para explicar los factores asociados a la deserción en las IES en Colombia. Niveles de formación.

\begin{tabular}{|c|c|c|c|}
\hline \multirow{2}{*}{$\begin{array}{c}\text { Variable dependiente: } \\
\text { Grupo de análisis }\end{array}$} & \multicolumn{3}{|c|}{$\begin{array}{c}\text { Deserción, discreto a a nivel del individuo (Al } \\
\text { Desertor=1; Mientras No Desertor=0) }\end{array}$} \\
\hline & $\begin{array}{c}\text { Técnica } \\
\text { Profesional }\end{array}$ & Tecnológica & Universitaria \\
\hline Número de observaciones & 425,058 & $1,482,236$ & $10,255,170$ \\
\hline LR Chi2(77) & 33191.99 & 109643.32 & 634786.35 \\
\hline Prob>Chi2 & 0 & 0 & 0 \\
\hline Pseudo R2 & 0.0741 & 0.0922 & 0.1183 \\
\hline Log likelihood & -207298.59 & -539934.71 & -2364749.5 \\
\hline Variables Independientes & $\begin{array}{c}\text { Técnica } \\
\text { Profesional }\end{array}$ & Tecnológica & Universitaria \\
\hline Mujer & $-0.017 * * *$ & $-0.014 * * *$ & $-0.010 * * *$ \\
\hline trabaja & $0.006 * * *$ & $0.004 * * *$ & $0.002 * * *$ \\
\hline edad & $0.016 * * *$ & $0.009 * * *$ & $0.005^{* * *}$ \\
\hline edad2 & $-0.000 * * *$ & $-0.000 * * *$ & $-0.000 * * *$ \\
\hline Ingreso del Hogar (medio) & $-0.007 * * *$ & $-0.002 * * *$ & $-0.001 * * *$ \\
\hline Ingreso del Hogar (alto) & -0.001 & -0.001 & $-0.004 * * *$ \\
\hline IES Oficial & $0.020 * * *$ & $-0.008 * * *$ & $-0.005 * * *$ \\
\hline Ingreso del Hogar (medio)*IES Oficial & $-0.006^{*}$ & $0.005^{* * *}$ & $0.002 * * *$ \\
\hline Ingreso del Hogar (alto)*IES Oficial & -0.005 & $0.021 * * *$ & $0.008 * * *$ \\
\hline Número de hermanos & $0.001 * * *$ & $0.002 * * *$ & $0.001 * * *$ \\
\hline Nivel educativo de la madre: Básica primaria completa & $0.017 * * *$ & $0.009 * * *$ & $0.005^{* * *}$ \\
\hline Nivel educativo de la madre: Básica secundaria completa & $0.015^{* * *}$ & $0.007^{* * *}$ & $0.004 * * *$ \\
\hline Nivel educativo de la madre: Media vocacional completa & $0.009 * * *$ & $0.006 * * *$ & $0.003 * * *$ \\
\hline Tasa de repitencia & $0.144 * * *$ & $0.125^{* * *}$ & $0.075 * * *$ \\
\hline Puntaje en las pruebas de Estado SABER11 & $-0.001 * * *$ & $-0.001 * * *$ & $-0.000 * * *$ \\
\hline Recibió crédito ICETEX de largo plazo durante el semestre & $-0.064 * * *$ & $-0.024 * * *$ & $-0.014 * * *$ \\
\hline Recibió crédito ICETEX de mediano plazo durante el semestre & $-0.056 * * *$ & $-0.023 * * *$ & $-0.010 * * *$ \\
\hline Recibió crédito ICETEX ACCES durante el semestre & $-0.070 * * *$ & $-0.032 * * *$ & $-0.017 * * *$ \\
\hline Recibió apoyo financiero durante el semestre & $-0.032 * * *$ & $-0.022 * * *$ & $-0.011 * * *$ \\
\hline Recibió apoyo académico durante el semestre & $-0.034 * * *$ & $-0.009 * * *$ & $-0.002 * * *$ \\
\hline Recibió otros apoyos durante el semestre & $-0.034 * * *$ & $-0.016 * * *$ & $-0.012 * * *$ \\
\hline Pertenece al A1: Agronomía, veterinaria y afines & $0.046 * * *$ & $0.068 * * *$ & $0.013 * * *$ \\
\hline Pertenece al A2: Bellas artes & $0.019 * * *$ & $0.040 * * *$ & $0.011 * * *$ \\
\hline Pertenece al A3: Ciencias de la educación & $0.135^{* * *}$ & $0.142 * * *$ & $0.013 * * *$ \\
\hline Pertenece al A5: Ciencias sociales, humanas, derecho y ciencias políticas & $0.019 * * *$ & $0.017^{* * *}$ & $0.011 * * *$ \\
\hline Pertenece al A6: Economía, administración, contaduría y afines & $0.032 * * *$ & $0.030 * * *$ & $0.013 * * *$ \\
\hline Pertenece al A8: Ingeniería, arquitectura, urbanismo y afines & $0.043 * * *$ & $0.042 * * *$ & $0.017^{* * *}$ \\
\hline Pertenece al A9: Matemáticas y ciencias naturales & $0.158^{* * *}$ & -0.002 & $0.028 * * *$ \\
\hline Instituciones Universitarias & $-0.067 * * *$ & $0.003 * * *$ & $0.003 * * *$ \\
\hline Instituciones Tecnológicas & $-0.029 * * *$ & $0.006^{* * *}$ & $0.035 * * *$ \\
\hline Instituciones Técnicas Profesionales & $-0.030 * * *$ & $0.017^{* * *}$ & $0.027^{* * *}$ \\
\hline Año 1999 & $-0.031 * * *$ & -0.000 & -0.000 \\
\hline Año 2000 & $-0.018 * * *$ & 0.003 & $0.001^{*}$ \\
\hline Año 2001 & $-0.024 * * *$ & $0.007 * * *$ & 0.001 \\
\hline Año 2002 & -0.011 & 0.001 & $0.002 * * *$ \\
\hline Año 2003 & $-0.017 * * *$ & $0.012 * * *$ & $0.001 * * *$ \\
\hline Año 2004 & 0.011 & $0.018 * * *$ & $0.002 * * *$ \\
\hline Año 2005 & -0.004 & $0.013^{* * *}$ & $0.002 * * *$ \\
\hline Año 2006 & -0.001 & $0.024 * * *$ & $0.003 * * *$ \\
\hline Año 2007 & $0.035 * * *$ & $0.012 * * *$ & $0.004 * * *$ \\
\hline
\end{tabular}




\begin{tabular}{|c|c|c|c|}
\hline \multirow{2}{*}{$\begin{array}{c}\text { Variable dependiente: } \\
\text { Grupo de análisis }\end{array}$} & \multicolumn{3}{|c|}{$\begin{array}{l}\text { Deserción, discreto a a nivel del individuo (Al } \\
\text { Desertor=1; Mientras No Desertor }=0 \text { ) }\end{array}$} \\
\hline & $\begin{array}{l}\text { Técnica } \\
\text { Profesional }\end{array}$ & Tecnológica & Universitaria \\
\hline Año 2008 & $0.044^{* * *}$ & $0.021^{* * *}$ & $0.009 * * *$ \\
\hline Año 2009 & $0.052^{* * *}$ & $0.017 * * *$ & $0.008 * * *$ \\
\hline Año 2010 & $0.015^{* *}$ & $0.013 * * *$ & $0.007^{* * *}$ \\
\hline Año 2011 & $0.023 * * *$ & $0.025^{* * *}$ & $0.009 * * *$ \\
\hline Año 2012 & 0.002 & $0.021 * * *$ & $0.005^{* * *}$ \\
\hline Año 2013 & $-0.211 * * *$ & $-0.120 * * *$ & $-0.051 * * *$ \\
\hline IES en Atlántico & $0.090 * * *$ & $0.004 * * *$ & $0.005^{* * *}$ \\
\hline IES en Bogotá D.C. & $0.077^{* * *}$ & $0.004 * * *$ & $0.002^{* * *}$ \\
\hline IES en Bolívar & $0.093 * * *$ & $-0.009 * * *$ & $-0.003 * * *$ \\
\hline IES en Boyacá & 0.087 & $-0.009 * * *$ & $-0.007 * * *$ \\
\hline IES en Caldas & 0.001 & -0.001 & $-0.005^{* * *}$ \\
\hline IES en Caquetá & & & $-0.010 * * *$ \\
\hline IES en Cauca & $0.202^{* * *}$ & $-0.010 * * *$ & $-0.008 * * *$ \\
\hline IES en Cesar & $0.106 * * *$ & $0.056 * * *$ & $0.005^{* * *}$ \\
\hline IES en Córdoba & & 0.010 & $0.004 * * *$ \\
\hline IES en Cundinamarca & & $-0.088 * * *$ & $-0.017 * * *$ \\
\hline IES en Chocó & & $-0.052 * * *$ & $-0.021 * * *$ \\
\hline IES en Huila & & $-0.011 * * *$ & $-0.007 * * *$ \\
\hline IES en La Guajira & -0.002 & $0.075^{* * *}$ & $0.007^{* * *}$ \\
\hline IES en Magdalena & $0.026^{* * *}$ & $0.015^{* * *}$ & $0.004^{* * *}$ \\
\hline IES en Meta & & 0.001 & $0.001 * *$ \\
\hline IES en Nariño & $-0.068^{*}$ & $0.012 * * *$ & $-0.006 * * *$ \\
\hline IES en Norte de Santander & $0.040 * * *$ & $-0.003 *$ & $0.006^{* * *}$ \\
\hline IES en Quindío & $0.025^{* * *}$ & $0.014^{* * *}$ & $0.010^{* * *}$ \\
\hline IES en Risaralda & $0.023 * * *$ & $-0.011 * * *$ & $0.002 * * *$ \\
\hline IES en Santander & $0.034 * * *$ & $0.006 * * *$ & $-0.002 * * *$ \\
\hline IES en Sucre & & $-0.016 * * *$ & $-0.007 * * *$ \\
\hline IES en Tolima & $0.064 * * *$ & $0.029 * * *$ & $0.002 * * *$ \\
\hline IES en Valle del Cauca & $0.019 * * *$ & $-0.006^{* * *}$ & $0.009 * * *$ \\
\hline IES en Arauca & & & -0.004 \\
\hline IES en Casanare & & $-0.054 * *$ & 0.004 \\
\hline IES en Putumayo & & $0.042^{* * *}$ & 0.008 \\
\hline IES en San Andrés y Providencia & $0.111^{* * *}$ & & \\
\hline Logaritmo del tiempo & $-0.091 * * *$ & $-0.078 * * *$ & $-0.043 * * *$ \\
\hline
\end{tabular}

*** $p<0.01,{ }^{* *} p<0.05, * p<0.1$

Fuente: SPADIES. Cálculos propios.

Nota: se presentan los efectos marginales.

Finalmente, la tabla 11 realiza el mismo ejercicio de las estimaciones anteriores pero para grupos regionales. En general, más mayoría de variables explicativas del riesgo de deserción son significativas para todas las regiones a excepción de la región Amazonía, en donde las únicas variables significativas son los que capturan la variación no observada de los años 1999 y 2000.

En general, no hay una variación en la dirección del efecto entre regiones. También se observa que la dirección del efecto de las variables es similar a los dos ejercicios anteriores.

\section{- Factores individuales}

El efecto negativo de ser mujer sobre el riesgo de deserción es muy similar en todas las regiones analizadas.

Mayor edad y estar trabajando son factores que pesan más en la región atlántica. 


\section{- Factores socioeconómicos}

Incrementos en el ingreso del hogar disminuye el riesgo de deserción para todas las regiones. Sin embargo, este efecto es particularmente fuerte en la región Orinoquía. Por el contrario, para los estudiantes en IES oficiales que vienen de hogares de mayor ingreso, el riesgo de la deserción aumenta a excepción de Bogotá para los hogares con ingreso medio.

El efecto de tener hermanos aumenta la deserción, al igual que un mayor nivel educativo de la madre. Sin embargo esto último no es significativo para la región de la Orinoquia.

\section{- Factores académicos}

Al igual que en los casos anteriores, el puntaje en las pruebas Saber 11 aunque disminuye la deserción, lo hace de manera marginal. Por su parte, la tasa de repitencia incrementa el riesgo de deserción, especialmente en la región de la Orinoquía.

En todos los casos todas las áreas aumentan el riesgo de deserción. Sin embargo, es de resaltar que dicho aumento es más alto en la región centro occidental.

\section{- Factores institucionales}

La Orinoquía presenta un comportamiento excepcional en la relación que tienen las variables institucionales con el riesgo de deserción.

En todas las regiones el riesgo de deserción es menor para los estudiantes de IES oficiales, a excepción de la región Orinoquía en donde estos tienen mayor riesgo de deserción.

En la Orinoquía no hay programas de formación técnica profesional dentro de los datos disponibles para las estimaciones. La formación técnica, profesional y tecnológica incrementa el riesgo de deserción, pero en la Orinoquia los programas de formación tecnológica disminuyen el riesgo de deserción. Respecto a los programas de formación universitaria, estos disminuyen en todas las regiones el riesgo de deserción, pero en mayor medida en la región de la Orinoquia.

Finalmente los créditos y apoyos (financieros, académicos y otros) disminuyen siempre el riesgo de deserción. De nuevo en la Orinoquía, los créditos de mediano plazo del ICETEX no tienen ningún efecto. 
Tabla 11. Modelo de duración (logit) con efectos fijos para explicar los factores asociados a la deserción en las IES en Colombia. Región ${ }^{14}$ donde se encuentra la IES.

\begin{tabular}{|c|c|c|c|c|c|c|c|}
\hline \multirow{2}{*}{$\begin{array}{c}\text { Variable dependiente: } \\
\text { Grupo de análisis }\end{array}$} & \multicolumn{7}{|c|}{ Deserción, discreto a a nivel del individuo (Al Desertor=1; Mientras No Desertor=0) } \\
\hline & Bogotá & $\begin{array}{l}\text { Centro- } \\
\text { Oriente }\end{array}$ & $\begin{array}{l}\text { Centro- } \\
\text { Occidente }\end{array}$ & Atlántica & Pacífica & Orinoquía & Amazonía \\
\hline Número de observaciones & $5,164,624$ & $7,364,987$ & $2,740,370$ & $1,878,318$ & $1,360,827$ & 89,778 & 6,645 \\
\hline LR Chi2(77) & 405280.47 & 555117.45 & 191801.61 & 113584.65 & 102372.13 & 6289.9 & 614.84 \\
\hline Prob>Chi2 & 0 & 0 & 0 & 0 & 0 & 0 & 0 \\
\hline Pseudo R2 & 0.1264 & 0.1249 & 0.1183 & 0.0987 & 0.1249 & 0.1325 & 0.16 \\
\hline & - & & & & - & - & \\
\hline Log likelihood & 1400368.2 & -1944431.6 & -714706.01 & -518715.2 & 358577.23 & 20595.901 & -1613.5545 \\
\hline Variables Independientes & Bogotá & $\begin{array}{l}\text { Centro- } \\
\text { Oriente }\end{array}$ & $\begin{array}{l}\text { Centro- } \\
\text { Occidente }\end{array}$ & Atlántica & Pacífica & Orinoquía & Amazonía \\
\hline Mujer & $-0.011 * * *$ & $-0.012 * * *$ & $-0.012^{* * *}$ & $-0.011^{* * *}$ & $-0.011^{* * *}$ & $-0.012^{* * *}$ & 0.002 \\
\hline trabaja & $0.003 * * *$ & $0.003 * * *$ & $0.002 * * *$ & $0.004 * * *$ & $0.003 * * *$ & 0.002 & 0.008 \\
\hline edad & $0.006 * * *$ & $0.006 * * *$ & $0.006 * * *$ & $0.010 * * *$ & $0.004 * * *$ & $0.006 * * *$ & 0.000 \\
\hline edad2 & $-0.000 * * *$ & $-0.000 * * *$ & $-0.000 * * *$ & $-0.000 * * *$ & $-0.000 * * *$ & $-0.000 * * *$ & 0.000 \\
\hline Ingreso del Hogar (medio) & $-0.001 * * *$ & $-0.002 * * *$ & $-0.004 * * *$ & -0.000 & -0.001 & $-0.006 * *$ & -0.001 \\
\hline Ingreso del Hogar (alto) & $-0.005 * * *$ & $-0.006 * * *$ & $-0.006 * * *$ & 0.001 & -0.001 & -0.008 & 0.015 \\
\hline $\begin{array}{l}\text { IES Oficial } \\
\text { Ingreso del Hogar (medio)*IES }\end{array}$ & $-0.001 * * *$ & $-0.006 * * *$ & $-0.003 * * *$ & $-0.006 * * *$ & $-0.014 * * *$ & $0.021 * * *$ & \\
\hline Oficial & $-0.002 * * *$ & $0.001 * * *$ & $0.005^{* * *}$ & 0.001 & $0.002^{* * *}$ & $0.010 * * *$ & \\
\hline Ingreso del Hogar (alto)*IES Oficial & $0.003^{* * *}$ & $0.011^{* * *}$ & $0.010 * * *$ & $0.011^{* * *}$ & $0.009 * * *$ & $0.034^{* *}$ & \\
\hline $\begin{array}{l}\text { Número de hermanos } \\
\text { Nivel educativo de la madre: Básica }\end{array}$ & $0.002 * * *$ & $0.002 * * *$ & $0.001 * * *$ & $0.001 * * *$ & $0.001 * * *$ & $0.002 * * *$ & 0.000 \\
\hline primaria completa & $0.007 * * *$ & $0.007 * * *$ & $0.008^{* * *}$ & $0.008^{* * *}$ & $0.003^{* * *}$ & 0.000 & 0.005 \\
\hline $\begin{array}{l}\text { Nivel educativo de la madre: Básica } \\
\text { secundaria completa }\end{array}$ & $0.006 * * *$ & $0.006 * * *$ & $0.007 * * *$ & $0.007^{* * *}$ & $0.003 * * *$ & 0.000 & -0.003 \\
\hline Nivel educativo de la madre: & & & & & & & \\
\hline Media vocacional completa & $0.005^{* * *}$ & $0.005^{* * *}$ & $0.005^{* * *}$ & $0.006^{* * *}$ & $0.003^{* * *}$ & 0.001 & 0.009 \\
\hline Tasa de repitencia & $0.082^{* * *}$ & $0.086^{* * *}$ & $0.101^{* * *}$ & $0.100^{* * *}$ & $0.098^{* * *}$ & $0.108^{* * *}$ & 0.058 \\
\hline Puntaje en las pruebas de Estado & & & & & & & \\
\hline SABER11 & $-0.000 * * *$ & $-0.000 * * *$ & $-0.000 * * *$ & $-0.000 * * *$ & $-0.000 * * *$ & $-0.000 * * *$ & -0.000 \\
\hline Nivel de formación Técnica & & & & & & & \\
\hline profesional & $0.012^{* * *}$ & $0.017^{* * *}$ & $0.040 * * *$ & $0.066^{* * *}$ & $0.101 * * *$ & & \\
\hline Nivel de formación Tecnológico & $0.007^{* * *}$ & $0.008 * * *$ & $0.010 * * *$ & $0.020 * * *$ & $0.010 * * *$ & $-0.036 * * *$ & \\
\hline Nivel de formación Universitaria & $-0.005 * * *$ & $-0.007 * * *$ & $-0.006 * * *$ & $0.004^{* * *}$ & $-0.004 * * *$ & $-0.088 * * *$ & \\
\hline Recibió crédito ICETEX de largo & & & & & & & \\
\hline plazo durante el semestre & $-0.015 * * *$ & $-0.017 * * *$ & $-0.021 * * *$ & $-0.018^{* * *}$ & $-0.018^{* * *}$ & $-0.030 * * *$ & -0.026 \\
\hline $\begin{array}{l}\text { Recibió crédito ICETEX de mediano } \\
\text { plazo durante el semestre }\end{array}$ & $-0.014 * * *$ & $-0.014 * * *$ & $-0.015^{* * *}$ & $-0.010 * * *$ & $-0.016^{* * *}$ & -0.001 & \\
\hline Recibió crédito ICETEX ACCES & & & & & & & \\
\hline $\begin{array}{l}\text { durante el semestre } \\
\text { Recibió apoyo financiero durant }\end{array}$ & $-0.020 * * *$ & $-0.021 * * *$ & $-0.020 * * *$ & $-0.024 * * *$ & $-0.021 * * *$ & $-0.020 * * *$ & -0.030 \\
\hline $\begin{array}{l}\text { el semestre } \\
\text { Recibió apovo académico durante }\end{array}$ & $-0.010 * * *$ & $-0.012 * * *$ & $-0.016^{* * *}$ & $-0.020 * * *$ & $-0.020 * * *$ & $-0.025^{* * *}$ & -0.016 \\
\hline el semestre & $-0.003 * * *$ & $-0.004 * * *$ & $-0.009 * * *$ & -0.001 & $-0.017^{* * *}$ & $-0.016^{* * *}$ & \\
\hline $\begin{array}{l}\text { Recibió otros apoyos durante el } \\
\text { semestre }\end{array}$ & $-0.006 * * *$ & $-0.013 * * *$ & $-0.010 * * *$ & $-0.016 * * *$ & $-0.013 * * *$ & & -0.012 \\
\hline $\begin{array}{l}\text { Pertenece al A1: Agronomía, } \\
\text { veterinaria y afines }\end{array}$ & $0.028 * * *$ & $0.019 * * *$ & $0.031 * * *$ & $0.035^{* * *}$ & $0.026 * * *$ & 0.003 & 0.010 \\
\hline Pertenece al A2: Bellas artes & $0.016 * * *$ & $0.013^{* * *}$ & $0.032 * * *$ & $0.031 * * *$ & $0.002 * *$ & $0.074 * * *$ & \\
\hline $\begin{array}{l}\text { Pertenece al A3: Ciencias de la } \\
\text { educación }\end{array}$ & $0.019 * * *$ & $0.013 * * *$ & $0.026 * * *$ & $0.021 * * *$ & $0.017 * * *$ & $0.025 * * *$ & 0.049 \\
\hline $\begin{array}{l}\text { Pertenece al A5: Ciencias sociales, } \\
\text { humanas, derecho y ciencias }\end{array}$ & & & & & & & \\
\hline políticas & $0.013^{* * *}$ & $0.007 * * *$ & $0.019 * * *$ & $0.016 * * *$ & $0.008 * * *$ & $0.012 * *$ & 0.008 \\
\hline Pertenece al A6: Economía, & $0.016^{* * *}$ & $0.011^{* * *}$ & $0.025 * * *$ & $0.021 * * *$ & $0.009 * * *$ & $0.021 * * *$ & 0.016 \\
\hline
\end{tabular}

\footnotetext{
${ }^{14}$ Las regiones están definidas de la siguiente manera: Centro-Oriente: Bogotá, D.C., Boyacá, Cundinamarca, Huila, Norte de Santander, Santander y Tolima. Centro-Occidente: Antioquia, Caldas, Quindío y Risaralda. Costa Atlántica: Archipiélago de San Andrés y Providencia, Atlántico, Bolívar, Cesar, Córdoba, La Guajira, Magdalena y Sucre. Costa Pacífica: Cauca, Chocó, Nariño y Valle del Cauca. Orinoquía: Arauca, Casanare, Guainía, Guaviare, Meta y Vichada. Amazonía: Amazonas, Caquetá, Putumayo y Vaupés.
} 


\begin{tabular}{|c|c|c|c|c|c|c|c|}
\hline \multirow{2}{*}{$\begin{array}{c}\text { Variable dependiente: } \\
\text { Grupo de análisis }\end{array}$} & \multicolumn{7}{|c|}{ Deserción, discreto a a nivel del individuo (Al Desertor=1; Mientras No Desertor=0) } \\
\hline & Bogotá & $\begin{array}{l}\text { Centro- } \\
\text { Oriente }\end{array}$ & $\begin{array}{l}\text { Centro- } \\
\text { Occidente }\end{array}$ & Atlántica & Pacífica & Orinoquía & Amazonía \\
\hline \multicolumn{8}{|l|}{ administración, contaduría y afines } \\
\hline $\begin{array}{l}\text { Pertenece al A8: Ingeniería, } \\
\text { arquitectura, urbanismo y afines }\end{array}$ & $0.020 * * *$ & $0.016 * * *$ & $0.035^{* * *}$ & $0.029 * * *$ & $0.020 * * *$ & $0.018 * * *$ & 0.060 \\
\hline Pertenece al A9: Matemáticas y & & & & & & & \\
\hline ciencias naturales & $0.018^{* * *}$ & $0.016^{* * *}$ & $0.050 * * *$ & $0.043^{* * *}$ & $0.034 * * *$ & $0.019 * * *$ & \\
\hline Instituciones Universitarias & $0.009 * * *$ & $0.007 * * *$ & $0.005^{* * *}$ & $0.011^{* * *}$ & $0.007 * * *$ & & \\
\hline Instituciones Tecnológicas & $0.033^{* * *}$ & $0.018^{* * *}$ & $-0.005^{* * *}$ & $0.016^{* * *}$ & -0.001 & & \\
\hline \multicolumn{8}{|l|}{ Instituciones Técnicas } \\
\hline Profesionales & $0.041 * * *$ & $0.032 * * *$ & $-0.023 * * *$ & -0.002 & $-0.030 * * *$ & & \\
\hline Año 1999 & $-0.004 * * *$ & -0.001 & -0.001 & -0.002 & 0.000 & -0.006 & $0.962 * *$ \\
\hline Año 2000 & -0.001 & $0.002 * * *$ & $-0.004^{* * *}$ & $0.009 * * *$ & $-0.008 * * *$ & 0.003 & $0.969 *$ \\
\hline Año 2001 & $-0.002 * *$ & 0.000 & 0.001 & $0.012 * * *$ & $-0.006 * * *$ & -0.000 & 0.975 \\
\hline Año 2002 & -0.001 & 0.001 & $0.004^{* * *}$ & $0.013^{* * *}$ & $-0.012 * * *$ & $0.012^{*}$ & 0.976 \\
\hline Año 2003 & $0.003^{* * *}$ & $0.004^{* * *}$ & 0.001 & $0.009 * * *$ & $-0.010^{* * *}$ & 0.001 & 0.979 \\
\hline Año 2004 & $0.007^{* * *}$ & $0.008 * * *$ & $0.003 * *$ & $0.012 * * *$ & $-0.008 * * *$ & 0.000 & 0.983 \\
\hline Año 2005 & $0.005^{* * *}$ & $0.006 * * *$ & $0.003^{* *}$ & $0.014^{* * *}$ & $-0.012 * * *$ & -0.004 & 0.989 \\
\hline Año 2006 & $0.009 * * *$ & $0.009 * * *$ & $0.007 * * *$ & $0.013^{* * *}$ & $-0.008 * * *$ & 0.003 & 0.988 \\
\hline Año 2007 & $0.008 * * *$ & $0.009 * * *$ & $0.004^{* * *}$ & $0.023 * * *$ & $-0.004 * * *$ & 0.005 & 0.984 \\
\hline Año 2008 & $0.017^{* * *}$ & $0.017^{* * *}$ & $0.006 * * *$ & $0.029 * * *$ & $-0.005^{* * *}$ & 0.000 & 0.986 \\
\hline Año 2009 & $0.016 * * *$ & $0.016 * * *$ & $0.004 * * *$ & $0.030 * * *$ & $-0.002 *$ & $0.022 * * *$ & 0.989 \\
\hline Año 2010 & $0.012 * * *$ & $0.011 * * *$ & $0.005^{* * *}$ & $0.020 * * *$ & $-0.004 * * *$ & $0.027 * * *$ & 0.989 \\
\hline Año 2011 & $0.011^{* * *}$ & $0.013^{* * *}$ & $0.007^{* * *}$ & $0.027^{* * *}$ & $-0.004^{* * *}$ & $0.048 * * *$ & 0.989 \\
\hline Año 2012 & $0.007^{* * *}$ & $0.008^{* * *}$ & $0.015^{* * *}$ & $0.013^{* * *}$ & $-0.003^{* *}$ & $0.073^{* * *}$ & 0.988 \\
\hline Año 2013 & $-0.071^{* * *}$ & $-0.064 * * *$ & & & $-0.064^{* * *}$ & & \\
\hline IES en Bogotá D.C. & & $-0.004^{* * *}$ & & & & & \\
\hline IES en Boyacá & & $-0.013^{* * *}$ & & & & & \\
\hline IES en Cundinamarca & & $-0.025 * * *$ & & & & & \\
\hline IES en Huila & & $-0.015^{* * *}$ & & & & & \\
\hline IES en Norte de Santander & & $0.001^{* *}$ & & & & & \\
\hline IES en Santander & & $-0.007^{* * *}$ & & & & & \\
\hline IES en Caldas & & & $-0.004 * * *$ & & & & \\
\hline IES en Quindío & & & $0.014 * * *$ & & & & \\
\hline IES en Risaralda & & & $0.003^{* * *}$ & & & & \\
\hline IES en Atlántico & & & & $-0.061 * * *$ & & & \\
\hline IES en Bolívar & & & & $-0.059 * * *$ & & & \\
\hline IES en Cesar & & & & $-0.044 * * *$ & & & \\
\hline IES en Córdoba & & & & $-0.048 * * *$ & & & \\
\hline IES en La Guajira & & & & $-0.042 * * *$ & & & \\
\hline IES en Magdalena & & & & $-0.046 * * *$ & & & \\
\hline IES en Sucre & & & & $-0.053 * * *$ & & & \\
\hline IES en Cauca & & & & & $-0.016 * * *$ & & \\
\hline IES en Chocó & & & & & $-0.026 * * *$ & & \\
\hline IES en Nariño & & & & & $-0.009 * * *$ & & \\
\hline IES en Meta & & & & & & $-0.032 * * *$ & \\
\hline IES en Arauca & & & & & & $-0.026^{* * *}$ & \\
\hline Logaritmo del tiempo & $-0.047 * * *$ & $-0.051 * * *$ & $-0.058^{* * *}$ & $-0.057 * * *$ & $-0.052 * * *$ & $-0.049 * * *$ & -0.056 \\
\hline
\end{tabular}

*** $p<0.01,{ }^{* *} p<0.05,{ }^{*} p<0.1$

Fuente: SPADIES. Cálculos propios.

Nota: se presentan los efectos marginales. 


\section{REFERENCIAS}

Alemany, R. (1990). "Modelación de la duración de estudios universitarios: una aplicación a la Universidad de Barcelona". Tesis doctoral, Universidad de Barcelona.

Angulo; Carlos (2004). Flexibilidad curricular y créditos académicos. Ponencia presentada en el primer congreso de miembros de CONACES. Universidad de Los Andes. Bogotá.

ASCUN. (2002). De la exclusión a la equidad: Agenda de políticas y estrategia para la educación superior colombiana. Bogotá: Mimeo.

Bank, J., Slavings, R. y Biddle, B. (1990). "Effects of Peer Faculty and Parental Influences on Student's Persistence." Studying Education. Vol. 63, Issue 3.

Bean. (1985). "Student Attrition, Intentions and Confidence". Research in Higher Education, 17: $291-320$.

Cabrera N. y Castañeda M. (1993). “College Persistence: Structural Equations Modeling Test of Integrated Model of Student Retention". Journal of Higher Education, 64(2): 123 - 320.

Cameron y Taber. (2001). "Estimation of Education Borrowing Constraint using Returns to Schooling". NBER Working Paper, No. W7761.

Cárdenas, E. (1996). "Estudio de la deserción estudiantil en programas de ingeniería en la Universidad Nacional de Colombia". Tesis Magíster dirección universitaria, Universidad de los Andes.

Carneiro, P. Heckman, J. (2002).The Evidence on Credit Constraints in Post- Secondary Schooling. Discussion Paper No. 518, IZA, June.

Castaño et al. (2004). "Deserción estudiantil universitaria: una aplicación de modelos de duración." Lecturas de Economía, No. 60 Enero - Junio.

Contreras, Gloria. (1994) "Balance Crítico de la Deserción en Unisur." Tesis Magíster Dirección Universitaria, Universidad de los Andes.

Cornwell, Christopher. (2002). The Enrolment Effects of Merit-Based Financial Aid:evidence from the Georgia's HOPE Scholarship. University of Georgia, Department of Economics, Terry College of Business, January.

De Larragaña, María; González, Pilar. Actitudes De Los Miembros. (1980). De La Universidad De Los Andes Hacia El Establecimiento De Un Servicio De Asesoría Psicológica Universitaria. Tesis de pregrado de Psicología, Universidad de los Andes, Bogotá. 
Desjardins, s. Ahlburg, D Mc Call, B. (2001). Simulating the Longitudinal Effects of Changes in Finantial Aid on Student Departure from College. En: The Journal of Human Resources, Vol. 37, no. 3.

Díaz, Mario; Gómez, Víctor (2003). Formación por ciclos en la educación Superior. ICFES. Bogotá.

Educación Superior en el Siglo XXI. Una propuesta de la ANUIES.

Elder, Glen, (1985). "Perspectives on the life course", en: Elder (ed.): Life course dynamics. Cornell University Press.

Franco, M. (1991). "Factores que influyen en el ingreso y permanencia de los estudiantes den la Universidad de la Sabana". Tesis de pregrado de Psicología, Universidad de la Sabana.

García, Azucena; Navarrete, Minerva (2005). Estrategias para mejorar la calidad educativa, con énfasis en la retención y eficiencia terminal. Universidad Autónoma de Hidalgo. Ponencia en el Encuentro Internacional sobre Deserción en Educación Superior: experiencias significativas. Bogotá.

Giovagnoli, P. (2002). "Determinantes de la deserción y graduación universitaria: una apliación utilizando modelos de duración". Documento de Trabajo 37, Universidad Nacional de la Plata.

González, Luis (2005). Estudio sobre la Repitencia y Deserción en la Educación Superior Chilena. Instituto Internacional para la Educación Superior en América Latina y el Caribe. Santiago de chile.

Grambsch P. M. and T.M. Therneau. (1994). "Proportional hazard test and diagnostics based on weighted residuals". Biométrica 81:515-526.

Grimaldos, Amelia; Muriel, Diana; Zambrano, Sonia (1999). Prevalencia de alteraciones psicológicas no severas en estudiantes de la Universidad Católica. Tesis de pregrado de Psicología, Universidad Católica, Bogotá.

Heckman J. and R. Richard. (1985). "Alternative Methods for Evaluating the Impact of Interventions." In James Heckman and Burton Singer, eds., Longitudinal Analysis of Labor Market Data, pp. 156-246. New York, NY: Cambridge University Press for Econometric Society Monograph Series.

Heckman J., J. Smith y Taber, C. (1998). "Accounting for Dropouts in Evaluations of Social Programs." Review of Economics and Statistics 80: 1-14.

ICFES (2002). "Estudio de la deserción estudiantil en la educación superior en Colombia." Documento convenio UN - ICFES.

y Universidad del Valle. (1998). Diagnóstico nacional de bienestar de las instituciones de educación superior. Bogotá: ICFES. 
Iragorri, Piedad; Peckel, Evelyn (1981). Implementación De Un Centro De Consejería En La Universidad De Los Andes: Intervención Y Evaluación. Tesis de pregrado de Psicología, Universidad de los Andes, Bogotá.

Jenkins, S. (2005). Essex Summer School Course "Survival Analysis". Notas de Clase. . (2004). "Survival Analysis".

Londoño, O. (2000). "Estudio del fenómeno de la deserción voluntaria estudiantil de la jornada nocturna en el programa de administración de empresas de la Universidad Cooperativa Seccional, Santa Marta en el periodo 1986 - 1996". Tesis Magíster dirección universitaria, Universidad de los Andes.

Medina Miryam, (2003). "Orientación vocacional para el ingreso a la educación superior en Cuba", Universidad de Matanzas, Cuba, Conferencia Universidad Nacional.

Montoya, Díaz. (1999). "Extended Stay at University: An Application of Multinomial Logia and Duration Models". Applied Economics, 31: 1411 - 1422.

Plan Institucional de Desarrollo: Fortalecimiento Del Acompañamiento Seguimiento y Control de los Estudiantes en sus Procesos Académicos.

Pontificia Universidad Javeriana (2005). Programa de créditos académicos. Ponencia en el Encuentro Internacional sobre Deserción en Educación Superior: experiencias significativas. Bogotá.

Porto, A y Di Gresia. (2001). "Rendimiento de estudiantes universitarios y sus determinantes". Asociación Argentina de Economía Política. Noviembre.

Rodríguez, María (1992). Estilo Pedagógico Y Aprendizaje De Conceptos En Estudiantes Universitarios. Tesis de pregrado de Psicología, Universidad de los Andes, Bogotá.

Sánchez et. al. (2002). Equidad Social en el Acceso y Permanencia en la Universidad Publica Determinantes y Factores Asociados. CEDE Universidad de los Andes, Bogotá.

y Núñez, J. (1995) “¿Por qué los niños pobres no van a la escuela?” En: Planeación y Desarrollo, Vol XXVI, número 4. octubre-diciembre. Departamento Nacional de Plantación.

Spady, W. (1970). "Dropout from Higher Education: An Interdisciplinary Review and Synthesis". Interchange 1: $64-85$.

Tinto, V. (1989): “Definir la deserción una cuestión de perspectiva”, Revista Educación Superior, 71, México.

(1982). "Limits of theory and practice of student attrition". Journal of Higher Education, 53 (6): $687-700$. 
(1975). "Dropout from Higher Education: A Theoretical Synthesis of Recent Research". Review of Educational Research, 45: 89 -125.

Universidad de La Salle (2003). Fortalecimiento del Acompañamiento, Seguimiento y Control de los Estudiantes en sus Procesos Académicos. Bogotá.

Universidad Distrital Francisco José de Caldas. Formación tecnológica por ciclos propedéuticos. Bogotá.

Universidad EAFIT (2005). Programa de Becas Universidad EAFIT - Medellín. Una Experiencia que da Cobertura y Evita la Deserción Estudiantil. Ponencia en el Encuentro Internacional sobre Deserción en Educación Superior: experiencias significativas. Bogotá.

Universidad Nacional de Colombia (2002). Estudio de la Deserción Estudiantil en la Educación Superior en Colombia. ICFES. Bogotá.

Universidad Pedagógica Nacional (2005). La deserción estudiantil. Reto investigativo y estratégico asumido de forma integral por la UPN. Bogotá.

Universidad Pontificia Bolivariana, seccional Bucaramanga (2005). Programa de Acompañamiento Académico: una Experiencia Exitosa para Disminuir la Deserción. Ponencia en el Encuentro Internacional sobre Deserción en Educación Superior: experiencias significativas. Bogotá.

Universidad Tecnológica de Pereira (2005). Proyecto Tutorías Académicas, Apoyo Psicológico y Social. Pereira.

Vahos, Martha (1995). Cómo Perciben Su Calidad De Vida Los Estudiantes De La Universidad Nacional. Tesis de pregrado de Psicología, Universidad Nacional de Colombia, Bogotá.

Vargas, Beatriz (1999). Opinión De Los Estudiantes Acerca Del Servicio De Atención Psicológica De La Universidad De Los Andes. Tesis de pregrado de Psicología, Universidad de los Andes, Bogotá.

Vivas, Jesús (2005). El abandono de Estudiantes Universitarios: Análisis y Reflexiones sobre la Experiencia de la Universitat Autónoma de Barcelona. Universidad Autónoma de Barcelona. Barcelona.

Willet J. y J. Singer. (1991). "From Weather to When: New Methods for Studying Student Dropout and Teacher Attrition". Review of Education Research, 61(4): 407 - 450. 


\section{ANEXOS}

\section{Anexo 1. El modelo de duración continuo}

Siguiendo los planteamientos realizados por Tony Lancaster en 1990, supóngase que las variables relevantes, correspondientes a cada factor que afecta la deserción de un estudiante que ha cursado $t$ semestres, están representadas por el vector $x(t)$. Estas variables determinantes de la deserción participan en la descripción de la probabilidad de desertar en el período transcurrido entre $t+d t$, lo cual se puede describir como:

$$
\lambda(x(t)) d t
$$

La expresión anterior describe la probabilidad de ocurrencia de sucesos que motiven la deserción en el periodo $t+d t$, o probabilidad de cambios en los niveles de las variables socioeconómicas, institucionales, individuales y demás que afecten la decisión de deserción de un individuo. Adicionalmente, la probabilidad de que el individuo tome la decisión de desertar una vez han sucedido cambio en los niveles de las variables $x(t)$, puede describirse como $P(x(t))$. Por consiguiente, la probabilidad de que este individuo abandone sus estudios, es:

$$
\theta(t)=\lambda(x(t)) P(x(t))
$$

La expresión anterior también conocida como la función de riesgo (hazard function), describe la probabilidad de deserción en un intervalo de tiempo $t+d t$. Esta función de riesgo tiene en cuenta una sola causa de finalización de la permanencia en la universidad, situación que se revaluará en la descripción del modelo más adelante, dado que realmente hay tres causas, la deserción, la graduación y el efecto de censura de la información producido por el limite en el periodo de observación, es decir los estudiantes podrán ser observados hasta el segundo semestre de 2004, periodo en el cual algunos de ellos siguen vinculados a la universidad, y para los cuales no se tendrá información sobre el fenómeno de deserción y tampoco sobre el de graduación.

La función de riesgo también puede ser expresada en términos de la función de densidad que generan las duraciones ${ }^{15}$ de los diferentes individuos. Si se representa la duración del estudiante en la universidad por la variable aleatoria $T$, de la cual supondremos inicialmente que es una variable continua, y si dejamos a $F(t)$ representar la función de distribución de la probabilidad de la variable $T^{16}$, entonces la distribución acumulativa de frecuencias puede ser expresada como:

$$
F(t)=\int f(s) d s=P(T<t)
$$

\footnotetext{
${ }^{15}$ La duración de cada estudiante se conocerá a partir de la información aportada por las IES.

${ }^{16}$ Esta función de distribución, supone que se trata de una población homogénea en cuanto a las variables explicativas de la duración en la Universidad $T$, lo cual implica que la función de distribución es aplicable a todos los individuos.
} 
Donde $f(s)$ representa la función de densidad para la probabilidad de $T$.

De acuerdo con la gráfica A, la proporción de personas que han desertado, durante t unidades de tiempo, es $F(t)$ y la porción de personas que continúan es $S(t)$. La función de supervivencia en educación superior puede ser escrita como $S(t)=1-F(t)=P(T \geq t)$. Asimismo, la proporción de individuos que han desertado en el período transcurrido entre 0 y $t$, condicional a que han sobrevivido hasta ese momento, se representa en la Gráfica A como $\theta(t)=f(t) / S(t)$.

Gráfica A. Función de Distribución Acumulativa

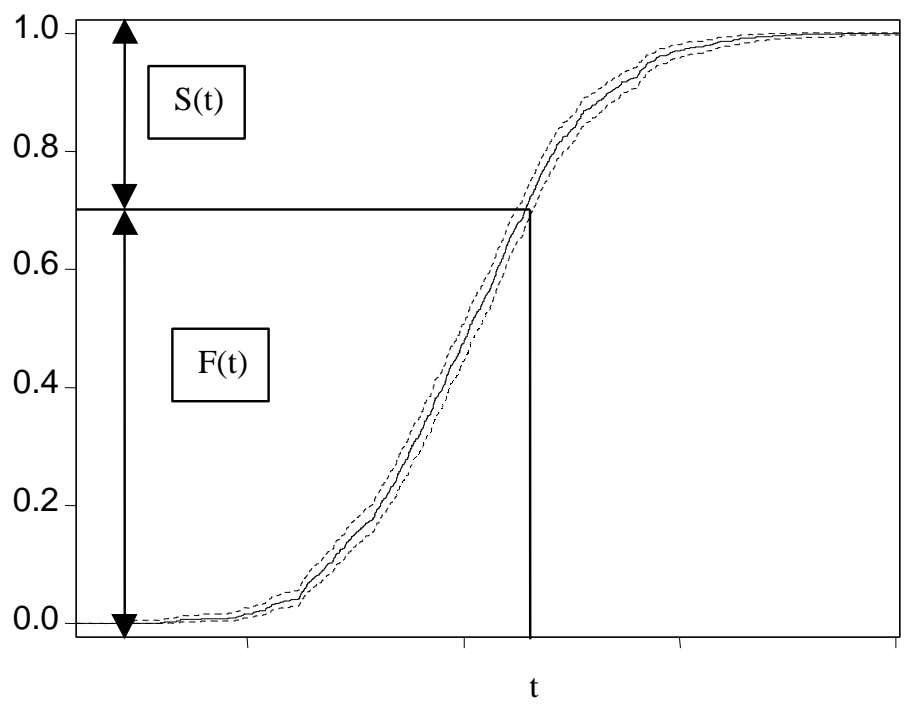

La función de riesgo también puede ser escrita como:

$$
\theta(t)=\frac{f(t)}{S(t)}=\frac{d F(t) / d t}{S(t)}=-\frac{\frac{d S(t)}{d t}}{S(t)}=-\frac{d \ln (S(t))}{d t}
$$




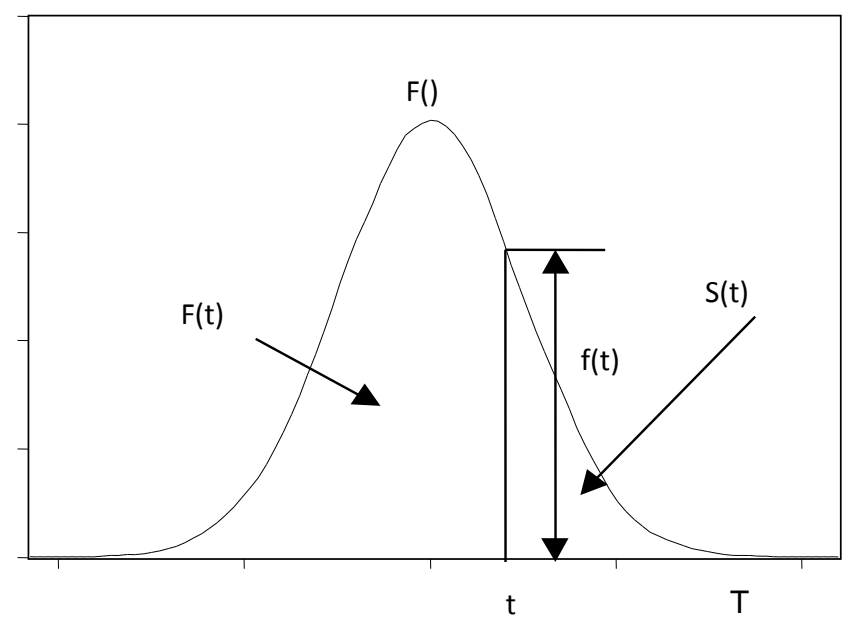

Puesto que $f(t)=-d S(t) / d t$, la ecuación (1) es una ecuación diferencial en $t$ que esta sujeta a la condición inicial $S(0)=1$ y su solución esta dada por la siguiente función de supervivencia:

$$
S(t)=e^{-\int_{0}^{t} \theta(s) d s}
$$

y utilizando las dos ecuaciones anteriores, la función de densidad puede ser escrita como

$$
f(t)=\theta(t) e^{-\int_{0}^{t} \theta(s) d s}
$$

Cuando la función de riesgo es independiente del tiempo que se ha estado en educación superior, la integral en (4) se convierte en:

$$
\int_{0}^{t} \theta(s) d s=\theta t
$$

y la función de supervivencia en $S(t)=e^{-\theta t}$. La función de probabilidad correspondiente es $f(t)=\theta e^{-\theta t}$ comúnmente conocida como la función de densidad exponencial. La función de supervivencia no es otra cosa que la probabilidad de sobrevivir más allá de t. Esta función toma el valor de 1 cuando el estudiante comienza su primer semestre y va disminuyendo hacia cero.

De acuerdo con el marco teórico, la probabilidad de deserción varía entre los individuos de acuerdo a cuatro factores principales: 1 ) características individuales como género, edad, entorno familiar, etc.; 2) características relacionadas con el aspecto académico como tipo de colegio, rendimiento académico, calidad del programa al que se inscribió; 3 ) factores institucionales como normatividad académica, becas y financiamiento, programas de acción afirmativa, etc.; y 4) factores socioeconómicos, entre los cuales se encuentra el estrato social, la situación laboral del estudiante, la dependencia económica, etc. (ver Tabla 1). Si estas variables relevantes se 
representan en el vector $x$, podemos introducirlo en la función de riesgo de una forma sencilla modificando la ecuación (2):

$$
\theta(t \mid x)=\frac{f(t \mid x)}{S(t \mid x)}=\frac{f(t \mid x)}{1-F(t \mid x)}
$$

De tal forma que la función de riesgo exponencial es

$$
\theta(t, x)=e^{-x^{\prime} \beta}
$$

\section{Generalización del Modelo ${ }^{17}$}

Distribuciones de probabilidad continuas, discretas y mixtas para la variable $T$ pueden ser tratadas de forma adecuada con una estructura generalizada. Para ver lo anterior inicialmente se debe definir $G(u)$ como una función continua, creciente, con un límite izquierdo y un número de discontinuidades en cualquier intervalo finito. Adicionalmente definiendo a $g(u)=G^{\prime}(u)$ que existe en todos los intervalos continuos, excepto en los puntos de discontinuidad $a_{j}$ donde se tiene que $G\left(a_{j}\right)-G\left(a_{j}-\right)=g_{j}$, donde $G\left(a_{j}-\right)=\lim _{\Delta a \rightarrow 0} G(a-\Delta a)$. La integral de RiemannStieltjes de $d G$ sobre el intervalo (a,b] está definida como:

$$
\int_{(a, b]} d G(u)=\int_{a}^{b} g(u) d u+\sum_{j: a<a_{j} \leq b} g_{j}
$$

Ahora, considerando que la función de distribución $F(t)=\operatorname{Pr}(T \leq t)$ es una función continua, creciente, con saltos de continuidad en los puntos $a_{j}$ para los cuales $\operatorname{Pr}\left(T=a_{j}\right)=f_{j}>0$ y una función de densidad de probabilidad $f(u)=F^{\prime}(u)$ para todos los puntos en donde $F(u)$ es continúa, se tiene que $\operatorname{Pr}(a<T \leq b)$ es:

$$
F(b)-F(a)=\int_{(a, b]} d F(u)=\int_{a}^{b} f(u) d u+\sum_{j: a<a_{j} \leq b} f_{j}
$$

Usando la definición de producto integral y definiendo $a=u_{0}<u_{1}<u_{2}<\ldots<u_{m}=b$ en el intervalo (a,b], con $\Delta u_{i}=u_{i}-u_{i-1}$. Además suponiendo que $\max \left(\Delta u_{i}\right) \rightarrow 0$ cuando $m \rightarrow \infty$. El producto integral de una función $d G(u)$ puede definirse como:

\footnotetext{
${ }^{17}$ Jerald F. Lawless. (2003). Statistical models and methods for lifetime data. Wiley Series in Probability and Statistics.
} 


$$
\prod_{(a, b]}\{1+d G(u)\}=\lim _{m \rightarrow 0} \prod_{i=1}^{m}\left\{1+G\left(u_{i}\right)-G\left(u_{i-1}\right)\right\}
$$

Si $G(u)$ es continua para todo $u$ en el intervalo $(\mathrm{a}, \mathrm{b}]$, entonces $d G(u)$ puede ser definida como:

$$
\begin{aligned}
\prod_{(a, b]}\{1+g(u) d u\} & =\lim _{m \rightarrow \infty} \prod_{i=1}^{m}\left\{1+g\left(u_{i}\right) \Delta u_{i}+0\left(\Delta u_{i}\right)\right\} \\
& =\lim _{m \rightarrow \infty} \prod_{i=1}^{m}\left\{1+g\left(u_{i}\right) \Delta u_{i}\right\}
\end{aligned}
$$

Donde $0(x)$ significa que la función $w(x)$ tal que $w(x) / x \rightarrow 0$ cuando $x \rightarrow 0$. Nótese que $\log \left\{1+g\left(u_{i}\right) \Delta u_{i}\right\}=g\left(u_{i}\right) \Delta u_{i}+O\left(\Delta u_{i}\right)$ para $\Delta u_{i}$ pequeños, y si se toma el log del producto integral se tiene que:

$$
\prod_{(a, b]}\{1+g(u) d u\}=\exp \left\{\int_{a}^{b} g(u) d u\right\}
$$

Relacionando la integral de Riemann-Stieltjes y el producto integral, si $G(u)$ presenta discontinuidades en los puntos $a_{j}(j=1,2, \ldots)$ de tamaño $g_{j}$ se tiene:

$$
\prod_{(a, b]}\{1+d G(u)\}=\prod_{(a, b]}\{1+g(u) d u\} \prod_{j: a<a_{j} \leq b}\left(1+g_{j}\right)
$$

La función de riesgo para los intervalos donde existe continuidad es $h(u)=f(u) / S(u)$, que representa la función de riesgo para $T$ donde $F(u)$ (o $S(u)$ ) es continua y $h_{j}=\operatorname{Pr}\left(T=a_{j} \mid T \geq a_{j}\right)$ representa la función de riesgo para todos los puntos $a_{j}$ donde se presenta discontinuidad en la función $F(u)$. Dado lo anterior y usando nuevamente la definición de la integral de Riemann-Stieltjes la función de riesgo acumulativa es:

$$
H(U)=\int_{0}^{t} d H(u)=\int_{0}^{t} h(u) d u+\sum_{j: a_{j} \leq t} h_{j}
$$

Una vez definida la función de riesgo acumulativo, se puede obtener la función de supervivencia para una secuencia de valores $0=u_{0}<u_{1}<u_{2}<\ldots<u_{m}=t$

$$
\operatorname{Pr}(T \geq t)=\prod_{i=1}^{m} \operatorname{Pr}\left(T \geq u_{i} \mid T \geq u_{i-1}\right)
$$

Cuando se presenta $\Delta u_{i}=u_{i}-u_{i-1}$ suficientemente pequeño, $\left[u_{i}-u_{i-1}\right)$ contiene cero o un salto de continuidad $y$ 


$$
\begin{aligned}
\operatorname{Pr}\left(T \geq u_{i} \mid T \geq u_{i-1}\right) & =1-\frac{\operatorname{Pr}\left(u_{i-1} \leq T<u_{i}\right)}{\operatorname{Pr}\left(T \geq u_{i-1}\right)} \\
& =1-\left[H\left(u_{i}-\right)-H\left(u_{i-1}-\right)\right]+0\left(\Delta u_{i}\right)
\end{aligned}
$$

Retomando las dos ecuaciones anteriores se tiene:

$$
\operatorname{Pr}(T \geq t)=\prod_{(0, t)}[1-d H(u)]
$$

La unificación del tratamiento continuo y discreto, mostrada anteriormente, evidencia como el problema puede ser esencialmente tratado de la misma manera. Dado lo anterior, queda entonces por discutir asuntos relacionadas con la aplicación empírica del modelo, lo cual se presenta en el siguiente apartado.

\section{Las estimaciones}

Las estimaciones de los parámetros $\beta$, que se obtienen maximizando la función de probabilidad (función de máxima verosimilitud), indican la probable dirección y magnitud de los efectos de las variables representadas en el vector $x$. Dada la función de supervivencia expresada en la ecuación (3), la probabilidad de deserción ( $\delta=0$ ) o un dato censurado ( $\delta=1$ ), en el período entre $\mathrm{t}_{0}$ y $\mathrm{t}_{1}$ es $\left[S\left(t_{1}\right) / S\left(t_{0}\right)\right] \theta\left(t_{1}\right)^{\delta}$ y la función de máxima verosimilitud a ser maximizada para $-\beta$ es

$$
\ln L=\sum_{j==1}^{N} \ln S\left(t_{1 j}\right)-\ln S\left(t_{0 j}\right)+\delta_{j} \ln \theta\left(t_{1 j}\right)
$$

en donde $\mathrm{N}$ es el número de observaciones.

De otro lado, la función de supervivencia puede ser calculada mediante el estimador Kaplan Meier. Si ${ }^{n}$ es el número de individuos que permanecen en $\mathrm{t} y{ }_{j}$ los que desertan, entonces la estimación mediante máxima verosimilitud de la función de supervivencia es

$$
\hat{S}(t)=\prod_{j: t_{j} \leq t}\left(\frac{n_{j}-d_{j}}{n_{j}}\right)
$$

En la práctica, inicialmente se utilizará una transformación Box-Cox para el cálculo de las funciones de riesgo. Este modelo específica que:

$$
\theta(t \mid x)=e^{-x^{\prime} \beta} \theta_{0}(t \mid x)
$$


en donde $\theta_{0}$ es un parámetro que debe ser estimado. Cox (1972) proporciona un método para estimar $\beta$ sin requerir la estimación de $\theta_{0}$. Sin embargo esta forma de estimación requiere de una serie de supuestos que normalmente no se cumplen (Lancaster, 1990).

La verdadera distribución de las duraciones de los estudiantes no se conoce a priori, debido a que el proceso subyacente que genera la deserción no es conocido. Desde el punto de vista estadístico, lo que se hace es construir unos supuestos sobre la forma de $\theta_{0}$ y posteriormente utilizar el criterio de información de Akaike (AIC) para escoger la distribución ${ }^{18}$.

La idea principal del análisis es encontrar el efecto de cada variable (vector $x$ ) sobre la probabilidad de desertar, y de esta forma, dadas las características de un estudiante, poder predecir dichas probabilidades en cada momento del tiempo (insumo principal para el software que requiere el Ministerio de Educación). Se comenzará utilizando un modelo de riesgo proporcional, conocido como Cox, el cual afirma que la tasa de riesgo para el estudiante i es:

$$
h\left(t \mid x_{j}\right)=h_{0}(t) * \exp \left(x_{j} b\right)=h_{0}(t) * \exp \left(b_{1} x_{1}+b_{2} x_{2}+\ldots b_{k} x_{k}\right)
$$

El modelo de Cox no hace supuestos acerca de la forma del riesgo en el tiempo, lo cual es una ventaja considerable cuando no se tiene supuestos razonables sobre ésta. En otras palabras, esta aproximación semiparamétrica no hace supuestos sobre la forma de $h_{0}(t)$, y esto puede conducir a estimaciones equivocadas del vector $b$ que no es otra cosa que el efecto de cada variable sobre la deserción. El costo es una pérdida de eficiencia en los estimadores. Sin embargo, la mejor manera de llegar al modelo correcto es estimando el modelo Cox y posteriormente evaluar si el supuesto de proporcionalidad es correcto.

Para probar el supuesto de proporcionalidad, implícito en el modelo de Cox, se debe verificar si se ha escogido correctamente la especificación de $x_{j} b$. Bajo el supuesto de que $x_{j} b$ es la especificación correcta, $L R H=b_{1} x_{j} b+b_{2}\left(x_{j} b\right)^{2}$, entonces $b_{1=1}$ y $b_{2}=0$. Por lo tanto, se debe probar que $b_{2}=0$. La prueba es poderosa para errores en $x_{j} b$ bajo el supuesto de que $x_{j}$ al menos contenga las variables correctas, o más exactamente, la prueba es débil en términos de detectar la presencia de variables omitidas.

En general, se puede probar el supuesto de proporcionalidad basado en el análisis de los residuos. La prueba de Schoenfeld recupera los residuos, estima una función suavizada del tiempo y prueba

\footnotetext{
${ }^{18}$ Las distribuciones mas comunes son: Exponential, Weibull, Gompertz.
} 
si existe una relación entre estas dos variables. Para llevar a cabo esta prueba, se utilizará la generalización de Grambsch y Therneau $(1994)^{19}$.

Si se encuentra evidencia de que el modelo de Cox viola el supuesto de proporcionalidad con los datos utilizados, es necesario escoger un modelo paramétrico, basados en la probabilidad de que un individuo deserte en un momento del tiempo dadas unas características socioeconómicas, $\operatorname{Pr}\left(\right.$ sujeto $j$ deserte en $\left.t \mid x_{j} b\right)$. La única diferencia con el modelo planteado por Cox en la ecuación (11) es que éstos hacen supuestos sobre la forma de $h_{0}(t)$. La estrategia para escoger la forma funcional que más se ajusta, parte de la estimación de diferentes modelos entre los cuales se escogerá el que más se ajuste a los datos utilizando el criterio de Akaike.

${ }^{19}$ Grambsch P. M. and T.M. Therneau. 1994. Proportional hazard test and diagnostics based on weighted residuals. Biométrica 81:515526. 